Portland State University

PDXScholar

\title{
Captive Environmental Influences on Behavior in Zoo Drills and Mandrills (Mandrillus), a Threatened Genus of Primate
}

Erik Terdal

Portland State University

Follow this and additional works at: https://pdxscholar.library.pdx.edu/open_access_etds

Part of the Biology Commons, Environmental Monitoring Commons, and the Zoology Commons Let us know how access to this document benefits you.

Recommended Citation

Terdal, Erik, "Captive Environmental Influences on Behavior in Zoo Drills and Mandrills (Mandrillus), a Threatened Genus of Primate" (1996). Dissertations and Theses. Paper 3014.

https://doi.org/10.15760/etd.3009

This Dissertation is brought to you for free and open access. It has been accepted for inclusion in Dissertations and Theses by an authorized administrator of PDXScholar. Please contact us if we can make this document more accessible: pdxscholar@pdx.edu. 
CAPTIVE ENVIRONMENTAL INFLUENCES ON BEHAVIOR IN ZOO DRILLS AND MANDRILLS (MANDRILLUS),

A THREATENED GENUS OF PRIMATE

\author{
by \\ ERIK TERDAL
}

A dissertation submitted in partial fulfillment of the requirements for the degree of

DOCTOR OF PHILOSOPHY

in

ENVIRONMENTAL SCIENCES AND RESOURCES:

BIOLOGY

Portland State University

1996 


\section{DISSERTATION APPROVAL}

The abstract and dissertation of Erik Terdal for the Doctor of Philosophy in Environmental Sciences and Resources: Biology were presented November 22, 1995, and accepted by the dissertation committee and the doctoral program.

COMMITTEE APPROVALS:

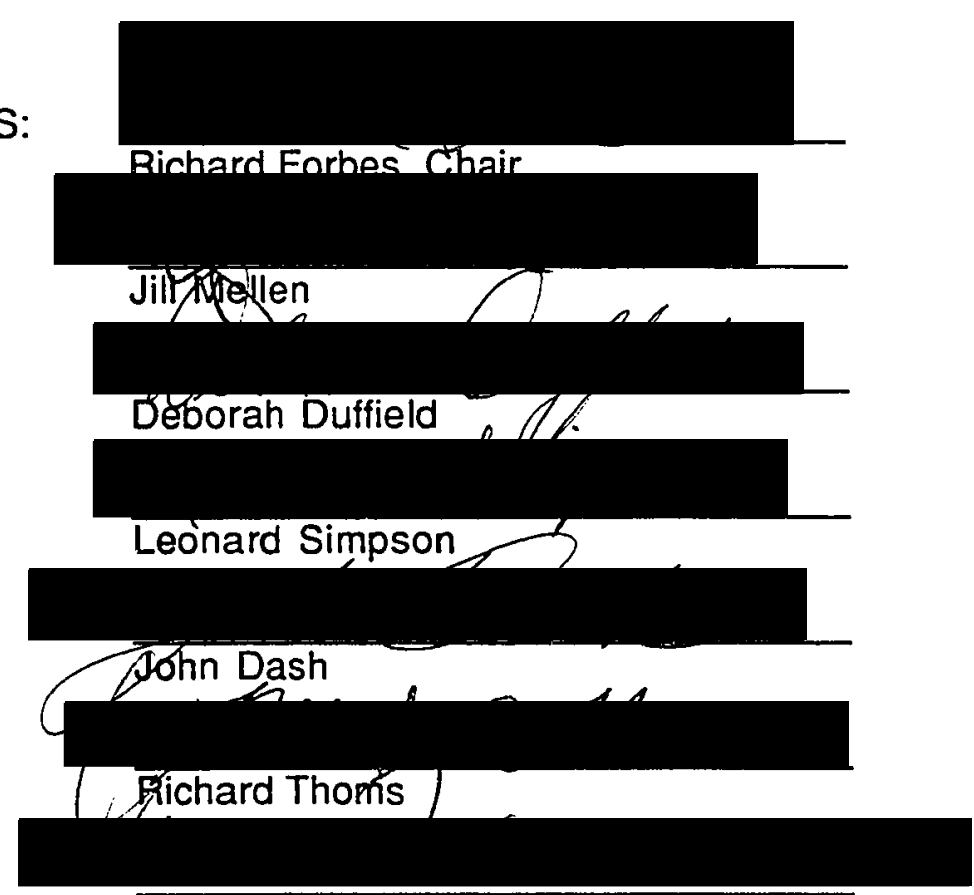

Marc Feldesman, Representative of the Office of Graduate Studies

DOCTORAL PROGRAM APPROVAL:

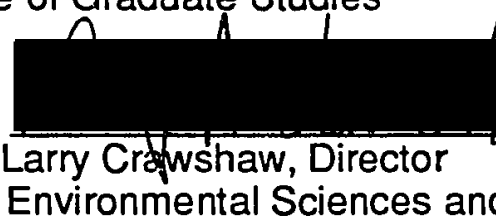

Resources Ph.D. Program

ACCEPTED FOR PORTLAND STATE UNIVERSITY BY THE LIBRARY 


\begin{abstract}
An abstract of the dissertation of Erik Terdal for the Doctor of Philosophy in Environmental Sciences and Resources: Biology presented November 22, 1995.
\end{abstract}

Title: Captive Environmental Influences on Behavior in Zoo Drills and Mandrills (Mandrillus), a Threatened Genus of Primate

Drills (Mandrillus leucophaeus) are an endangered species of African monkey (Cercopithecidae), and their sole congener the mandrill (Mandrillus sphinx) is vulnerable to extinction. Both species are threatened in the wild by deforestation and hunting.

Drills have a poor record of captive reproduction. Many individuals appear to have behavioral deficiencies which interfere with reproduction. Thus, the zoo population of drills does not serve as a "hedge" against the species' total extinction: drills are endangered in captivity as well as in the wild. Mandrills, by contrast, reproduce well in captivity. Information on the behavior of mandrills in captivity may help zoo managers impro'se husbandry for both species.

The intent of this research was to study the relationship between aspects of the captive environment and behaviors which lead to reproduction. A review of the literature on both drills and mandrills, in the wild and captivity, was used to suggest "essential characteristics" of the captive environment that may encourage animals of both species to engage in natural, active 
behaviors, to form cohesive dyads with opposite-sex adults, to develop affiliative bonds, and to engage in sexual behavior. Sixty-two drills and mandrills in 14 groups in the U.S. and Germany were studied with behavior sampling methods, using the Drill Species Survival Plan ethogram.

Data were analyzed by multiple regression using transformed variables. No over-all species differences in behavior were found. Results suggested that two factors promoted natural activity: 1) environmental enrichment which provides positive reinforcement for active behaviors, and 2) an affiliative husbandry style by the animal's keepers. Active animals were more likely to engage in social behaviors leading to copulation.

Many of the non-reproducing drills appeared to be "passive and withdrawn," and shared a constellation of signs that appeared to be analogous to human clinical depression. An etiological model for "passive and withdrawn" Mandrillus, based on biobehavioral theories of human depressive disorders, was developed to link early rearing conditions and environmental enrichment. This model was then used to develop a historicdemographic hypothesis for why mandrills have historically had greater reproductive success than drills in zoos. 
TABLE OF CONTENTS

PAGE

ACKNOWLEDGMENTS $\ldots \ldots \ldots \ldots \ldots \ldots \ldots \ldots \ldots \ldots \ldots$

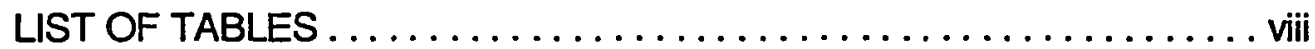

LIST OF FIGURES $\ldots \ldots \ldots \ldots \ldots \ldots \ldots \ldots \ldots \ldots \ldots \ldots \ldots$

CHAPTER

I INTRODUCTION $\ldots \ldots \ldots \ldots \ldots \ldots \ldots \ldots \ldots \ldots \ldots \ldots$

Relating Captive Environment to

Behavior and Reproduction ............ 1

$\| \quad$ LITERATURE REVIEW $\ldots \ldots \ldots \ldots \ldots \ldots \ldots \ldots, 4$

History $\ldots \ldots \ldots \ldots \ldots \ldots \ldots \ldots \ldots \ldots, \ldots$

Taxonomy......................... 6

Distribution

Status in the Wild $\ldots \ldots \ldots \ldots \ldots \ldots \ldots \ldots, 12$

Habitat Destruction

Hunting

Status in Captivity . . . . . . . . . . . . . . . 17

Why are Drills Reproducing

Poorly in Captivity?

Theory in Zoo Biology

Mandrillus in the Wild.

Group Size and Composition

Spatial Relationships

Polyspecific Associations

Habitat Structure

Foraging and Feeding

Humans 
Mandrillus in Captivity . . . . . . . . . . . 34

Mandrills at CIRMF

Development of Hypotheses

Studies on Mandrillus in Zoos

Exhibits and Husbandry

Activity, Cohesion, Affiliative Bonding and Sexual Behavior

Summary of Zoo Studies Relationg to

Development of my

Hypotheses

III METHODS

Mandrillus Groups: Composition, Exhibits and Husbandry . . . . . . . . . . . 44

Criteria used to Define Age Classes

Exhibit and Husbandry Variables

Behavioral Data 48

Ethogram

Data Collection Methods . . . . . . . . . . . . 57

Data Analysis . . . . . . . . . . . . . . . 60

Proportion of Time

Social Behavior Hourly Rates

Screening Data

Multiple Regression Analyses

Statistical Procedures used for

Visualization of Data

IV

RESULTS 69

Species Differences . . . . . . . . . . . . . . . 69

Hypotheses ................... 71

Hypothesis One

Hypothesis Two

Hypothesis Three

Hypothesis Four

Overall Summary of Results 
$\checkmark \quad$ DISCUSSION OF RESULTS $\ldots \ldots \ldots \ldots \ldots \ldots 92$

Species Differences .................. 92

Species Differences in

Captive Environments

Discussion of Results of Hypothesis Tests . . . . 996

Hypothesis One

Hypotheses Two, Three and Four

Proposed Experiments

Two Examples of Reproductively

Successful Drill Groups . . . . . . . . . . . 107

Environments

Activity Budgets

Cohesion and Affiliative Bonding

Sexual Behavior

VI A PROPOSED MODEL TO EXPLAIN THE RESULTS . 120

A Constellation of Signs ............... 120

Theory in Zoo Biology Revisited

Towards a New Model

The Human Model of Primate Psychopathology .124

Rationale for Using Humans as a Model Species for a Non-Human Primate

Human Depressive Disorders ............. 126

Effect of Early Rearing Environment on

Behavior andNeurodevelopment

in Laboratory Macaques

A Proposed Experiment to Evaluate

the Suggested Model. .............. 134

A Historic-Demographic Hypothesis for the

Species Difference in Captive

Mandrillus Reproductive Success . . . . . .136

Conclusion ....................... 140 
REFERENCES. . . . . . . . . . . . . . . 141

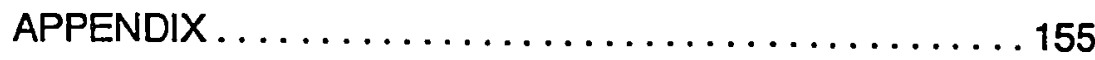




\section{ACKNOWLEDGMENTS}

Scores of people in the U.S. and Germany helped me with this study. Even though I cannot thank them all by name, I appreciate all of their help.

Jill Mellen (Metro Washington Park Zoo, Portland, OR, USA) has taught me since 1990 about mandrills and how to study them, and about all aspects of behavioral and zoo biology. Elizabeth Gadsby and Peter Jenkins (Drill Rehabilitation and Breeding Center, Calabar, Nigeria) were the people who led me to expand my interest in captive mandrills to drills, both in zoos and in Africa.

At the Metro Washington Park Zoo, Dennis Pate, Rick Horton and Jan Baker helped me with planning the study and arranging the travel. Many people have helped me during my visits to several zoos in the U.S. since 1992. I especially wish to thank the dozens of keepers who have taught me so much about Mandrillus behavior and husbandry. Cathleen Cox (Los Angeles Zoo, Los Angeles, CA, USA) introduced me to drills and helped me to learn the Drill Species Survival Plan ethogram. Ed and Tammie Bettinger invited me to stay in their home when I visited Tulsa Zoo (Tulsa, OK, USA). In Atlanta, Gail and Nevin Lash invited me to stay in their home. I thank Debra Forthman (Zoo Atlanta, Atlanta, GA, USA) for making those arrangements. Zoo Atlanta's curator, C. Dietrich Schaaf, shared with me his extensive knowledge about drills both in zoos and in Africa.

Gail Hearn (Beaver College, Glenside, PA, USA) helped me to prepare for travel to Germany. Once I was in Germany, my parents provided considerable logistical support. At Zoo Hannover, Roland Wolf and Ursula Otto taught me many things about drill behavior and husbandry. Head monkey 
keeper Roland's energy, knowledge and dedication to drills both in zoos and in Africa should be an example to everyone who cares about drills! Zoo Wuppertal's curator, Gea Olbricht, helped me with housing, and with information on her zoo's drills. At the Saarbrucken Zoo, all the staff were grieving Uwe Roth's tragic death just prior to my visit. Uwe Roth (1964 - 1995) was an expert on the husbandry of drills and many other animals. Despite their grief, many people at the Saarbrucken Zoo helped me in many ways. Ela and Jarek Janiszewski provided me with a home stay; they and their children were very warm hosts. I thank director Vaclav Ceska for making those arrangements. Hans-Ulrich Hoffman and Alexandra Jungman provided me with information on both drills and mandrills, as did keepers Harald Weissgerber and Markus Hinker.

I wish to thank all of my committee at Portland State University (Portland, OR, USA) for commenting on drafts of my proposal and dissertation, especially my research advisor, Jill Mellen, and my committee chair, Richard Forbes. My mother, Marge Terdal (Portland State University), also commented on dissertation drafts. My father, Leif Terdal (professor emeritus of medical psychology at Oregon Health Sciences University, Portland, OR, USA), suggested to me human clinical depression as a model for understanding the "passive and withdrawn" appearance I observed in many non-reproducing drills. Zoo biologists Debra Forthman and David Shepherdson (Metro Washington Park Zoo) helpfully discussed this model with me.

An Institute for Museum Services grant (IC-40127-94) to the Metro Washington Park Zoo covered the costs of transportation to zoos in the U.S. and Germany, and also for a computer. A camera and a lens were provided by Portland State University. The Metro Washington Park Zoo provided use of 
telephone, FAX, mail, computer, copier, and general office support. Summer employment at the Metro Washington Park Zoo as "Golden Lion Tamarin Project Coordinator" helped with other expenses while I was doing this research. My wife, Megan Oehlke, her parents, Roger and Barbara Oehlke, and my parents, together provided the rest of the financial support for my study.

My extended family provided emotional as well as financial support for me during my study. I am especially grateful to parents, my in-laws, my wife, and to my son, Finn Terdal. 


\section{LIST OF TABLES}

TABLE

PAGE

II-1 Mandrillus subspecies .................... 9

II-2 Field studies on Mandrillus . . . . . . . . . . . . . 25

III-1 Drill and mandrill groups viewed . .............. 45

III-2 Age classes of female and male Mandrillus . ...... 46

III-3 Exhibit and husbandry variables . . . . . . . . . . 47

III-4 Ethogram: behavior states ................. 49

III-5 Ethogram: behavior events ................ 51

III-6 Summary of hypotheses $\ldots \ldots \ldots \ldots \ldots \ldots \ldots \ldots 66$

IV-1 Effects of species, sex and age on activity budgets . . . 70

IV-2 Hypothesis one predictor variables ............. 72

IV-3 Activity budget: social behavioral states ..........73

IV-4 Activity budget: non-social active behavioral states . . . 73

IV-5 Activity budget: inactive behavioral states ........ 73

IV-7 Effects of environmental variables of inactivity . . . . 75

IV-8 Effect of inactivity on proximity $\ldots \ldots \ldots \ldots \ldots \ldots \ldots 79$

IV-9 Effect of inactivity on coactivity $\ldots \ldots \ldots \ldots \ldots \ldots 79$

IV-10 Effect of cohesion on allogrooming ............ 83

IV-11 Effect of cohesion on posterior presentation ... . . . 84

IV-12 Effect of cohesion on "smiling" . . . . . . . . . . . 84

IV-13 Female perineal swelling stages $\ldots \ldots \ldots \ldots \ldots \ldots 88$ 
IV-14 Effect of affiliation on anogenital inspection . . . . . . 88

IV-15 Effect of affiliation on posterior presenting $\ldots \ldots \ldots . \ldots 90$

V-1 Drill versus mandrill captive environments . . . . . . . 94

V-2 Activity budget at Zoo Hannover: social states. . . . . 111

V-3 Activity budget at Zoo Atlanta: social states . . . . . . . 111

V-4 Activity budget at Zoo Hannover: active states . . . . . 112

V-5 Activity budget at Zoo Atlanta: active states . . . . . . 112

V-6 Activity budget at Zoo Hannover: inactive ........ 113

V-7 Activity budget at Zoo Atlanta: inactive . . . . . . 113

V-8 Activity budget at Zoo Hannover: non visible . . . . . . 114

V-9 Activity budget at Zoo Atlanta: not visible . . . . . . . 115

VI-1 Constellation of signs in "passive and withdrawn" drills . 121

A-1 Drills at Los Angeles Zoo ............... 161

A-2 Drills at the Center for the Reproduction of Endangered Species . . . . . . . . . . . 163

A-3 Drills at Knoxville Zoo ................ 165

A-4 Drills at Zoo Atlanta ................... 166

A-5 Drills at Zoo Wuppertal . . . . . . . . . . . . 168

A-6 Drills at Zoo Hannover .................. 169

A-7 Drills at Saarbrucken Zoo .............. 172 
A-8 Mandrills at Saarbrucken Z0o ............ 173

A-9 Mandrills at Lincoln Park Zoo .............. 176

A-10 Mandrills at Brookfield Zoo ................ 176

A-11 Mandrills at Milwaukee County Zoo ............ 178

A-12 Mandrills at Tulsa Zoo ................ 179 


\section{LIST OF FIGURES}

FIGURE
PAGE

$\|$ Papionin mtDNA cladogram $\ldots \ldots \ldots \ldots \ldots \ldots \ldots \ldots$

II-2 Historic distribution of drills and mandrills in Africa . . . . . 11

II-3 Historic population of zoo mandrills . . . . . . . . . 19

II-4 Summary of hypotheses $\ldots \ldots \ldots \ldots \ldots \ldots \ldots \ldots \ldots \ldots$

IV-1 Summary of hypotheses $\ldots \ldots \ldots \ldots \ldots \ldots \ldots \ldots \ldots \ldots$

IV-2 Effect of forage on activity $\ldots \ldots \ldots \ldots \ldots \ldots \ldots \ldots \ldots$

IV-3 Effects of husbandry style on activity $\ldots \ldots \ldots \ldots \ldots \ldots$

IV-4 Effect of rearing history on aberrant behaviors . . . . . . . 77

IV-5 Effect of female inactivity on proximity $\ldots \ldots \ldots \ldots \ldots \ldots . . .80$

IV-6 Clusters of female-to-male social behaviors $\ldots \ldots \ldots \ldots \ldots 81$

IV-7 Clusters of male-to-female social behaviors $\ldots \ldots \ldots \ldots \ldots 8$

IV-8 Effect of proximity on allogrooming $\ldots \ldots \ldots \ldots \ldots \ldots$

IV-9 Effect of coactivity on allogrooming . . . . . . . . 85

IV-10 Sequence of sexual behaviors . . . . . . . . . . 87

IV-11 Effect of allogrooming on anogenital examination $\ldots \ldots \ldots 89$

IV-12 Summary of main results of hypothesis tests $\ldots \ldots \ldots \ldots . .91$

V-1 Summary of hypotheses $\ldots \ldots \ldots \ldots \ldots \ldots \ldots \ldots \ldots \ldots$

V-2 Assumed causality of hypotheses ............. 105

V-3 Proximity relations in Zoo Hanover drill group . . . . . . . . 117

V-4 Proximity relations in Zoo Atlanta drill group . . . . . . . 118

VI-1 Model for "passive and withdrawn" appearing drills . . . . . 130 


\section{CHAPTER I}

\section{INTRODUCTION}

The drill (Mandrillus leucophaeus) is an endangered species of African monkey, and its sole congener, the mandrill ( $M$. sphinx), is vulnerable to extinction (Groombridge, 1993). Both species are threatened by deforestation and hunting (Gadsby et al., 1994). Drills are endangered in captivity as well (Gadsby et al., 1994), apparently because of behavioral deficits in many captive drills which have reduced breeding and mother-rearing of offspring (Cox, 1987a, 1989; Schaaf, 1990). Mandrills have been reproductively successful in captivity (LaRue, 1995). It has been suggested that information from research on captive mandrills could be used to enhance captive drill environments with the goal of allieviating drill behavioral problems, and so facilitate drill reproduction (Cox, 1989).

\section{RELATING CAPTIVE ENVIRONMENT TO BEHAVIOR AND REPRODUCTION}

Hediger (1964) argued that captive environments should be based on knowledge of a species' natural history. Recently, Carlstead and Shepherdson (1994) have reviewed studies relating to the proximal psychological miechanisms by which captive environments affect behavior 
and reproduction in various zoo mammals. An enriched environment during an animal's early development allows many and varied opportunities for it to learn about contingencies between their behavior and its outcomes. This allows them to make active behavioral responses to new experiences throughout their life, including key reproductive events such as mating, parturition, and offspring development. Also, an enriched environment permits animals to learn to cope with stressors by giving them options for appropriate responses to those stressors. This reduces chronic stress, which is known to depress reproductive function. They conclude by summarizing what is known and what remains to be learned:

We know that increasing the physical and temporal complexity of captive environments can facilitate normal development and coping with stress, reduces abnormal behaviors, increases activity and behavioral diversity, and promotes appropriate social interactions.

However, there is still much to be gained from behavioral research that focuses on a more direct understanding of the relationship between environmental variables and behavioral and physiological reproductive parameters in captive animals.... This requires multivariate analyses on a multi-institutional level designed to investigate the relationships between behavior and specific environmental stimuli, health, husbandry and reproductive results. (Carlstead and Shepherdson, 1994, p. 455)

My dissertation is this kind of multi-institutional study on the relationship between captive environmental variables and behaviors leading to reproduction. I use the literature on wild and semi-free-ranging Mandrillus in Africa, and on zoo Mandrillus, to propose four linked hypotheses: 
1) Genus-appropriate enriched environments increase activity;

2) Active animals form cohesive dyads;

3) Cohesive dyads form affiliative-bonds; and

4) Affiliative dyads show more sexual behavior.

The purpose of this study is to evaluate these hypotheses using data obtained on several captive groups of both drills and mandrills. 


\title{
CHAPTER II
}

\section{LITERATURE REVIEW}

\author{
HISTORY
}

The recorded history of Mandrillus-human interactions in Africa is brief, as the earliest documents are those of Europeans who came to their range when Africa came under European colonial administration late in the 19th century. The following story was told to anthropologist P. Amaury Talbot (1912) in his study of the Ekoi people of the Oban Hills, Cross River State, Nigeria:

\section{WHY [DRILLS] NO LONGER LIVE IN TOWNS By Nitui Nenshaw of Mfamosing}

Once long ago a man named Nshum (Drill Ape) lived in a town. The other men were building houses, but Nshum only ran around, ate their chop, and would do nothing to help. One of the chiefs called to the idler and said, "Why do you not work like all the rest?" To this Nshum did not answer.

A few weeks later all the townsfolk went to cut farm, but Nshum refused to go with them and rernained idle in the town.

Again the chief called and said, "Why do you not go and cut farm like the others?"

On this Nshum was angry, so he said, "I will live by myself, I will not stay in your town any more." With that he left them, and went into the bush.

The head chief ordered the people to take their nets, and go out to catch him. They tried to do this, but he went too far and so escaped them.

At that time men did not like to kill Nshum, because he was a man like themselves, though a very bad one, but in course of years all the lazy people gathered together in the bush, and 
not only drove away the good people who went near them, but tried to do them harm.

One day a hunter went into the bush. He saw some creature moving in the branches of a great tree and shot it. It was Nshum.

Then the hunter caught up the body and dragged it home to his town. He took it before the charm and said to the Diviner:

"I have brought this creature who was once a man, but has now become a bush-beast. You may practice on him on account of his laziness."

The diviner practiced the charm and said:

"He is no longer a human being, but only a wild animal now. You may kill him and eat his flesh."

This is the reason why it is no longer unlawful to eat Nshum. Before the charm was practiced, no one ate him. His name is still that of a person, and if a man is lazy we sometimes call him "Nshum." (Talbot, 1912, p. 78-79)

In addition to the story (above), Talbot (1912) described "taboos" pertaining to the distribution of drill meat among community members. He also reports that among the Ekoi the drill was used as a substitute for human sacrifice because of its resemblance to humans. Talbot also listed names for the drill in five local languages: Nshum, Nsimmbo, Edum, Etum, Eyum in the singular. In the absence of earlier records of drill-human interactions in Africa, the history can only be assumed to be lengthy.

By contrast, a record exists for the exhibition of mandrills and drills in Europe for nearly four centuries (reviewed by Hill, 1970). Mandrills are dramatic in appearance, with bright blue and red skin on their face and anogenital region, orange hair under the chin, and (in the males) exceptionally long canines. They are the largest monkey species. Not surprisingly, they have long been popular zoo animals. The earliest undisputed report of exhibition in Europe is from the Danish royal menagerie in 1670. Buffon in 1766 described male and female mandrills that he had seen in the Paris Menagerie. London Zoo has exhibited mandrills almost continuously since 1829 (Cousins, 1979), and also had mandrills in 1702 and 
1750 (Hill, 1970). Charles Darwin used observations of zoo mandrills in his studies on sexual selection (1871) and animal emotion (1872).

Drills are less colorful than mandrills. Where mandrills have a brilliant blue and red face with a yellow beard, drills have a jet-black face and a white beard; however, the drills' posteriors are nearly as colorful as the mandrills', and their canines are equally long. This facial chromatic difference presumably explains the drills' relative rarity in zoological collections. Nevertheless, several zoos have held drills. Cuvier described the species in 1807 from specimens at the Paris Menagerie (Hill, 1970). The London Zoo also acquired a drill in 1829, but kept only eight during the rest of the 19th century (Cousins, 1979). In England, besides London, zoos in Bristol, Chester and Paignton have kept drills (Cousins, 1979). Twenty-two U.S. zoos have housed drills in the past quarter century (Cox, 1987).

\section{TAXONOMY}

Linnaeus described the mandrill as Simia sphinx Linnaeus 1758, based on Gesner's description and illustration (Hill, 1970). Later, Müller described the genus Papio Müller 1773 and used Simia sphinx as the type species. Baboon species were soon added to Papio, and "baboon" is now used as the common name for Papio. Mandrillus was first used as the genus for mandrills and drills alone by Ritgen (1824; Hill, 1970).

Morphologists have debated often whether Mandrillus is sufficiently distinct from Papio to warrant generic rank (reviewed by Hill, 1970; Disotell, 1994). Jolly (1970) argued that the facial elongation common to mandrills, drills and baboons was reason to consider them congeneric in Papio. Hill 
(1970) used the Cercocebus-mangabey-like sexual swellings in female mandrills and drills, among other characters, to argue for genus rank. More recently, Inagaki and Yamashita (1994) compared hair structure in Mandrillus, Papio and Cercocebus.

Molecular data on papionin phylogeny began to accumulate in the 1970s. A variety of methods, including protein electrophoresis, immunodiffusion, hemoglobin structure, DNA-DNA hybridization, and chromosomal banding, were used (reviewed by Disotell, 1994). None of these methods linked mandrills and drills to the baboons. Instead, geladas (Theropithecus gelada) were found to be the sister-species to the baboons. Next closest were two mangabey species usually referred to subgenus Lophocebus. The remaining mangabey species (Cercocebus) formed a separate group with the mandrills and drills.

Recently, mitochondrial DNA (mtDNA) sequences have been used to investigate papionin phylogeny. Disotell et al. (1992) found that Theropithecus and Papio were very closely related, as were Mandrillus and Cercocebus mangabeys. These two clades were only weakly, and not statistically significantly, more closely related to each other than to the macaques (Macaca). In short, the Papionini tribe of the subfamily Cercopithecinae was divided trichotomously into macaques, baboon/geladas, and mangabey/drills; the latter two groups may be more closely related to each other than to the macaques. Disotell (1994) summarized these relationships in a cladogram (Figure II-1).

A different part of the mtDNA molecule was recently sequenced in several individuals each of 26 catarrhine primate species by van der Kuyl et al. (1995). Their results were the same as Disotell et al. (1992). Mandrillus and 
Cercocebus were closely linked, and only barely more closely tied to Papio/Lophocebus than to Macaca. Van der Kuyl et al. are blunt in applying their results to the taxonomic debate about papionin generic relationships: "Baboons (Papio species) and mandrills (Mandrillus species) form two zeparate clusters, indicating that referring to mandrills (Mandrillus sphinx) as Papio sphinx is not correct" (1995, p. 175).

Tribe: Papionini

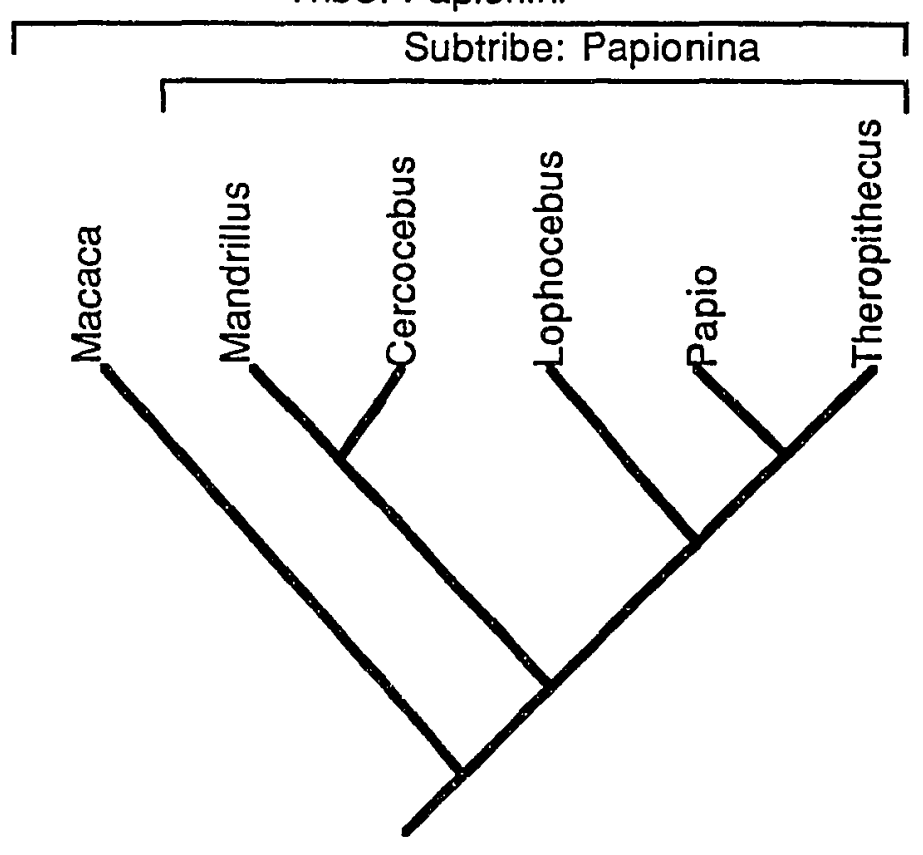

Figure I-1. Old-World Monkey tribe Papionini relationships, based on mtDNA sequences in Disotell et al. (1992) and van der Kuyl (1995).

While it is now clear that mandrills and drills are not baboons, the problem of their correct genus name remains. This is because Linnaeus' Simia sphinx was the first species Müller placed in Papio. The savanna baboons were added to Papio later. By the taxonomist's rule of priority, mandrills and drills are Papio Müller, and the baboons must take the next 
available genus name, Chaeropithecus Blainville (Hill, 1970; Holthuis et al., 1977). Upholding the rule of priority in this case would cause a great deal of confusion, however, as Papio is invariably used for the more common and widespread baboons. Also, baboons are often used in medical research laboratories while mandrills are very rarely used in laboratories. It would be very difficult in practice to change the baboon's generic name (Hill, 1970; Holthuis et al., 1977). If paraphyletic genera are to be avoided, mandrills and drills could not be Papio with the baboons without also including Theropithecus, Lophocebus and Cercocebus in Papio. While this may appear to be the simplest solution to the dilemma, Theropithecus and baboons have lengthy fossil histories showing that they have undergone separate and speciose evolutionary paths since the Pliocene (Fleagle, 1988). The other taxa have less complete or no fossil records. Combining all these genera in one genus (Papio) would contradict accepted practice in other primate taxa. In this study I will follow recent practice by students of the mandrill and drill and use the genus Mandrillus.

\section{Distribution}

Drills and mandrills were once considered to be sympatric over most of their range in equatorial West Africa (reviewed in Hill, 1970). Three subspecies for both were described, based on geography (Table II-1).

Table II-1. Previously recognized Mandrillus subspecies (Hill, 1970).

\begin{tabular}{|c|c|c|}
\hline Geographic Area: & Mandrill subspecies: & Drill subspecies: \\
\hline S.E. Nigeria, S.W. Cameroon & M. sphin $x$ sphinx & $\begin{array}{l}\text { M. leucophaeus } \\
\text { mundamensis }\end{array}$ \\
\hline $\begin{array}{l}\text { S. Cameroon, Gabon, Rio } \\
\text { Muni (Equatorial Guinea) }\end{array}$ & M. sphinx madarogaster & $\begin{array}{l}\text { M. leucophaeus } \\
\text { lescophaeus }\end{array}$ \\
\hline Bioko (Equatorial Guinea) & M. sphinx insularis & M. leucophaeus poensis \\
\hline
\end{tabular}


Grubb (1973) reviewed the museum specimens for the two species and concluded that drills and mandrills were allopatric: drills only occurred north of Cameroon's Sanaga river ( $M$. leucophaeus mundamensis) and on the island of Bioko (M. I. poensis) while mandrills were found only south of the Sanaga river and throughout forested regions of Gabon and Rio Muni ( $M$. sphinx madarogaster). Note the interesting taxonomic nomenclatural result that there is no $M$. leucophaeus leucophaeus or $M$. sphinx sphinx. Figure II-2 shows the historic distribution of the two species.

A study has recently been completed to determine if drills from Bioko and the mainland differ enough genetically to be considered separate subspecies, and it was found that their mtDNA differed significantly (C. D. Schaaf, letter, Sept. 1995). This suggests that M. I. mundamensis and M. I. poensis may be valid subspecies. (Mitochondrial DNA has also been used to identify drill-mandrill hybrids in a captive population: Painter et al., 1993).

Grubb's (1973) museum research preceded several efforts to study drills and mandrills in the wild beginning in the 1970s, which have provided new data on Mandrillus distribution. Most of the field research supports Grubb. Drills, but not mandrills, have been reported from north of Cameroon's Sanaga river (Gadsby, 1990; Gadsby and Jenkins, 1991; Gadsby, 1992; Gadsby et al., 1994) and on Bioko (Schaaf et al., 1990; Gonzalez-Kirchner, 1990). Mandrills, but not drills, have been reported south of the Sanaga river in Cameroon and in extreme northwestern Congo (Hoshino et a!., 1984; Mitani, 1990), and in Rio Muni (Sabater Pi, 1972). 


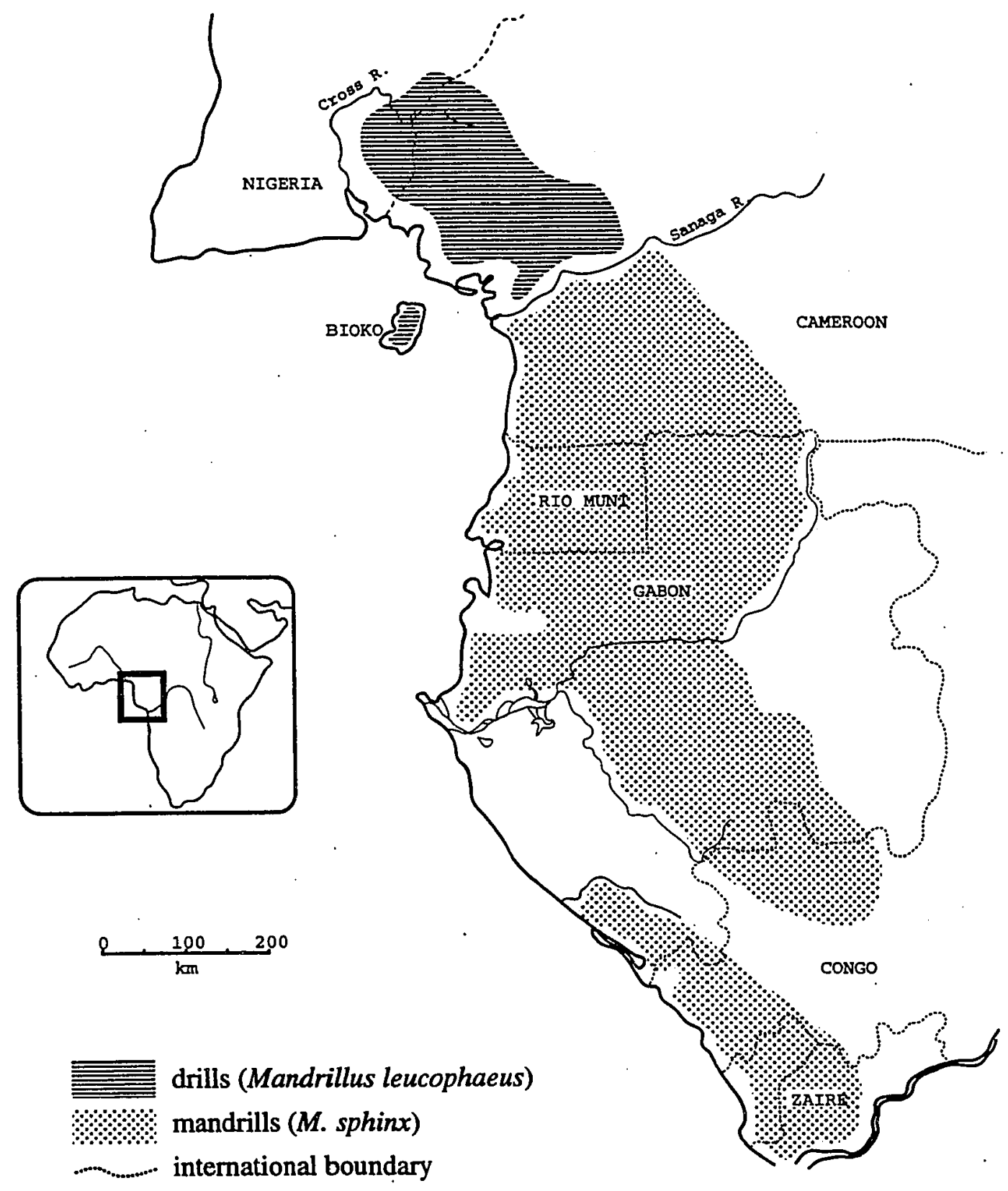

Figure II-2. Historic distribution of drills, Mandrillus leucophaeus, and mandrills, $M$. sphinx, in equatorial west-central Africa. Based on Gadsby et al. (1994). 
The situation in Gabon is more complex. Most field researchers have seen mandrills, but not drills (Jouventin, 1975a; Lahm, 1985, 1986; Harrison, 1988). However, other primatologists have reported seeing drills in the Lopé reserve in central Gabon, where mandrills are also known to be present (Tutin and Fernandez, 1987). K. Barnes, an experienced drill and mandrill keeper at the San Diego Wild Animal Park, told me that she saw a large group of drills, including a fully adult male, cross a road in northern Gabon during daylight in front of her vehicle (pers. comm., Oct. 1994). Blom et al. (1992) (of which K. Barnes is a co-author) conclude that the occurrence of drills in Gabon is an open question that can be answered in the arifirmative only with a photograph or specimen.

Within the geographic range of each species, the monkeys appear to be limited to forest. Mandrills are reported to cross small grassy areas within forests (Jouventin, 1975a; Lahm, 1986; Harrison, 1988), but they do not use savannas, or even savanna gallery forest along streambeds (Lahm, 1986; Harrison, 1988; Blom et al., 1992). Lahm (1986) concluded that mandrills prefer primary forests, but will forage in secondary forests. They also forage in cultivated lands near forests (Sabater Pi, 1972; Jouventin, 1975a; Lahm, 1986; Harrison, 1988). Drills are also limited to forests (Gartlan, 1970; Gadsby, 1990, 1992; Gadsby and Jenkins, 1991; Gadsby et al., 1994), and occasionally eat crops (Gadsby, 1990).

\section{STATUS IN THE WILD}

Drills are considered endangered with extinction, and mandrills are vulnerable to becoming endangered (Oates, 1986, 1994; Lee et al., 1988; 
Stevenson et al., 1992; Groombridge, 1993; Gadsby et al., 1994). There are three reasons for the risk to Mandrillus: 1) limited species' range; 2) habitat destruction; and 3) commercial hunting (Lahm, 1985; Harrison, 1988; Blom et al., 1992; Gadsby et al., 1994; Gadsby and Jenkins, 1995; Anonymous, 1994). It is the difference between drills and mandrills in these three factors that accounts for the drill's more precarious status. The smaller historic range of the drill compared to the mandrill was described above.

\section{Habitat Destruction}

Forest area in the drill's and mandrill's range is decreasing, as it is throughout tropical Africa (Oates et al., 1987). In the mandrill's larger range of southern Cameroon, Rio Muni and, especially, Gabon, human population densities are low (e.g., 1.6 people/km² in rural Gabon in 1983: Blom et al., 1992). As a result, large areas of Gabon's forest are intact, instead of having been cleared for conversion to farmland. Selective logging as practiced in Gabon may not be directly devastating to wildlife (Lahm, 1986; Harrison, 1988; Blom et al. 1992), assuming that the forest is allowed to recover. In a Malaysian forest, Johns and Johns (1995) found that selective logging had a long-term (12 - 18 years) impact on monkey populations only if hunters were allowed access to the recovering forests via the logging roads.

Drills have a smaller historic range, the smallest of any large African primate. Their range in Nigeria and Cameroon is densely populated by people, who clear the forest for cultivation. As a result, the drill's mainland range is split into at least 11 small "islands" of forest totaling about $40,000 \mathrm{~km}^{2}$ (Gadsby et al., 1994). Perhaps half $\left(15,000\right.$ to $\left.20,000 \mathrm{~km}^{2}\right)$ of this remaining forest is actually usable by drills (Gadsby et al., 1994; Gadsby and Jenkins, 
1995). Some of this remaining habitat has been included in the Cross River National Park, Nigeria, and Korup National Park, Cameroon, but in general forests have not received strong legal protection (Anuadu, 1987; Areola, 1987; Oates, 1995). Gadsby and Jenkins (1995) estimate that only 5,000 - 6,000 mainland drills remain. The drills on Bioko are divided between two small areas (Gonzalez-Kirchner, 1990).

\section{Hunting}

Drills and mandrills, as with most other large forest primates, have probably been hunted for as long as people have inhabited their range (Mittermeier, 1987). Talbot (1912) described Ekoi hunting "taboos" pertaining to drills in Nigeria: hunters must share certain parts of male and female drills with particular members of their village. Gadsby (1990) also describes these customs from others areas of Nigeria's Cross River state.

Drills apparently taste good to humans. The late Gerald Durrell, in Cameroon in 1948 on a collecting trip for British zoos, purchased a smoked dril's leg from a hunter: "I ate this leg in a stew, and the hunter was proved correct: it was very fine chop indeed, with a delicate and succulent flavour of beef with the faintest tang of wood smoke about it" (Durrell, 1953, p. 83). Sabater Pi (1972) reported that among the Fang tribe of Rio Muni, 20\% preferred mandrill meat to all other. Gadsby (1990) reported that $77 \%$ of the hunters she interviewed preferred drill meat to that of any other monkey, and overall prefer drill to any other forest animal.

In recent years the economics of hunting have changed completely. Drills and mandrills (and other species) are now hunted commercially for sale in village or city markets, and not primarily for consumption by the hunter 
(Blom et al., 1992; Gadsby et al., 1994). Gadsby and Jenkins have been studying the bushmeat (especially drill) trade in Nigeria and Cameroon since 1989 by interviewing hunters. The following discussion, based on their work, is extensive because most of their results have not been widely distributed (Gadsby, 1990; Gadsby and Jenkins, 1991, 1995; but see Gadsby, 1992; Gadsby et al., 1994).

Professional bushmeat traders called "hunting contractors" supply hunters operating in remote hunting camps with provisions, sophisticated firearms (usually 12-gauge shotguns) and ammunition. The hunters use trained hunting dogs to locate animals and hold them at bay in trees until the hunters arrive to shoot the entire group. The animals are smoked to preserve them until the contractor comes on regular visits. This change in market hunting economics has been made possible by the construction of logging roads that give hunters, and the bushmeat traders who buy from them, access to all parts of the remaining forests. Previously, only forest margins, within about $10 \mathrm{~km}$ of villages or the few roads, were hunted. Loggers, working for cash salaries, are also important purchasers of bushmeat. Bushmeat is considered a luxury food item. It costs considerably more than meat from domesticated animals such as beef, pork, goat, and chicken, which are widely available.

Many species of mammals are hunted. Some hunting methods, such as setting wire snares, are non-specific. Drills, and mandrills within their range, are specifically targeted for three reasons: 1) they draw the highest price per kilogram of all bushmeat types, because of the taste characteristics discussed above; 2) they are heavy: up to $15 \mathrm{~kg}$ in females and $35 \mathrm{~kg}$ in males; and 3) they live in large groups: usually 20 or more. A single drill group could be sold 
for many times the monthly salary of an urban worker. Drills are quite easy to hunt using trained dogs. The only obstacle to a would-be drill hunter is that drills are now quite rare. Talbot (1912) wrote that Ekoi hunters told him that drills were common in the Oban Hills of Nigeria in 1907. Older hunters interviewed by Gadsby and Jenkins reported that drills used to be much more abundant. Elder hunters interviewed by Gadsby (1990) said that drills used to be the most common primate, but that populations had declined. The modal response to the question about the cause of the drill's decline was, "We are killing them plenty"; the next most common response was that hunters now have more and better guns (Gadsby, 1990, p. 24).

Hunting endangered species is illegal throughout the drill's and mandrill's range. The bushmeat hunters are therefore poachers, but enforcement of game laws is weak. Mandrills fare better than drills because they occur throughout much of Gabon (Blom et al., 1992). Gabon has few roads through its forests, making much of it inaccessible to commercial hunters, and a low human population density, reducing bushmeat demand (Lahm, 1985; Tutin and Fernandez, 1987; Harrison, 1988; Blom et al., 1992). However, a railroad has been built across Gabon recently to open the country to logging, and this may impact forest animals like mandrills there (Blom et al., 1992). As has already happened in Nigeria and Cameroon, logging opens the forest to commercial hunters; additionally, loggers provide a ready market for bushmeat because they are already in the forest and they are paid with cash.

Nursing drill infants recovered from their mother's bodies, assuming they survived both the shotgun blast and the fall from the tree, may be sold as pets, but the pet trade does not appear to be an economic force driving the hunting. Recently, Nigerian law enforcement officials have begun confiscating 
some of these pet drills and turning them over to the Drill Rehabilitation and Breeding Center (DRBC) in Calabar, Nigeria. Gadsby and Jenkins founded and administer the DRBC as an in situ captive breeding center for drills (Gadsby et al. 1994). The DRBC is also used to educate Nigerians about drills, and has 150-200 visitors/day. Upon seeing a drill female nursing her infant, one visitor told Gadsby and Jenkins (1995), "That is not bushmeat. That is mother and child." This suggests to me that mythical Nshum (drill: recall the story, above) can be rehabilitated if people who care about drills are not Nshum ("lazy").

I hope that zoos in the U.S., Europe and elsewhere will strive to educate their visitors about drills, mandrills and other endangered wildlife. To do this, zoos must successfully breed animals ex situ. The purpose of my study is to learn about drills and mandrills in captivity so that they can be successfully bred.

\section{STATUS IN CAPTIVITY}

This section reviews the difficulties zoos have had with captive propagation of Mandrillus and concludes that the situation in captivity is the same as in the wild: drills are endangered with extinction, while mandrills fare better.

The 1989 masterplan for the Drill Species Survival Plan (SSP) (Cox, 1989) summarized the status of drills in zoos. Between 1960 and 1989, drill births in captivity had decreased from about 10/year worldwide to around five. Infant survivorship to six months had decreased during this period from about $85 \%$ to around $50 \%$. Total population size and the number of zoos with drills 
also decreased. In the U.S., only five of 22 zoos that historically housed them still had drills in 1989. One goal of an SSP is to preserve most of the original genetic diversity of captive populations, but there has been no way to do that for drills. In fact, with low rates of reproduction, the international zoo drill population has been shrinking.

Mandrills appear to be doing much better in zoos. There is not a mandrill masterplan, but a North American mandrill studbook has been compiled and is updated annually (LaRue, 1995). I have used the software edition of the mandrill studbook and the SPARKS Software (ISIS, vers. 1.3, 1994) to perform some demographic analyses to permit comparisons of mandrills with Cox's (1989) results for drills.

During the same years in which the drill population was in decline, the North American mandrill population soared (Figure II-3). The mandrill population plateaued at about 200 around 1986 as zoos' carrying capacities were reached: fertility declined as females were contracepted. These demographic changes occurred without population-level management. As a result, some individuals contributed disproportionately to the genetic composition of the present population, although actual inbreeding has been avoided (data not shown).

In conclusion, mandrills are reproducing well in captivity, but the population needs to be managed to preserve genetic diversity. Genetically underrepresented individuals, such as those with low mean kinship to the population as a whole (Ballou and Lacy, 1995), need to be encouraged to reproduce. The captive drill population, by contrast, is imperiled demographically. Further, there is no way that the small number of reproducing drills can preserve the genetic diversity that the population once 


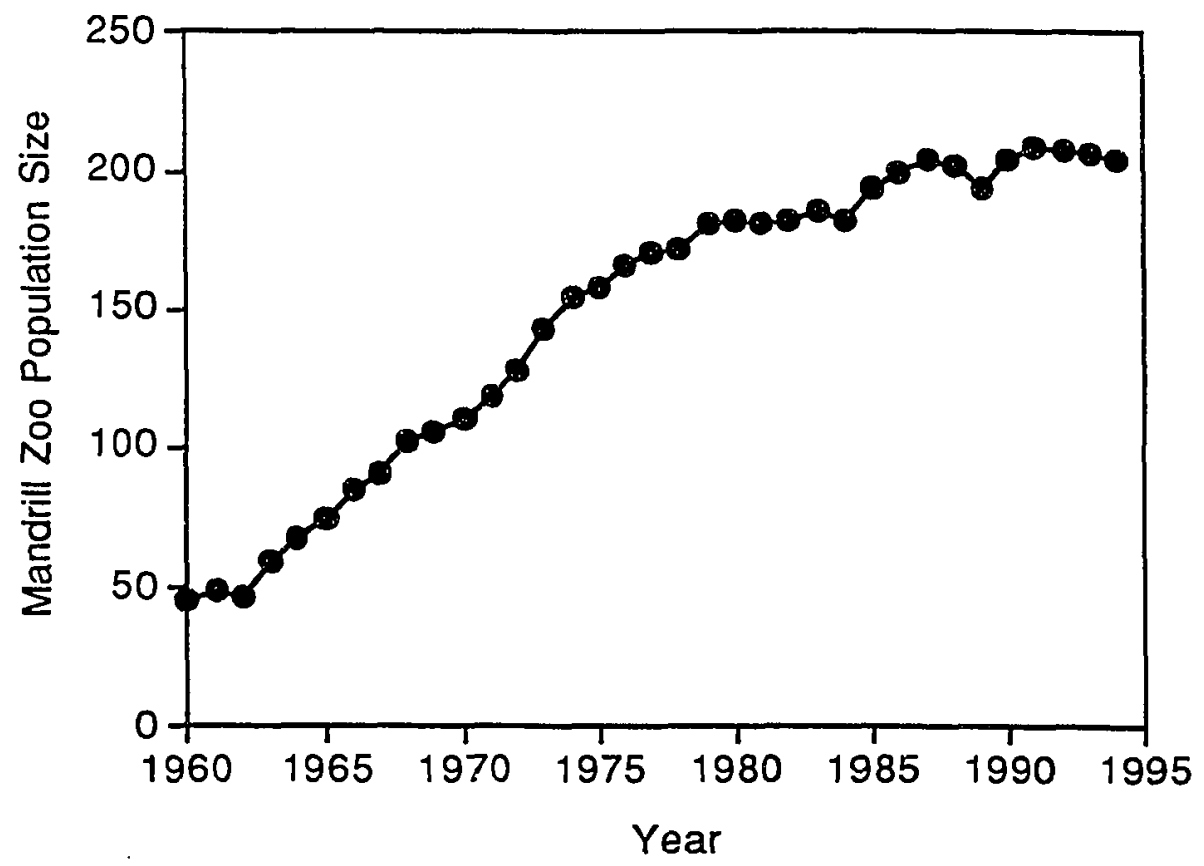

Figure II-3. North American Zoo population of mandrills (Mandrillus sphinx), 1960 to 1994. Data from Mandrill Studbook (LaRue, 1995).

represented, even if the captive drill population does not decline to extinction from lack of reproduction, as appears likely. My research will identify factors that may help underrepresented mandrills, and drills in general, to reproduce in captivity.

\section{Why are Drills Reproducing Poorly in Captivity?}

There are three possible reasons drills are not reproductively successful: 1) they rarely copulate;2) males have low sperm counts and defective sperm; and, 3) the offspring that are produced often die. These three factors--sexual behavior, reproductive physiology, infant mortality--are reviewed below. 
Sexual Behavior. Cox $(1987 a, 1987 b)$ found that drills at the Los Angeles Zoo (Los Angeles, CA, USA) and elsewhere (1989) were not showing normal sexual behavior: copulation occurred very rarely, if at all. Masturbation was the primary male sexual behavior in the drills Cox studied. Hearn et al. (1988) found that the drills then at the Philadelphia Zoological Gardens (Philadelphia, PA, USA) rarely copulated, although copulation was observed at Zoo Hannover (Hannover, Germany), which has a long history of successful drill reproduction (Boër, 1987). Forthman et al. (1994) reported more sexual behavior by a subadult male drill brought from Zoo Hannover to Zoo Atlanta (Atlanta, GA, USA) than by a hand-reared male. The latter masturbated more often, however. These studies strongly imply that the proximal cause for the lack of reproduction in captive drills is the lack of appropriate sexual behavior.

Reproductive Physiology. Recently, Gould and Schaaf (1994) reported on comparative semen parameters in captive drill $(n=6)$ and mandrill $(n=3)$ males. Males of both species produced comparable volumes of semen, but the mandrills had much higher sperm counts. Interestingly, testes volumes when measured under pressure were lower in the drills, but there was no testicular volume difference between drills and mandrills when measured without applied pressure. In other words, male drills had softer, not smaller, testes than did male mandrills. Gould and Schaaf (1994) speculated that this could be a result of altered gonadotropin releasing hormone (GnRH) activity, as experimental manipulations of GnRH levels in rhesus macaques (Macaca mulatta) reduced testes turgidity and inhibited spermatogenesis. The authors note that low sperm counts, as seen in the drills in their study, are not necessarily indicative of infertility, as aspermia would be. One drill in their 
study was a subadult (four years old) and, as expected for his age, had a low sperm count, but his testes were as turgid as the mandrills'. This male sired an offspring not long after the semen sampling, which showed that a drill with a presumably low sperm count was also fertile. This male was the same motherreared male who showed copulatory behavior in the study by Forthman et al. (1994) cited above. Gould and Schaaf (in prep.) are currently investigating reproductive parameters in female drills and mandrills. Preliminary results did not show significant species differences (Schaaf, 1990).

In conclusion, the one study of reproductive physiology is suggestive of endocrinological differences between drills (with poor reproductive success) and mandrills (who are generally reproductively successful). More research is needed to investigate the possibility that there are hormonal differences related to reproductive success in the captive Mandrillus population. However, it must be stressed that sexual behavior and endocrinology are intimately linked, as is emphasized in the name of the productive field of "socioendocrinology." Aspects of socioendocrinology were reviewed for mammals in general by Bronson (1989), by Dixson and Lioyd (1988) for various new-world and old-world monkeys, by Abbott (1993) for marmosets and tamarins, by Bercovitch and Goy (1990) for macaques, and by Sapolsky (1993) for baboon males. Reproductive function is affected by brain activity, in part via the hypothalamus-pituitary gland-gonad axes.

Infant Mortality. Cox (1987a, 1989) reported that captive drill infant survival had declined from $86 \%$ in the 1960 s $(1960-1968)$ to $51 \%$ in the early 1980 s (1978 - 1986). Cox has proposed two explanations. First, the captive drill population may be becoming inbred (Cox, 1987a). Close inbreeding is known to increase stillbirths and neonatal mortality in various species of 
captive mammals, including one group of mandrills (Ralls and Ballou, 1982). However, the pedigrees of captive drills are so incomplete that this hypothesis cannot be tested with existing studbook data. The genetics of the captive drill population may need to be investigated to determine whether a potential problem with inbreeding exists. I suggest that this could occur in conjunction with an effort to determine the subspecific status of captive drills.

The other explanation proposed for the high infant mortality in captive drills is inadequate maternal care (Cox, 1989). Inadequate maternal care has been directly implicated in the death of at least one mandrill infant (Littlewood and Smith, 1979). Cox (1989) has suggested that enclosure size and design might be improved to enhance maternal care, as has been proposed for mammals generally by Baker (1994). There is also a large body of literature from laboratory rhesus macaques indicating that hand-reared females are not good mothers ("motherless-mothers": Harlow and Harlow, 1962; Ruppenthal and Sackett, 1979; Champoux et al., 1992), in addition to showing other behavioral abnormalities (Harlow and Harlow, 1962; Erwin and Deni, 1979).

In conclusion, there is good reason to believe that the problem with captive drill reproduction is primarily behavioral, either directly or indirectly via socioendocrinological influences. Zoo biologists have argued that behavior is the logical starting point for studies of reproductive failure in captive animals (Thompson, 1993; Lindburg and Fitch-Snyder, 1994).

\section{Theory in Zoo Biology}

The problem of poor reproduction in captive drills is typical of those addressed by the field of zoo biology, the applied field of zoology concerned with captive exotic animals. The theoretical foundation for zoo biology was 
established by its founder, Heini Hediger. Hediger (1964) asserted that knowledge of a species' natural history, from study of the species in the wild, was the logical basis for husbandry of the species in captivity. Hutchins et al. (1984) used this theory to guide them as they re-designed exhibits at the Woodland Park Zoo (Seattle, WA, USA) to be more "naturalistic:"

Ideally, a captive environment would be a true simulation of a species' natural habitat, with the possible exception of its predators, parasites and diseases. This, of course, is not possible, but certain essential characteristics of the physical and social environment can and should be duplicated. (Hutchins et al., 1984, p. 28; emphasis added)

Maple and Finlay (1989) also used knowledge of species' natural history as gleaned from extensive literature reviews to redesign primate exhibits at Zoo Atlanta. They argued that "...the greater the space, the more complex the environment, the more variable and changing the stimuli are within it, and the more appropriate the social organization, the closer the captive animal will resemble its counterpart in the wild. This is the result that modern zoos are seeking to achieve" (p. 112).

Recently, Snowdon $(1989,1991,1994)$ has used this theory, that captive conditions should be based on the environment in the wild, to define a stringent criterion for evaluating the success of captive breeding programs for endangered primates: animals should be maintained in captive conditions designed so that they have the ability to survive if reintroduced into the wild. Reintroduction of zoo-born golden lion tamarins (Leontopithecus rosalia) to the Atlantic-coast rainforest of Brazil is an ongoing example of the application of this ideal (Beck and Castro, 1994). 
Given this ideal, what are the "essential characteristics" of Mandrillus' environment? Following is a review of the literature on Mandrillus in the wild, designed to suggest possible "essential characteristics" for successful captive propagation. My research will then evaluate the effect of these features on the behavior of captive Mandrillus.

\section{MANDRILLUS IN THE WILD}

Table II-2 summarizes the field studies conducted on drills and mandrills. In contrast with research on monkeys living in open habitats, the number of encounters was low. This is because drills and mandrills live at low densities in rainforest habitats where visibility is limited to about 20 meters. Also, observation times were short because the animals fled when they detected the presence of human observers, presumably because humans are their major predators, as discussed above. In none of these studies were groups habituated to observers. Gadsby (1990) relied on interviews with experienced drill hunters to cope with these methodological problems. It is difficult to assess the reliability of this method, but it is reassuring that her results corresponded closely to those of researchers who observed Mandrillus directly.

From these studies (Table II-2), I gleaned information about six topics that appear to be relevant to the maintenance of this genus in captivity: group size and composition, use of space, polyspecific associations, habitat structure, foraging and feeding, and responses to humans. Below is a summary of the data on each of these topics. Each section concludes with a summary and a brief description of how an ideal captive environment might 
incorporate the characteristics identified, where "ideal" is based on Snowdon's reintroduction criterion $(1989,1991,1994)$. My study tests the hypothesis that the features identified affect behavior in captivity, however.

Table II-2. Reports of field studies on Mandrillus.

\begin{tabular}{|c|c|c|c|c|c|}
\hline Source & Species & Location & $\begin{array}{l}\text { Duration } \\
\text { (months) }\end{array}$ & $\begin{array}{l}\text { Number of } \\
\text { Encounters }\end{array}$ & $\begin{array}{l}\text { Total Hours of } \\
\text { Observation }\end{array}$ \\
\hline Gartlan, 1970 & Drill & Cameroon & 15 & 29 & 77.8 \\
\hline Sabater Pi, 1972 & Mandrill & Rio Muni & 21 & 16 & 11.12 \\
\hline Jouventin, 1975a & Mandrill & Gabon & 6 & 39 & 48 \\
\hline $\begin{array}{l}\text { Hoshino et al., 1984; } \\
\text { Hoshino, } 1985\end{array}$ & Mandrill & Cameroon & 27 & 187 & Not specified \\
\hline $\begin{array}{l}\text { Kudo and Mitani, } \\
\text { 1985; Kudo, } 1987\end{array}$ & Mandrill & Cameroon & 14 & 39 & 89.6 \\
\hline Lahm, 1986 & Mandrill & Gabon & 12 & 14 & 16.91 \\
\hline Harrison, 1988 & Mandrill & Gabon & 15 & 11 & Not specified \\
\hline Gadsby, 1990 & Drill & Nigeria & 61 & 2 & Not specified \\
\hline $\begin{array}{l}\text { Gonzalez-Kirchner, } \\
1990\end{array}$ & Drill & Bioko & 3 & 11 & Not specified \\
\hline Schaaf et al., 1990 & Drill & Bioko & 0.5 & 13 & Not specified \\
\hline Mitani, 1992 & Mandrill & Cameroon & 9 & 14 & Not Specified \\
\hline
\end{tabular}

1 Gadsby primarily interviewed hunters in villages.

\section{Group Size and Composition}

Determining the composition of drill and mandrill groups has been a principle objective of many of the studies (Gartlan, 1970; Sabater Pi, 1972; Jouventin, 1975a; Hoshino et al., 1984; Kudo, 1987; Harrison, 1988), and all of the sources on Table II-2 contain some information on this topic. Despite this considerable effort, the data are still insufficient to answer the question definitively. 
Most of the studies (Gartlan, 1970; Sabater Pi, 1972; Jouventin, 1975a; Hoshino et al., 1984; Harrison, 1988) report that drills have a multi-level society similar to that observed in Hamadryas baboons (Papio hamadryas) and geladas (Theropithecus gelada) (reviewed by Stammbach, 1987). Two or more levels of social organization exist. One-male groups consisting of one fully adult male, several adult females (3-10) with infants, and numerous juveniles (8-10). The total group size is about $20(15-30)$. Subadult males (usually only one) are also often present. Two or more of these groups may associate with each other seasonally. Sometimes up to eight or more unimale groups come together, forming very large troops or herds (over 100, up to 344 individuals). These huge assemblages are often referred to by the French term, grandes hordes. Harrison (1988) reported that individual one-male groups were spatially distinct within the grandes hordes he observed.

Kudo (1987), by contrast, used her data on vocalizations to argue that the basic mandrill social group was multi-male. The smaller groups she studied had varying numbers of males, including sometimes none, and these small groups vocalized to each other as if they were one social unit when they dispersed and re-coalesced. She concluded that the small groups that previous studies had reported were actually temporary foraging units, not social groups.

Finally, some studies (Gonzalez-Kirchner, 1990; Schaaf et al., 1990) have reported finding only small (5-20 individuals) one-male groups, and no grandes hordes. Interestingly, both of these studies were of drills in one location on Bioko. This raises the possibility that drill social structure varies geographically. 
A disturbing alternative explanation for variation in drill group structure was proposed by Gadsby (1990). The hunters throughout her study area reported that grandes hordes (called "jams" locally) occurred less often now than in the past because hunting has lowered population densities. Also, Gadsby found that drill group size varied according to local hunting pressure. In areas where the drills had access to large areas of undisturbed forest, groups were larger (over 30 ) than where hunting pressure was heavy (groups of 5-15). The large drill groups in undisturbed forests had one "chief" drill and one to six subordinate "junior chief" adult males, who might be as large as or larger than the dominant male (i.e., they were not all subadults). This would support Kudo's (1987) multi-male group hypothesis.

All of the studies have reported that only adult males are found living solitarily. The assumption is that intense male-male competition for access to females forces the "losers" to leave the groups. Presumably, maturing subadult males are driven away from their natal groups by aggression received from the adult male, and they live alone until they fully mature and can challenge aging "leaders" in other one-male groups. This would also suggest that groups are matrifocal (i.e., females stay together with matrilineal kin, and males disperse). This process, it is important to note, was never actually observed. Alternatively, I speculate that some of the subadult males seen associating with one-male groups might be unrelated "followers" who are in the process of trying to lure juvenile females away in order to establish new one-male groups. This is one alternative male reproductive tactic used by' some subadult Hamadryas baboons (Kummer, 1968; Abegglen, 1984) and geladas (Dunbar and Dunbar, 1975; Dunbar, 1984). Gartlan (1970) observed that the subadult male drills in his study groups occasionally "herded" 
juveniles, but insufficient detail exists to determine if this is functionally the same behavior used by some subadult male Hamadryas baboons and geladas. All-male groups, such as those composed of subadult geladas seen by Dunbar and Dunbar (1975), have never been reported in Mandrillus. In conclusion, the structure of wild Mandrillus groups is not known with certainty. Assuming that the majority of authors (Gartlan, 1970; Sabater Pi, 1972; Jouventin, 1975a; Hoshino et al., 1984; Harrison, 1988) are correct, that Mandrillus social groups are essentially unimale and matrifocal, naturalistic captive groups should at a minimum have one adult male, multiple (at least three) adult females with infants, and numerous (at least eight) juveniles; a subadult male should sometimes be present as well. The adult females would have the opportunity to form kinship matrilines. In such a group, infants and juveniles would grow up with many peers of varying ages to play with, and there would be numerous adults whose behavior they could observe. If zoos attempted to replicate Mandrillus groups observed in the wild they would have groups of at least this size ( $15-20$ total), but ideally they would house multiple males so that male-male competition and/or female choice, the agents of sexual selection that are thought to account for the evolution of sexual dimorphism in mandrills (Small, 1992), could operate in mate selection.

\section{Spatial Relationships}

Hoshino et al. (1984) provide the most complete data on home range in mandrills, but Gartlan (1970) and Jouventin (1975a) provide some additional data. Mandrills use a very large home range in comparison to other sympatric monkeys (Harrison, 1988). The home range of the smallest mandrill group (15 individuals, only one adult male) studied by Hoshino et al. (1984) was $5 \mathrm{~km}^{2}$; 
the larger, multi-male, groups ranged over much larger areas. Groups were not territorial; home ranges of different groups overlapped. Maridrills traveled long distances each day (mean $\geq 2.5 \mathrm{~km} /$ day, depending on the season; Hoshino et al., 1984) looking for food.

In captivity, animals never deplete their local food supply, so they do not need to travel in search of new food sources. More relevant, then, is information on intra-group spacing: over what area do the animals in a group spread themselves out? Unfortunately, the published studies provide few quantitative data on this. I will review what little has been reported.

Gartlan (1970) once observed a group oi 20 individuals (one adult male) moving together so closely that all were within a 35 meter diameter circle. This corresponds to an area of $962 \mathrm{~m}^{2}$. It seems that Gartlan reported this observation only because this group appeared unusually cohesive; i.e., this was a minimum area.

Hoshino et al. (1984) once observed a large mandrill group (at least 39 individuals, including four adult males) together in an even smaller area: 26 meters by 16 meters $\left(416 \mathrm{~m}^{2}\right)$. They speculate that mandrill groups stay close together to maintain cohesion where dense undergrowth reduces visibility, and especially when alarmed (e.g., when observed).

Kudo (1987) did not report spatial relationships within the foraging subgroups of mandrills she studied, but they were apparently fairly cohesive. As already noted, the foraging groups vocalized to each other. Groups were often within 100 meters of each other.

Additionally, Jouventin (1975a) reported that at dusk the members of a one-male group usually slept in the same tree at night. Infants and juveniles slept in clusters around individual adult females, presumably their mothers. 
On one occasion a group slept in three neighboring trees, but this was apparently unusual.

In conclusion, it appears that Mandrillus groups are spatially cohesive even though they use large home-ranges through which they travel long distances in search of food. If zoos are to emulate wild conditions, captive environments need not be enormous, but they should permit natural-sized groups to forage over areas large enough for the animals to spread themselves out: ideally several hectares, but perhaps $400 \mathrm{~m}^{2}$ at a minimum.

\section{Polyspecific Associations}

Several studies have reported that Mandrillus groups are occasionally found near (within 50 meters) other groups of other primates (Sabater $\mathrm{Pi}$, 1972; Jouventin, 1975a; Harrison, 1988; Gonzalez-Kirchner, 1990; Schaaf et al., 1990; Gadsby, 1990; Mitani, 1993). Guenons (Cercopithecus spp.), colobines (Colobus and Procolubus spp.), and mangabeys (Cercocebus and Lophocebus spp.) are mentioned most often, and sometimes chimpanzees (Pan troglodytes) and gorillas (Gorilla gorilla). With the monkeys it is sometimes noted that mandrills foraged terrestrially on fruit dropped by the more arboreal guenons.

These associations appeared to be temporary, but were frequent enough that Mandrillus individuals could learn to recognize and respond to alarm vocalizations of other species (Jouventin, 1975a).

In conclusion, Mandrillus groups sometimes associate with groups of other monkeys. Ideal captive environments for Mandrillus would include one or more species of arboreal monkey, at least occasionally. 


\section{Habitat Structure}

Every study (Table $11-2$ ) reported that Mandrillus lives in rainforests, which are structurally complex. The rainforests have trees which the animals climb to find food, although actual travel is done on the ground. Trees are also used to escape predators (unsuccessfully in the case of predation by humans, as was described above). In one environment where tree heights were low (30 meters), drills fled by climbing down cliffs into canyons (Schaaf et al., 1990). The forests have undergrowth limiting visibility (to about 20 meters: Hoshino et al., 1984), and so individuals always have access to visual cover from other group members or human observers.

In conclusion, Mandrillus lives in rainforests, which are structurally complex. Animals have ample opportunities to climb and to take visual cover. Captive habitats, therefore, should be similarly complex. There should also be numerous manipulable objects in addition to these large structural features. $A$ hot, humid climate, with occasional storms and other weather features, such as in an outside enclosure, would also be natural.

\section{Foraging and Feeding}

All of the studies (Table II-2) report that Mandrillus eat fruit as the major component of their diet, but they are omnivorous as they also eat leaves, roots, fungi and animals (arthropods, mollusks and vertebrates; even mammals up to the size of duiker antelopes [Cephalophus spp.]: Kudo and Mitani, 1985). The most detailed studies are those of Hoshino (1985) and Lahm (1986). Hoshino (1985) concluded that mandrills were seed-specialists within the community of frugivorous primates. 
Foraging occurred throughout the day (0700 to 1700 ) and appeared to be the major activity whenever the groups were not traveling between food sites (Hoshino, 1985). Mandrills sometimes forage high in trees, even adult males on occasion (Jouventin, 1975a). More commonly, mandrills forage close to the ground. Hoshino (1985) found that mandrills were within five meters of the ground $66.8 \%$ of the time during the day, even though half of their preferred food items were found above five meters. On the ground, animals frequently turned over objects or dug into the soil in their search for food items. This distinctive turned-soil sign is used by hunters to track drills (Gadsby, 1990).

In conclusion, Mandrillus forage throughout the day for a great variety of food items, especially fruit and seeds but also various animals including vertebrates. About one-third of the foraging is done arboreally (above five meters height). Much of the food is found by turning over objects on the ground or by actual digging. In ideal captivite environments, Mandrillus should have the opportunity to forage continuously. Some of the food (one-third to a half) should be located up high so as to require climbing. Much of the food should be hidden under objects or actually buried in the substrate. The diet should emphasize whole fruit and seeds, but also include leaf and root vegetables, mushrooms, mollusks, arthropods, eggs and small vertebrates. By Snowdon's $(1989,1991,1994)$ criterion, the animals should be skilled predators.

\section{Humans}

The response of wild Mandrillus to humans is typically that of prey to predator: the animals flee immediately upon detecting people (Sabater Pi, 
1972; Jouventin, 1975a; Hoshino et al., 1984; Lahm, 1986; Schaaf et al., 1990). Schaaf et al. (1990) reported that drills had the least tolerance to human observers of any of the seven monkeys in their study area.

There is some evidence that this is a learned response. Gartian (1970) reported that juvenile drills sometimes approached to investigate him, while adult females fled and adult (and subadult) males threatened. Hunters informed Gadsby (1990) that formerly (before intensive hunting of drills began), drills would tolerate human proximity. Some older hunters even reported that in the past they could approach drills close enough to strike them with machetes! Many older hunters said that while drills used to stop and watch humans, they now fled. Drills were also reported to be quieter now than they used to be.

When wild Mandrillus are captured, they appear to habituate quickly to humans. Sabater Pi (1972) reported that he could enter enclosures with mandrills four or five hours after their capture and groom them. This was from an area where mandrills were hunted intensively. Durrell (1953) reported similar behavior in six juvenile drills he purchased from hunters. The drills also directed affiliative behaviors to him.

In conclusion, Mandrillus apparently learn responses to humans appropriate to their relationship with them. In captivity, they would be expected to acclimate to being viewed by the public if they are not harassed, although the provision of cover would be appropriate. Their keepers should develop an affiliative relationship with the animals. 
In the preceding section, I used the literature on wild Mandrillus to suggest possible "essential characteristics" for their maintenance in captivity such that the animals might reasonably be expected to survive if released in the wild (Snowdon's criterion, 1989, 1991, 1994). At this point, the reader familiar with husbandry of zoo animals is likely to dismiss this ideal as impossible in practice. However, just such a facility exists for mandrills: the International Medical Research Center of Franceville (CIRMF), Gabon; another is being developed for drills by the Drill Rehabilitation and Breeding Center (DRBC; Calabar, Nigeria) (Gadsby et al., 1994). Because both reproduction and successful mother-rearing of offspring are occurring at both of these captive facilities, as predicted by the theory developed above, the research that has been conducted at one of these facilities (CIRMF) will be reviewed.

\section{Mandrills at CIRMF}

Feistner et al. (1992) has described the establishment of the CIRMF mandrill facility. Between 1979 and 1984 CIRMF acquired 15 (seven males and eight females) infant and juvenile mandrills from hunters. They were thought to be from 6 to 24 months of age, mostly 12 months, based on dentition. The animals were placed in a 5.3 hectare electrified-fence enclosure of steep gallery forest. They were fed once daily, but obtained most of their food naturally. With the exception of lacking any opportunity to form polyspecific associations with other monkeys, this group appeared to have 
had all of the characteristics of an ideal captive environment which I listed above.

Group Size and Composition. The 15 founders began breeding at an early age: females conceived when about 3.5 years old; males bred as early as five, but usually much later (Feistner, 1988, 1990, 1992; Feistner et al., 1992; Wickings and Dixson, 1992a). This led the population to grow quickly, and by 1990 the group numbered 45 (Wickings and Dixson, 1992a, b, c; Dixson et al., 1993). At this time there were six adult males. Of these, three lived in the group and three were solitary. The social and solitary males were the same age and weight but differed in other ways (Wickings and Dixson, 1992b). The social males were "fatted" in appearance, being shorter and stockier than the solitary males, had larger testes, and had higher blood testosterone levels. They also had more fully developed secondary sexual characteristics. When the two types of males interacted, the social males were dominant to the solitary males. In addition to the adult males, three subadult males also lived in the group.

Feeding and Foraging: Habitat Structure: Spatial Relationships. Norris (1988) studied feeding behavior in the CIRMF mandrill group shortly after it was formed. The mandrills ate a great variety of foods, just as Hoshino (1985) and Lahm (1986) reported for wild mandrills. Foraging occupied an average of $64 \%$ of their time, and occupied over $50 \%$ of their time each hour of the day, between 0700 and 1700 . They did not sleep or rest for long periods during the day. The animals were terrestrial an average of $80 \%$ of the time between 0700 and 1700 , and $77 \%$ of their foraging time was spent on the ground. When they were in trees they were usually within 10 meters of the ground. They foraged in a group, moving through the forest overturning leaf litter and digging in the 
soil. Dominant animals could displace subordinates from preferred foods. At night the group did not all sleep in the same tree. They generally did not sleep in the same trees consecutive nights.

As noted above, Wickings and Dixson (1992b) found that subordinate adult males lived solitarily, almost always more than 100 meters from the group. This was possible because of the large size of the enclosure.

Humans. Boysen (1991) described the experiences of a photographer who entered the CIRMF enclosure while Feistner was conducting her 15month behavioral research study (Feistner, 1990), and has a photograph of Feistner recording data while standing less than one meter from an adult male; the male appears to be ignoring her. The photographer, however, was threatened on two occasions. No other information is available on mandrillhuman relations at the facility.

\section{Development of Hypotheses}

In conclusion, the CIRMF mandrill facility included most of the "ideal characteristics" for a captive environment which I have drawn from a review of literature on wild Mandrillus. Reproduction and mother-rearing of offspring occurred. Is there a connection between these? This question leads to the consideration of the mandrill's behavior. Unfortunately, few details of social behavior in the CIRMF mandrill group have been published, with the notable exception of Feistner's (1991) report of scent marking. The following scenario is based on published information augmented by reviews of behavior in other papionin monkeys (in Smuts et al., 1987; also, Kummer, 1968; Dunbar and Dunbar, 1975; Dunbar, 1984; Abbeglen, 1984; Smuts, 1985). 
The CIRMF mandrills were active throughout the day, as reported by Norris (1986). Their activity promoted group cohesion; i.e., they foraged and engaged in other behaviors together, and were often in proximity (Norris, 1986). This cohesiveness presumably facilitated affiliative-bonding, at least between the dominant adult male and females (Feistner, 1990; Dixson et al., 1993). These affiliative male-female pairs showed behaviors leading to copulation (Feistner, 1990; Dixson et al., 1993).

The scenario just described, based on the successfully reproducing mandrill group at CIRMF, is the basis for four linked hypotheses; Figure II-4 illustrates the assumed direction of causality for the variables.

1) Naturalistic environments encourage activity in captive Mandrillus;

2) Active adults form cohesive female-male dyads;

3) Cohesive male-female dyads show evidence of affiliative bonds;

4) Affiliated pairs display sexual behavior leading to copulation.

Hypothesis: 1

2

3

4

Environment

Activity

$\rightarrow$ Cohesion

Affiliation Breeding

Figure II-4. Summary of hypotheses one through four. Arrows indicate the presumed direction of causality.

The remainder of the literature review will describe zoo studies that bear on the development of these hypotheses. The variables involved in testing these hypotheses will be operationally defined in the next chapter. 


\section{Studies on Mandrillus in Zoos}

Mandrills have been the subjects of several zoo studies. Some of these are of narrow theoretical interest, and all concern mandrills, presumably because mandrills have always been available at more zoos. Jouventin (1975b) investigated the significance of male coloration. Jouventin et al. (1977) reported on observational learning. Harlow and coworkers (cited in Hill, 1970) and Balasch et al. (1974) have studied cognitive ability in comparison with other monkey species using various tests. Vincent (1973) described an instance of spontaneous tool-use by an adult male. Horwich (1974) described nursing patterns. Emory (1975a, b, c, 1976) compared the "attention structures" of a mandrill and a gelada group. Below I will review the studies that pertain directly to the variables in the four hypotheses listed above: exhibits and husbandry style, activity, cohesiveness, affiliation, and sexual behavior.

\section{Exhibts and Husbandry}

Group Size and Composition. Zoo mandrills are always kept in smaller groups than the typical group described in the wild, and drills are housed in even smailer groups. The only mandrill group in U.S. zoos whose composition approached that of (smaller) wild groups was at the Tulsa Zoo (Tulsa, OK, USA). Hartley and Bettinger (1995) described some aspects of social behavior in the multimale, multifemale mandrill group at the Tulsa Zoo. Copulation frequency appeared to be high by the two fully adult males. Most aggression was between females of different matrilines. Cox (1987b) simulated an increase in group size by moving a small drill group to an exhibit adjacent to a mandrill group at the Los Angeles Zoo. The presence of 
mandrills nearby increased the rate of several social behaviors in the drill group.

Another important aspect of group composition is the complexity of the social environment experienced by infants and juveniles. Boër (1987) describes infant development in the Zoo Hannover drill group. Verbeek (1987a, b) and Leithoff (1990) wrote college research reports on aspects of infant and juvenile development and play behavior in relatively complex zoo mandrill groups at the Lowry Park Zoo (Tampa, FL, USA) and Milwaukee County Zoo (Milwaukee, WI, USA), respectively. All agree that young Mandrillus do not interact only with their mothers; instead, infants begin leaving their mothers to play with other infants and juveniles when just a few weeks old. Interestingly, sexual behavior is a component of play from an early age.

Several papers describe hand-rearing procedures for infants that are neglected by their mothers (Davis, 1976; Mellen and Littlewood, 1978a, b; Mellen et al., 1978; Littlewood and Smith, 1979; Linke, 1990). Mellen and Littlewood (1978a) describe a successful attempt to reintroduce a handreared male infant (seven months) to its natal group at the Metro Washington Park Zoo. Boër and Sommer (1992) described an unsuccessful attempt to integrate a hand-reared infant (2 months) brought to Zoo Hannover's drill group from another zoo. The adult male threatened the infant. Boër and Sommer (1992) interpreted this behavior to be adaptive male infanticide.

The behavioral development of a hand-reared male infant mandrill has been compared to that of a mother-reared male and a female (Mellen and Littlewood, 1978b; Littlewood and Smith, 1979). The hand-reared infant did not appear to differ behaviorally from the mother-reared infants. As a juvenile 
in a social group with adults and mother-reared juveniles, he was apparently subordinate and mounted others less often than did the mother-reared male (Mellen et al., 1981). Forthman et al. (1994) compared the adult social behavior of a male-female pair of hand-reared drills with a similar pair of mother-reared drills at Zoo Atlanta. The hand-reared drills showed behavioral abnormalities. It was not stated whether the hand-reared animals were reintroduced as infants to a functioning social group containing peers and adults, but $I$ assume that this did not happen as there were no such drill groups in the U.S. when the pair was born.

Area. Spatial Relationships. Chang (1991) reported that time spent in proximity between the adult male and female mandrill more than doubled in the new, naturalistic "habitat" at Zoo Atlanta even though the total area was more than ten times greater than in the former exhibit. Fried and Whitehouse (1991), however, did not find a similar increase in proximity in a mandrill group introduced to a larger enclosure at the Dallas Zoo (Dallas, TX, USA). Previously, I described association patterns in a mandrill group in a two-room enclosure (Terdal, 1993a) at the Milwaukee County Zoo. Low-ranking animals, and especially the subadult male, tended to occupy whichever room the adult male was not in. The two-room design functionally simulated a larger area.

Feeding and Foraging. Chang (1991) found that the Zoo Atlanta mandrills spent $66 \%$ of their time when on exhibit foraging. This is comparable, she notes, to the results Norris (1986) obtained from the CIRMF mandrill group, and much higher than has been found in any previous study of zoo Mandrillus, including the same mandrills prior to their move to the new enclosure. This increase in activity was a result of a move to a large, 
naturalistic, outside enclosure. In a simpler manipulation, Cox and duBois (1992) reported that certain forms of simple feeding enrichment could increase the time spent foraging by two drill groups at the Los Angeles Zoo. Hamilton and Widner (1994) did not find large effects on social behavior of the addition of a planter to a drill group at the Knoxville Zoo (Knoxville, TN, USA). However, the only allogrooming (the important affiliative behavior in which one animal grooms another) ever observed in the group took place a few minutes after the animals were given access to the planter. The animals were said to have spent more time feeding after the planter was added, but specific results were not given.

A unique "foraging" device was tested on a mandrill group at the Metro Washington Park Zoo (Yanofsky and Markowitz, 1978; Markowitz, 1982). A reaction-time game permitted visitors to compete against a mandrill (always the male, who monopolized it). The addition of the game increased the male's activity, even when he was not actually playing the game, and decreased stereotypic pacing in both the male and female.

Humans. Chamove et al. (1988) found that the presence of visitors had very negative effects on the behavior of the small mandrill group (one adult male and two adult females, one a mandrill-drill hybrid) at the Zoological Garden of Vienna (Vienna, Austria). The male watched visitors, threatened them and paced. He never rested when more than five visitors were present, and masturbated only when more than five visitors were present. The females ceased allogrooming when visitors were present and paced. No other studies on the effects of visitors on Mandrillus behavior have been published.

Better interactions between humans and drills occur in positivereinforcement training programs, where the humans are trainers (Desmond 
and Laule, 1994). Desmond et al. (1987) describe efforts to train drills at the Los Angeles Zoo to feed in proximity to each other and to cooperate with artificial insemination efforts. Coincident with this effort, social behaviors increased (Cox, 1987a, b). Positive reinforcement training was used to facilitate husbandry and promote socialization of drills at the San Diego Zoo (Simerson, 1995).

\section{Activity. Cohesion. Affiliative Bonding and Sexual Behavior}

The ability of a naturalistic exhibit to result in activity budgets of $z 00$ animals that resemble those in the CIRMF mandrill group (Chang, 1991) has already been noted. Chang's (1991) study lends support for developing my first hypothesis, that naturalistic captive environments increase activity. As previously noted, Chang (1991) also found that the adult pair's proximity increased along with activity after the move to a naturalistic exhibit, in support of developing my second hypothesis that active animals form cohesive pairs. The adult male-female pair showed somewhat more affiliative behavior after the move, but less sexual behavior. These results support development of my third hypothesis, that cohesive pairs show affiliative behavior, but not my fourth hypothesis, that affiliative behavior leads to sexual behavior.

Terdal (1993a) found that matrilineal kinship enhanced proximity in a mandrill group at the Milwaukee County Zoo. The most frequently proximal non-kin dyad, the adult male and dominant adult female, also showed the highest rates of affiliative social behaviors, including allogrooming, and sexual behaviors leading to copulation (Terdal, 1993b, and unpubl. data). These results supported the development of my third and fourth hypotheses, that cohesive dyads engage in more affiliative behaviors, and that affiliative pairs 
are more sexually active. Terdal (1993b) also contained some information about affiliative behaviors in heterosexual adult dyads at three zoos. Mellen et al. (1981) described affiliative social behaviors in a mandrill group at the Metro Washington Park Zoo. Virtually all allogrooming was by mothers to offspring. The adult male never gave or received allogrooming. Mellen et al. (1981) also described sexual behavior in the Metro Washington Park Zoo mandrill group. Particular affiliative social behaviors were used in courtship leading to mating.

Summary of Zoo Studies Relating to Development of my Hypotheses In conclusion, an evaluation of studies on zoo Mandrillus provided background for development of four hypotheses from a review of Mandrillus in the wild and at CIRMF. Only Chang's thesis (1991) addressed several of the relevant variables simultaneously. Her research was on just one mandrill group, however, and it is difficult to know how generalizable her findings of beneficial effects of a naturalistic environment are to other groups. Also, her pre-post, case-study design does not permit analysis of the effects of the various components of the captive environment which were a part of their new habitat. Exactly which specific aspects of the new environment truly benefited the animals? How do the effects vary between groups, and why? A different research design is necessary to answer these questions. My study used travel to multiple institutions with Mandrillus groups to answers these questions, a method used previously by doctoral students to collect data for their dissertations on other taxa (reviewed by Mellen, 1994). The details of the design of my present research project, to evaluate the hypotheses, are covered in the next chapter. 


\section{CHAPTER III}

\section{METHODS}

\section{MANDRILLUS GROUPS: COMPOSITION, EXHIBITS AND HUSBANDRY}

All of the drill and mandrill groups visited are listed in Table III-1. The groups are described in detail in the appendix.

Every drill in the U.S. and German zoo population was observed; there are very few other captive drills outside of their range in Africa (R. Wolf, pers. comm., Jan. 1995). Mandrill groups were chosen primarily on geographical criteria; most were in Portland (Oregon, USA) or nearby (San Fransisco, California, USA), or in a cluster of five zoos in and around Chicago (Illinois, USA). The Knoxville Zoo and the Saarbrucken Zoo (Saarbrucken, Germany) had both drills and mandrills. The only exception was Tulsa Zoo, whose large mandrill group was selected for a visit because of its size.

\section{Criteria used to Define Age Classes}

Wickings and Dixson (1992b) described mandrill sexual and somatic maturation, and I have used their results from CIRMF to define four ageclassifications (infant, juvenile, subadult, adult; Table III-2). For my hypotheses two, three and four, which concern the behavior of female-male pairs, only the behavior of subadult or adult animals, as defined using these age criteria, was considered. 
Table III-1. Drill and mandrill groups viewed.Details of groups are in the appendix. "Hours" represents the number of hours of formal observations used in this study. Hours in parentheses indicates data collected previously but not used for this study. The number of males and females is indicated with numerals left and right of the decimal: "1.2" means one male and two females.

\begin{tabular}{llllll}
\hline Species & Zoo, Group & Time of Visit & Hours & M.F Adults & Juveniles \\
\hline Drill & Los Angeles, N. & October, 1994 & 10 & 0.1 & 1.0 \\
Drill & Los Angeles, S. & October, 1994 & 20 & 1.1 & 0 \\
Drill & Los Angeles, Off & October, 1994 & 10 & 1.1 & 0 \\
Drill & San Diego, CRES & October, 1994 & 40 & 1.3 & 0 \\
Drill & San Diego, MH & October, 1994 & 0 & 1.0 & 0 \\
Drill & San Diego, MH & October, 1994 & 0 & 0.2 & 0 \\
Drill & San Diego, Res. & October, 1994 & 0 & 1.0 & 0 \\
Drill & San Diego, Res. & October, 1994 & 0 & 0.1 & 0 \\
Drill + & Knoxville & November, 1994 & 40 & $1.2(+0.1$ & \\
Mandrill & & & & mandrill) & \\
Drill & Atlanta & November, 1994 & 40 & 1.2 & 1.1 \\
Drill & Wuppertal, AH & February, 1994 & 40 & 1.2 & 0 \\
Drill & Wuppertal, Hosp. & February, 1994 & 0 & $0.1 / 0.1$ & 0 \\
Drill & Hannover, AH & January, 1994 & 40 & 1.3 & 1.1 \\
Drill & Hannover, Off & January, 1994 & 0 & 0 & 2.0 \\
Drill & Stuttgart & March, 1994 & 0 & 0 & 1.1 \\
Drill & Saarbrucken & February, 1994 & 20 & 1.3 & 0 \\
Mandrill & Saarbrucken & February, 1994 & 20 & 1.1 & 0.1 \\
Mandrill & Lincoln Park, S. & December, 1994 & 30 & 1.1 & 0.1 \\
Mandrill & Lincoln Park, N. & Dec., 1994 (et al.) & 0 & 1.1 & 0 \\
Mandrill & Brookfield & Dec., 1994 (et al.) & $10(50)$ & 1.4 & 2.0 \\
Mandrill & Milwaukee & Dec., 1994 (et al.) & $10(50)$ & 1.3 & 0 \\
Mandrill & Tulsa, Group & March, 1994 & 20 & 0.4 & 3.5 \\
Mandrill & Tulsa, Males & March, 1994 & 0 & $1.0 / 1.0$ & 0 \\
Mandrill & Portland & From August, 1990 & $0(50)$ & 1.5 & 0 \\
Mandrill & Lansing & September, 1992 & 0 & 1.3 & 2.1 \\
Mandrill & San Francisco & July, 1993 & 0 & 1.2 & 0 \\
Mandrill & Madison & December, 1993 & 0 & 1.1 & 1.0 \\
\hline & & & & & \\
\hline
\end{tabular}


Table III-2. Age classes of female and male Mandrillus, based on data from the CIRMF mandrill group (Wickings and Dixson, 1992b). Events associated with attainment of each age class are noted in parentheses. Age of occurrence of these events varied among individuals, however.

\begin{tabular}{lll}
\hline Age Class: & Female Age (criteria): & Male Age (criteria): \\
\hline Infant & Birth to 12 months & Birth to 12 months \\
Juvenile & 12 months (complete deciduous & 12 months (complete deciduous \\
& dentition) to 36 months & dentition) to $48-60$ months \\
Subadult & Three years (typical first perineal & Four or five years (testicular volume \\
& swelling [and sometimes & increasing linearly; Leydig celis \\
& conception]) to five years & responsive to GnRH) to eight years \\
Adult & Five years (adult body weight [10- & Eight years (adult testosterone level, \\
& 15 kg] nearly achieved, and weight & testicular volume and body weight \\
& gain declines; usually the female is & [30-35 kg] achieved) and older. \\
& a mother) and older. & Fatted or non-fatted body type. \\
\hline
\end{tabular}

\section{Exhibit and Husbandry Variables}

The descriptions of the exhibits and husbandry for each group studied, contained in the appendix, are based on notes made, and photographs taken, throughout my visits to each zoo. These original notes and the photographs were referenced when I quantified aspects of exhibitry and husbandry as variables to use as hypothesis one predictor variables. These exhibit and husbandry variables are listed on Table III-3. The ordinal variables, those for which I assigned each group an integer score of $1-5$, were based on the full range of environments observed at all of the groups listed on Table III-1 - not just those from which behavior data was recorded. A " 3 " was assigned to "typical" groups, based on my experience with the full range of environments observed. 


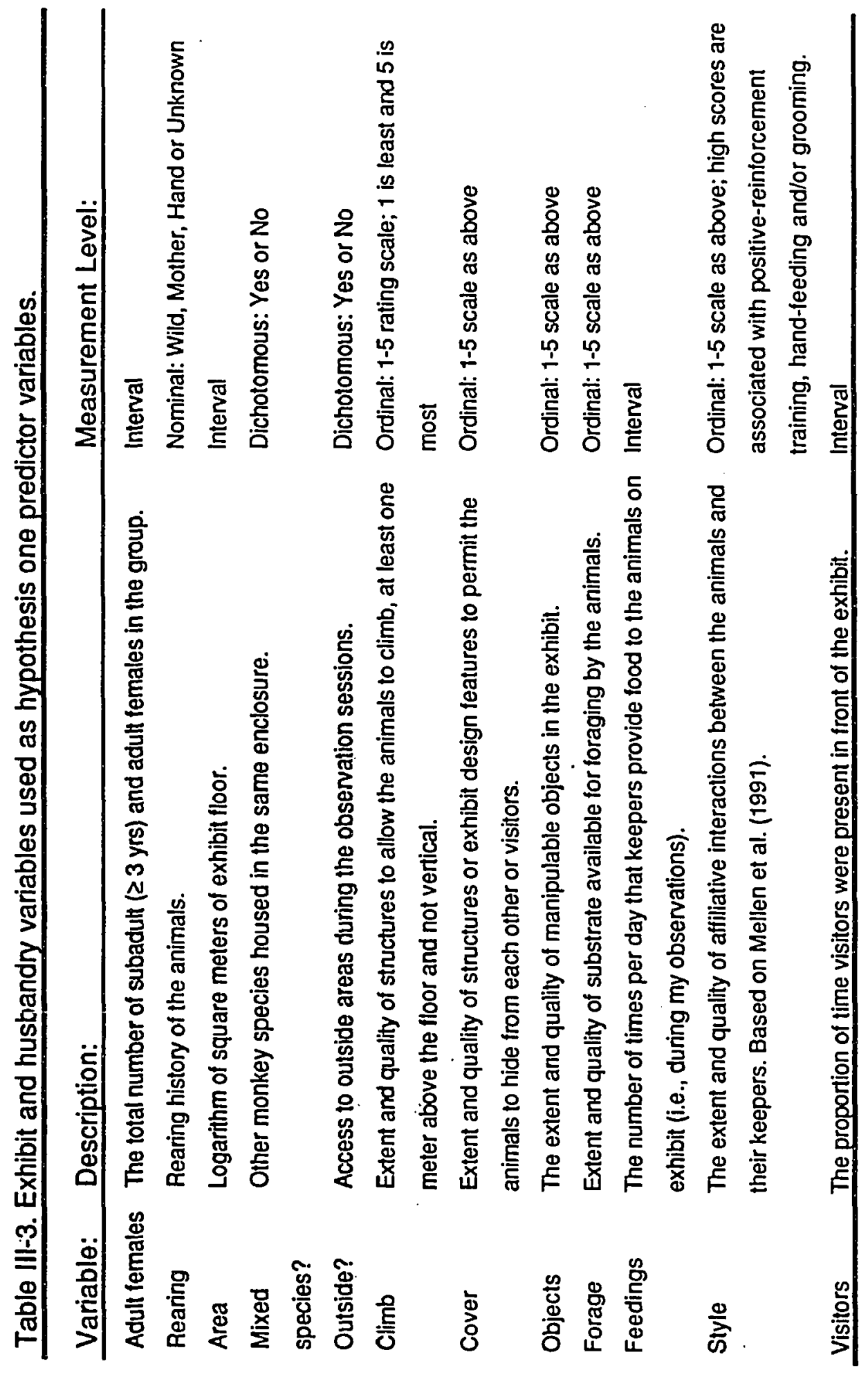




\section{BEHAVIORAL DATA}

\section{Ethogram}

Two sorts of behaviors were recorded: states and events. The behavioral states considered are listed in Table III-4. The list is exhaustive and mutually exclusive; recording rules are discussed below. The states are listed in order of priority for scoring, such that if the descriptions of two or more states are both applicable, only the higher state is recorded. For example, if an animal is "foraging" while "exploring" the substrate and "locomoting," only "foraging" is scored. Other states recorded were four levels of proximity (in contact with an animal, within one meter of an animal, or greater than five meters from any animal) and height (on the ground vs. at least one meter above ground). The presence or absence of visitors was also recorded simultaneously.

Behavioral events recorded are listed in Table III-5. Both lists--of states and events--are based on the Drill Species Survival Plan (SSP) ethogram (Cox and Hearn, 1989) and differ from that source only slightly. The Drill SSP ethogram is based on Cox (1987a) and Hearn et al. (1989). Fried and Whitehouse (1991) and Bettinger (unpubl.) have developed mandrill ethograms; all of the Mandrillus ethograms are similar to the mandrill ethogram of Mellen et al. (1981), which I have used previously. Over 150 hours of data I collected previously on three mandrill groups (Terdal, 1993b, and unpubl. data) were not used for this study, and may be considered practice. Prior to collecting data on any drills, I viewed a videotaped version of 


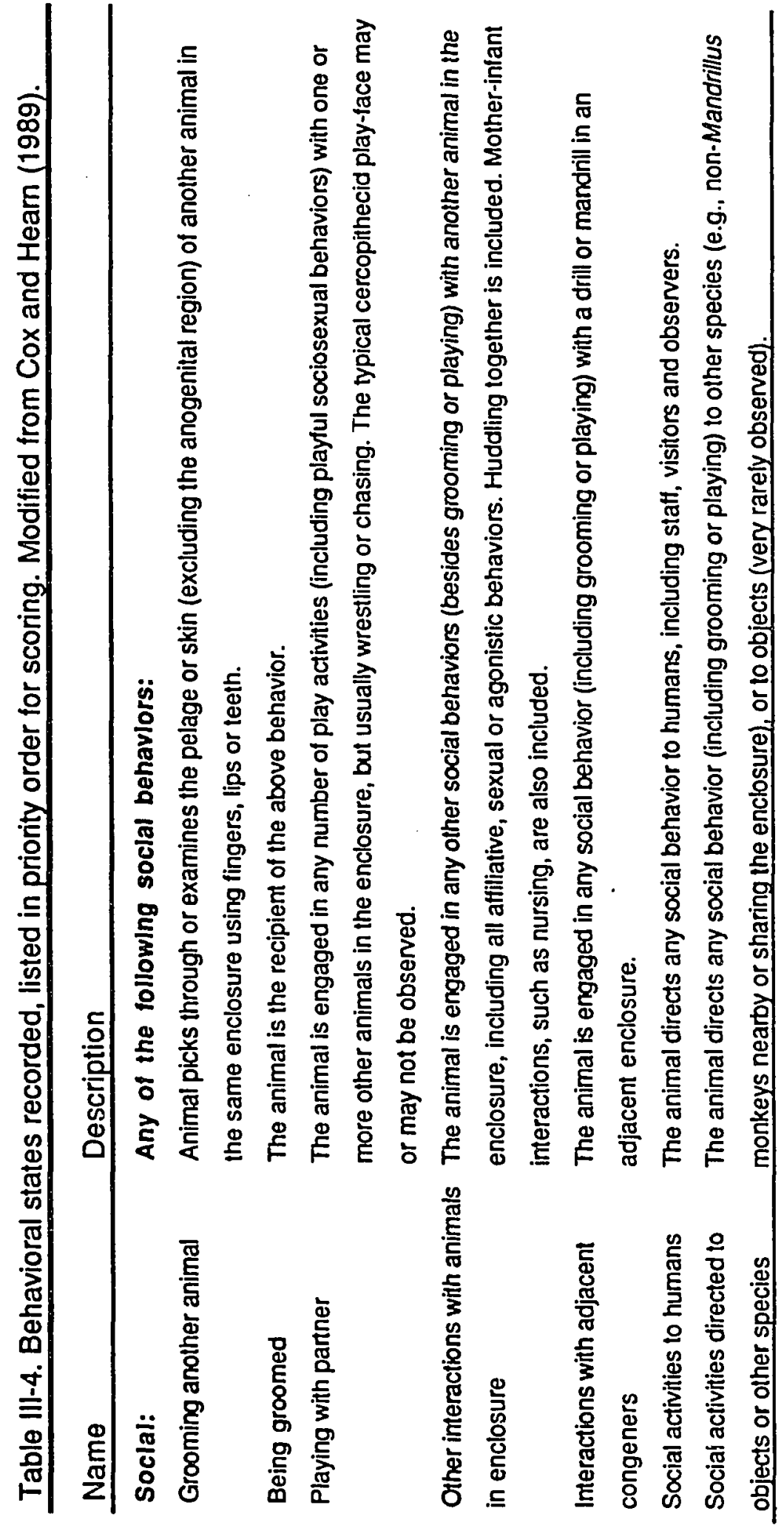




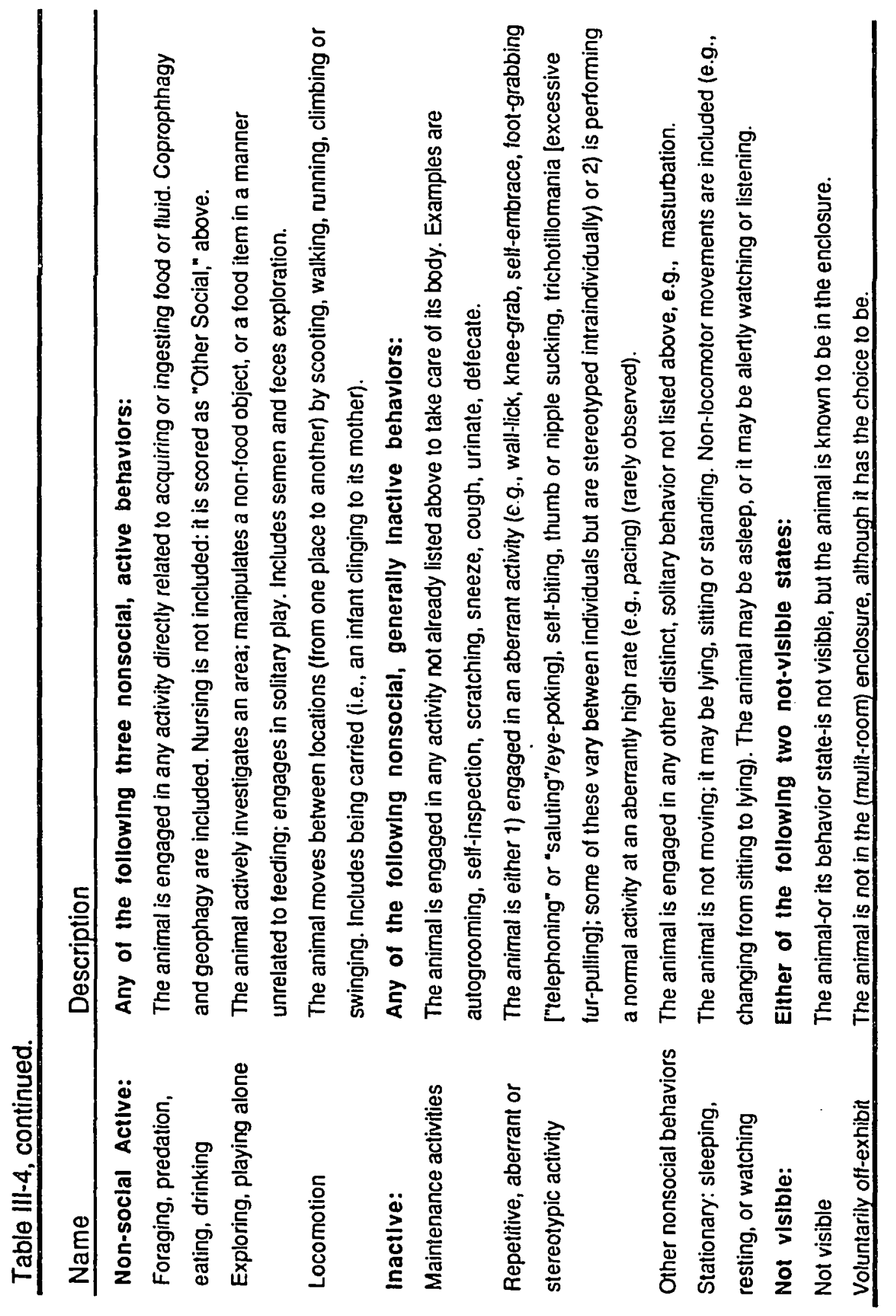




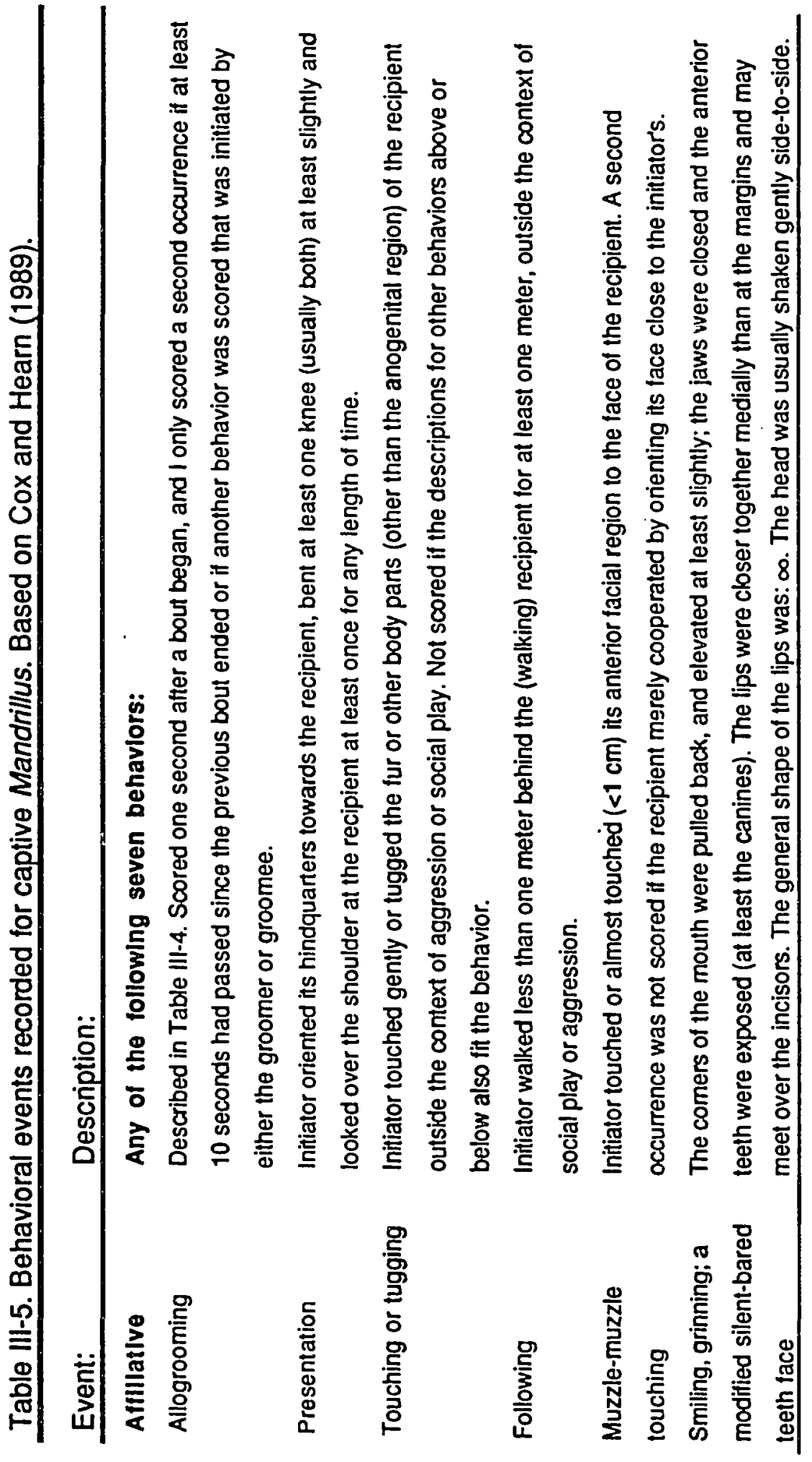




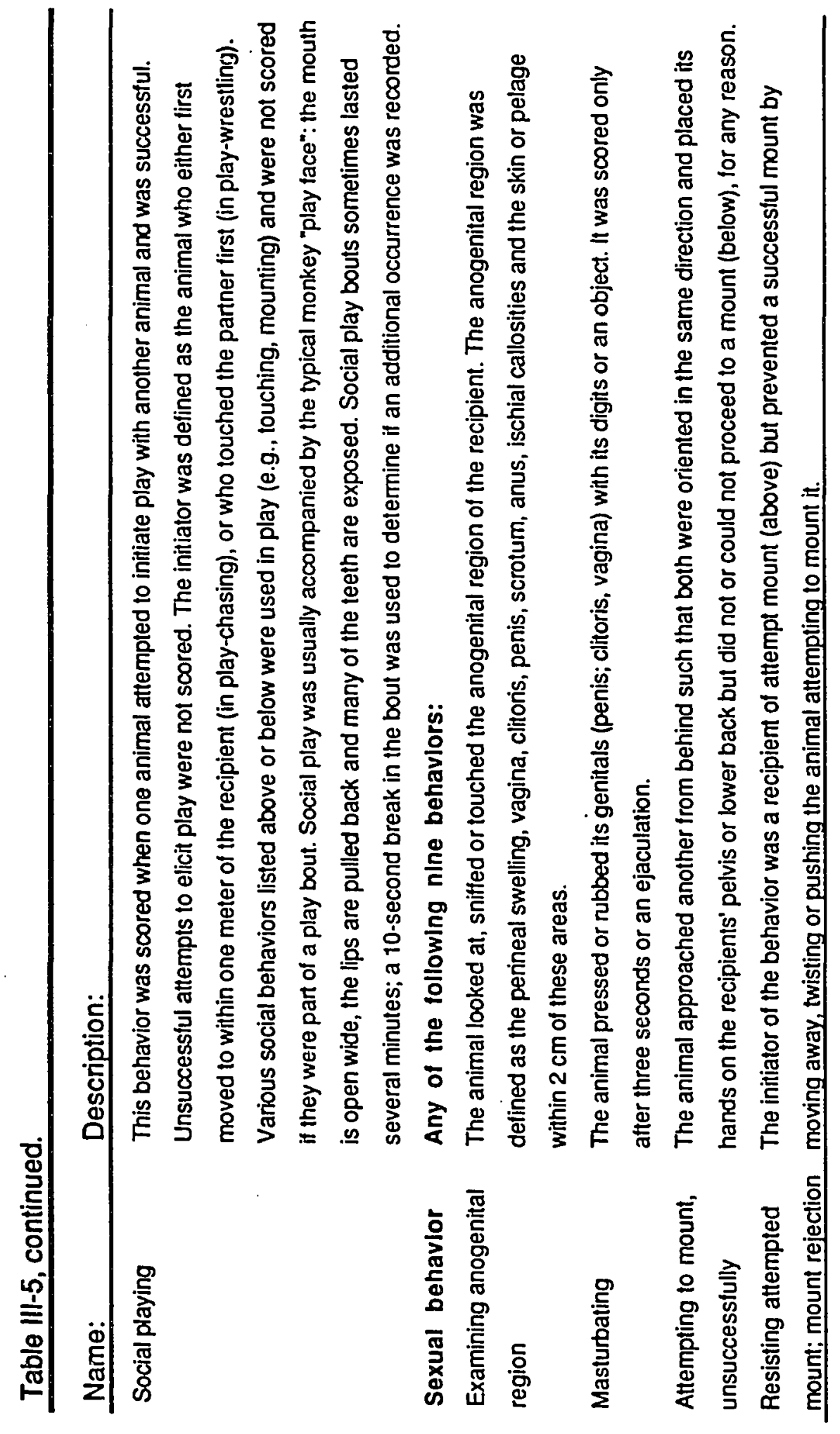




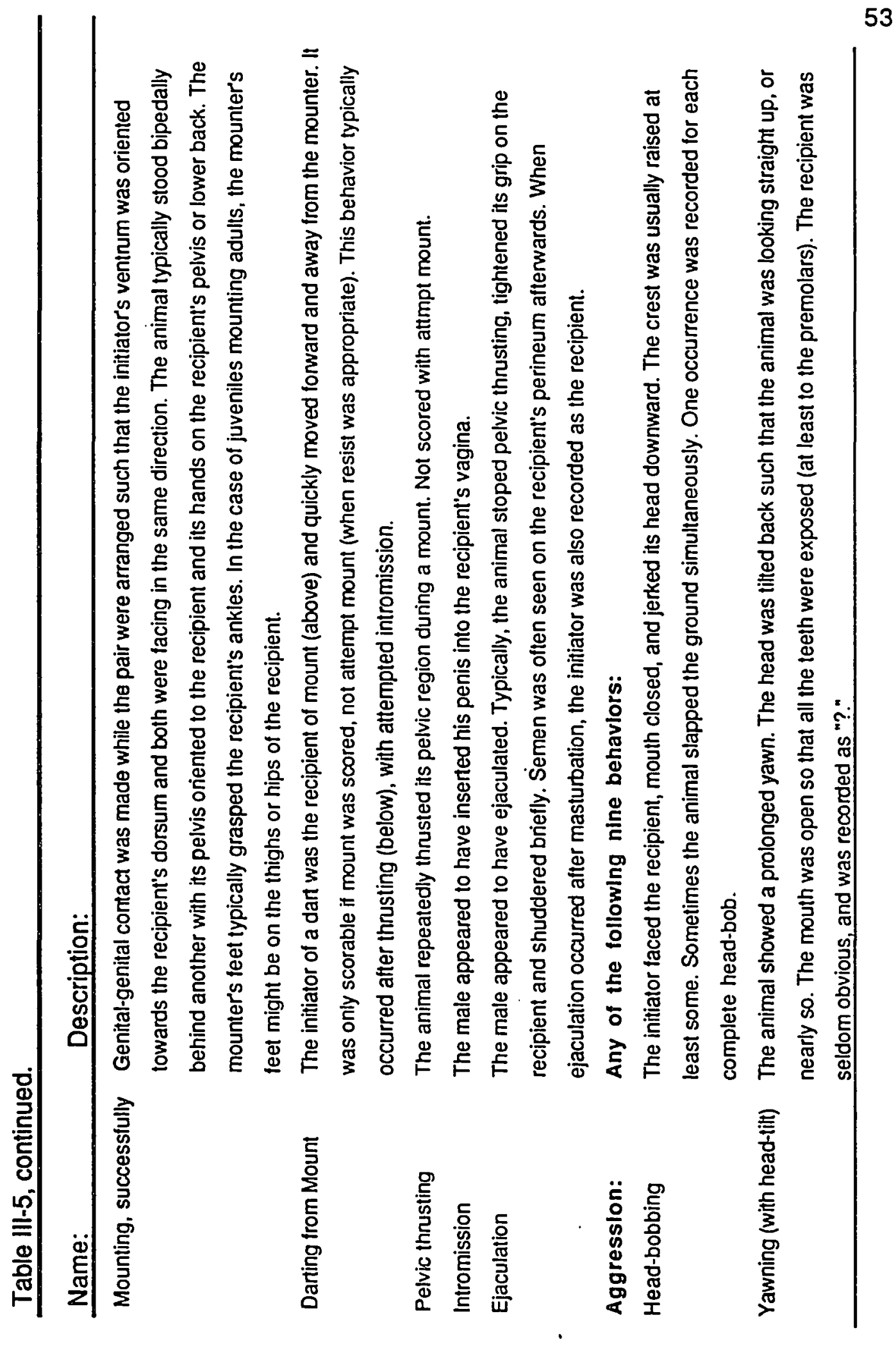




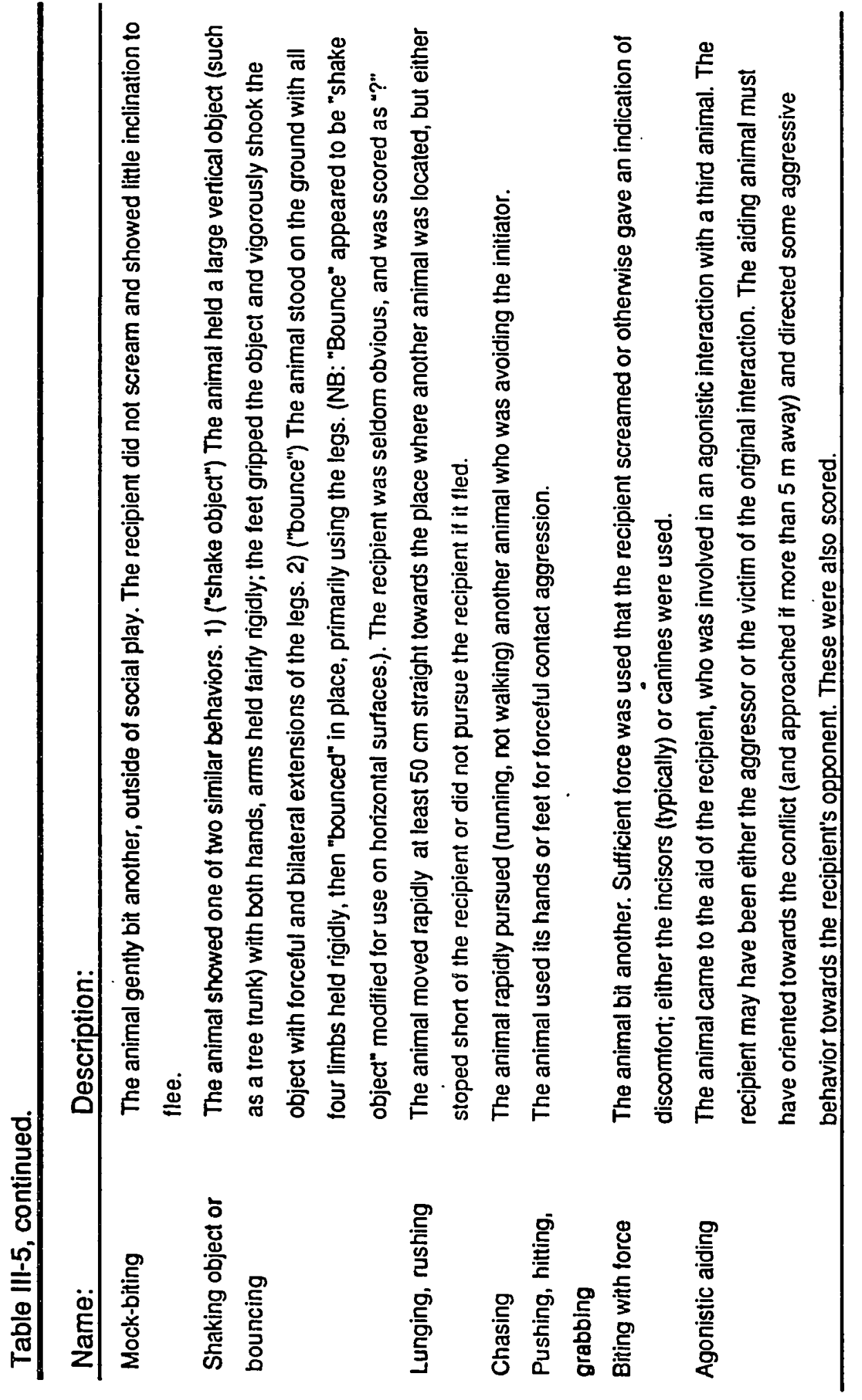




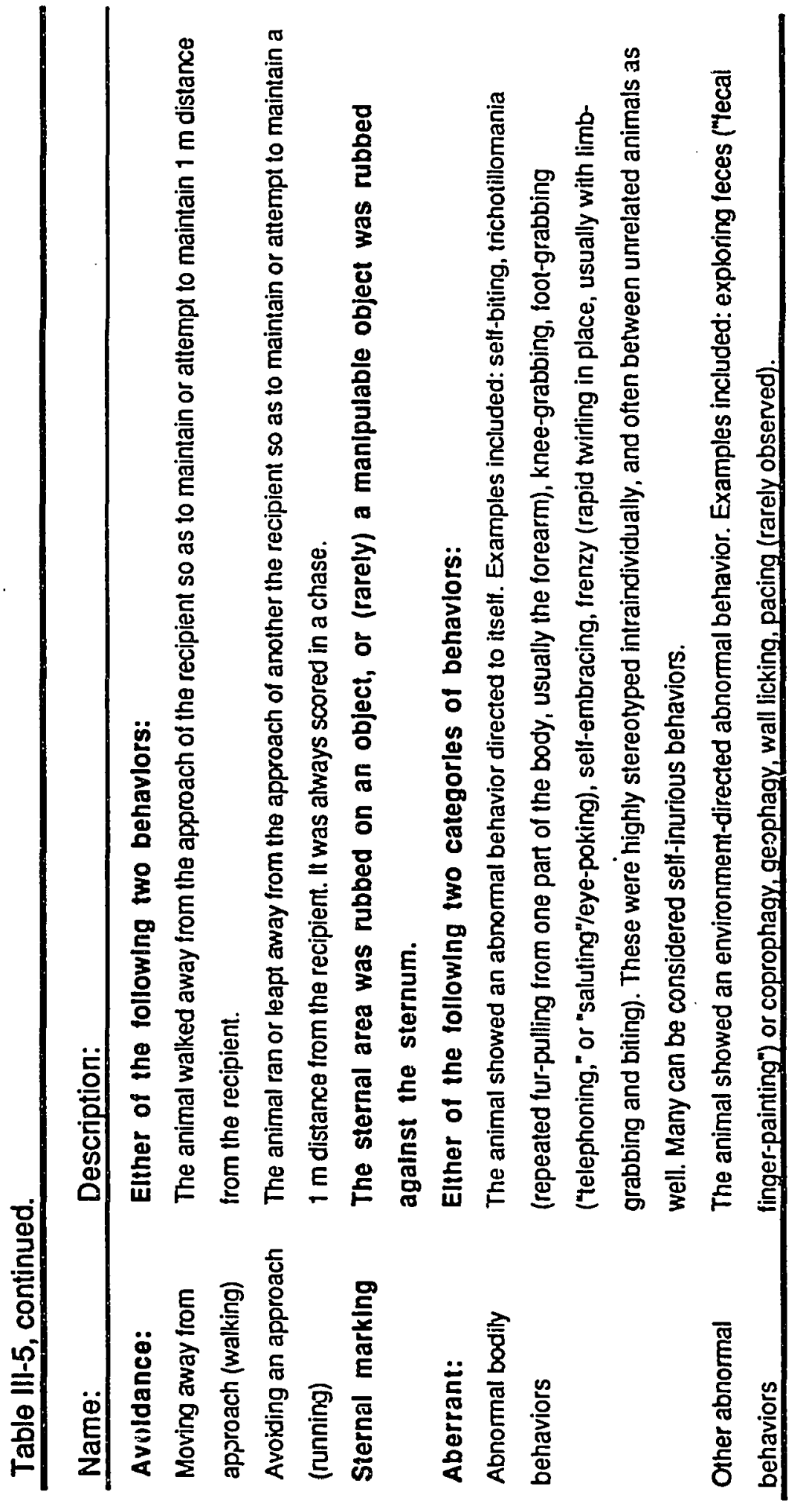


the Drill SSP ethogram with co-author Cox (Oct., 1994) and discussed the behaviors with her. I viewed the videotape repeatedly thereafter.

Two social behaviors I have added to Cox and Hearn (1989) are "resist (attempted mount)" and "dart (from mount)," both female sexual behaviors that function to reject or postpone male copulation attempts which I had seen previously in mandrills. Bercovitch (1995) has described a behavior in female baboons (Papio cynocephalus), "mount attempt rejection," similar to what I am calling "resist." The "dart" behavior is based on Gust and Gordon's (1991) description of reproductive behavior in sooty mangabeys; recall from the literature review chapter that Cercocebus mangabeys are the closest relative to Mandrillus.

Social events involving non-Mandrillus monkeys were recorded if a drill or mandrill was either the initiator or receiver. For interactions with humans, only behaviors initiated by the animals were recorded (e.g., I did not record human "smiles" to animals, but I did score the opposite).

At Tulsa Zoo, an abbreviated ethogram was used for events. The behaviors from Table III-5 recorded at Tulsa were: allogroom, present, smile, masturbate (not seen, however), mount, head-bob, shake-object and scent mark (also not seen). Lunge and chase were combined as one behavior, threat-rush. The two contact aggression behaviors (push and bite) were combined. This abbreviated ethogram was used because the Tulsa group was so large (12 animals, most of whom were very active young animals). I have used this abbreviated ethogram previously (Terdal, 1993a, 1993b, 1994). The states in Table III-4 were used at Tulsa for scan sampling, but proximity, height, and the presence or absence of visitors at each scan were not recorded. 
Data Collection Methods

Behavioral data can be collected in several ways (Altmann, 1974). In categorizing these methods, Martin and Bateson (1986) distinguish between sampling rules (whose behavior is watched and when) and recording rules (how the behavior is recorded). For my research I used two recording methods simultaneously because I wanted to know both: 1) how the animals spent their time (activity budgets); and, 2) how social behaviors were patterned ("who does what to whom, and how often"). The sampling and recording rules for the two methods are described below.

Activity Budgets. Activity budgets were estimated with "instantaneous scan sampling" (Altmann, 1974; Martin and Bateson, 1986). "Scan sampling" refers to the sampling rule: the entire group is scanned simultaneously. It is called "instantaneous" because the behavioral state of each individual is recorded exactly at each sample point. The sample interval (the time between sample points) was five minutes. I usually used a small electronic timer that produced an audible beep through an earpiece every five minutes; when the timer did not work I used a digital wrist watch. Five minutes is longer than the one-minute sample interval used for instantaneous focal sampling in the Drill SSP protocol. I made the decision to use a different sample interval because I thought it would increase the accuracy of my time budget estimates without sacrificing precision greatly. The justification for this follows.

The total number of sample points determines the precision of estimates of time spent in various behavior states, and so for a given amount of observation time (e.g., 10-40 hours as in the present research) shorter sample intervals yield greater precision. However, shorter sample intervals also can decrease accuracy: it is more difficult to record the behavior with less 
time in which to do so. As I was using scan sampling (the whole group), instead of focal sampling (one animal), this was an important consideration. Further, I was also doing behavior sampling simultaneously. I needed to minimize the total time spent looking at the data sheets (while recording on them) as I was also trying to record all occurrences of several behaviors. I had had considerable practice with increasingly shorter sample intervals (from one hour to 15 minutes to five minutes) and decided that five minutes was the shortest sample interval I could use accurately on groups of up to eight animals. For the largest group--12 mandrills at Tulsa Zoo--I used a 15 minute sample interval. I believed that with a one-minute sample interval some accuracy would be lost to gain some precision.

Precision of activity budget estimates was improved by using scan sampling instead of focal sampling (the sampling rule in which only one animal is watched at a time). As an example, for a group with five animals and 10 hours available for observation, focal sampling with a one-minute sampling interval gives about the same number of sample points ( 2 hours/animal $\times 61$ sample points/hour = 122 sample points/animal) as scan sampling with fiveminute sample intervals ( 10 hours $\times 13$ sample points/hour/animal $=130$ sample points/animal). The latter method has two further advantages: 1) the sample points are sufficiently far apart (five minutes) that each might be considered statistically independent and used as an independent sample (of the "population" of that animal's total activity) in analyses; and 2) by recording what two animal are doing at the same time it is possible to measure dyadic co-activity, the degree to which two animals do the same thing at the same time. I have used only the latter advantage in this study (below). 
Social Behavior Events. The distribution of social behavior events ("who does what to whom, and how often") was recorded with all-occurrences of selected behavior sampling (Altmann, 1974), also known as alloccurrences behavior sampling (Martin and Bateson 1986). I watched the entire group in an enclosure (sampling rule) and recorded each occurrence of the behaviors on Table III-5 continuously in one-hour observation sessions (recording rule). The observation sessions began at a pre-determined time at least five minutes after the previous session ended. I usually took a longer break between sessions to avoid "observer fatigue." In a typical day I had two observation sessions in the morning with a 15-minute break between them and another two sessions in the afternoon. Time between session was used to rest, eat, talk to keepers about husbandry or rare events (e.g., births, injuries and introductions), make general notes about the group and its environment, or view other animals. Observation sessions were scheduled during zoo visitor hours on the assumption that the animals were habituated to human presence during that time; for the same reason, I observed the animals from visitor viewing areas wherever possible. During the observation sessions, I attempted to watch each animal all of the time. When animals were dispersed over large areas, I scanned the enclosure continuously, paying especially close attention to animals within five meters of one another or rapidly moving. This bias may have caused me to miss some solitary behaviors, but was intended to ensure that I missed as few social behaviors as possible. At some zoos the animals had access to off-exhibit holding areas or to places where they were not visible to me. Behaviors that I did not see were not recorded.

Sequence Sampling. The behaviors on Table III-5 were recorded sequentially on the data sheet. In other words, sequence sampling was 
incorporated into the recording rules for behavioral events. Behaviors occurring as part of a discrete sequence were identified by drawing a circle around the scoring codes. The circle was numbered to identify the sequence, and notes (ad libitum data) were made about the sequence. These notes helped "flesh out" the sequence to facilitate interpretation later. The two sequences of interest were escalaited aggression (long series of threats, often with agonistic aiding and contact aggression) and breeding behavior (lengthy series of affiliative and sexual behaviors). These sequences sometimes lasted longer than five-minutes.

\section{DATA ANALYSIS}

I accumulated voluminous data from the groups on Table III- 1 by recording the behaviors listed on Tables III-4 and III-5 and using the rules described above. The data sheets were transcribed to Microsoft Excel spreadsheets for each data type (scan and all-occurrences) from each group. The spreadsheets were exported to the JMP statistical software (SAS, 1994) for analysis. Summary statistics for each individual or dyad were calculated directly. The number of hours of observation varied between groups from 10 to 40. To facilitate inter-group comparisons, I divided the number of occurrences of each behavior by the number of sample points, for scan sample data, or by the number of observation hours, for all-occurrences data. This data transformation merely requires assuming that the number of times a behavior was recorded was linearly related to the time spent watching for it. These transformed data - "proportion of time" for activity budgets and "hourly rates" for social behaviors - were the basis for further transformations prior to 
analysis. These data manipulations are described below, separately for the two data types.

\section{Proportion of Time}

The proportion of time spent in the 16 states listed in Table III-4 was assigned to four broader categories: social, active, inactive and not visible. The states included in each category are also given in Table III-4. These categories were chosen a priori (to this study) on theoretical grounds and on the basis of previous experience with scan sampling of three mandrill groups (Terdal, 1993a; unpubl. data).

Measures of Dyadic Cohesiveness. The reason I used activity categories was my desire to assess dyadic coactivity: the proportion of time two animals were doing the "same thing" at the same time. It seemed to be inaccurate for this purpose to consider two animals to be engaged in different activities if one was scored as "foraging" in a clump of grass while the other was "exploring" the clump. It seemed to me that both were doing approximately the same thing, but were doing something clearly different from a third animal who was sleeping. I used a modified estimate of the proportion of time spent in the same category (social, non-social active, inactive) when both were visible to measure dyadic coactivity. A simple calculation of the time two animals spent in the same category would over-estimate dyadic coactivity in some dyads because it would not adjust for chance levels of coactivity. For an example of this point, consider the hypothetical situation of two animals who both spent $90 \%$ of their time resting (inactive). A simple calculation of the time they spent in the same category is at least $(.9 \times .9=.81) 81 \%$. It would be very difficult for a pair of animals who each spent one-third of their visible time 
in each of the three categories (instead of $90 \%$ in just one) to achieve this level of simple coactivity, even if they actually were coordinating their activity budgets to a great extent. I choose to use kappa (Fleiss, 1981) as a measure of concordance that corrects for chance levels of agreement. Kappa is most familiar to behavioral scientists as a measure of agreement between two raters making nominal-level of measurement judgments. Kappa was calculated for each dyad as a measure of dyadic coactivity that corrects for chance levels of agreement. Large positive kappa values (approaching one) indicate a high level of coactivty, while kappa values near zero indicate that the two animals' activity states were independent of each other. Negative kappa values would indicate that the two animals' activity was dependent on each other's such that they were less likely than expected by chance to be doing the same thing at the same time.

Kappa estimates of dyadic coactivity were one of two ways to measure a dyad's cohesiveness using the scan data. The other measure was the proportion of time two animals spent within one meter of each other.

Proportions have peculiar characteristics that must be considered in analyses, however. Proportions near zero and one cannot be treated as interval scales in parametric analyses. While 0.5 is about as much greater than 0.4 as 0.4 is than 0.3 , this quasi-interval quality breaks down at the tails of the distribution. For example, 0.01 is one-half of 0.02 , but 0.09 is much more than one-half of 0.1 even though 0.1 is also 0.01 greater than 0.09 . The angular transformation $(A=2$ arcsine $\sqrt{ } p)$ is often used for proportions where $0.05<p<0.95$ (Walker and Lev, 1953). For more extreme proportions ( $p<0.05$ or $>0.95$ ), the logit transformation is used for "tail stretching." The logit transformation is: $L=0.5$ in $(p / 1-p)$, where "In" is the naturial logarithm (Cohen and Cohen, 1983). The logit 
transformation has the desirable quality that it produces an interval scale: the difference between $L$ and $2 L$ is the same for all $L$ (Cohen and Cohen, 1983). I used the least "extreme" transformation necessary to produce an approximately normal distribution.

\section{Social Behavior Hourly Rates}

In previous studies using versions of the Drill SSP ethogram (Cox and Hearn, 1989), the hourly rates of the various social behavior events have been summed in four categories (Table III-5): affiliative, sexual, aggressive and avoidance/submission (e.g., Cox, 1987a; Hearn et al., 1988; Hearn and McColgon, 1992; Chang, 1991; Forthman et al., 1994). I choose not to do that a pusteriori because an analysis of sexual sequences (next chapter) revealed that behaviors from all four of these categories were used together within sexual sequences. Also, cluster analysis of social behaviors (next chapter) did not reproduce the assignment of behaviors to the four categories used by the Drill SSP ethogram (Cox and Hearn, 1989). It was, therefore, considered conservative, albeit inconvenient, to consider each social behavior separately, unlike the situation with activity budget data, above, where it was both conservative and convenient to assign behavior states to a few higher categories.

The Square Root Transformation: Not Used (and Why). The distribution of social behavior hourly rates is expected to be Poisson, not normal. This is true whenever "data are counts of events that are rare in the sense that for any given condition, the mean of such a set is much smaller than the largest value...." (Cohen and Cohen, 1983, p. 263). Distribution of hourly rates of many social behaviors are expected to have a long, right-hand tail (be 
positively skewed) for this reason. The square-root transformation $(S=$ Vhourly rate) is commonly used for variables that arise from a foisson distribution, where the values are the numbers of occurrences per time period and when occurrences are independent of each other (Cohen and Cohen, 1983). If the occurrences are not independent, the variances may be even greater than the means. This often occurs with behavioral data, with the result that null hypotheses are rejected too often (Kramer and Schmidthammer, 1992). For example, drills rarely "head-bob", but when they do it is often in bouts. If one head-bob threat occurs, it is likely that another will soon follow: head-bob events are not necessarily "independent." The square root transformation is not able to eliminate the large positive skew that results from this non-poisson process.

The Rank Transformation: Used (and Why). Another transformation has been proposed for data in which the variance exceeds the mean, such as behavioral scientists often encounter: rank-transformation (Kramer and Schmidthammer, 1992). This method has been reviewed by Conover and Imam (1981). Each subset of observations is ranked, with ties receiving equal ranks. The analysis is conducted on the ranks of the data. If the data were in fact normally distributed to begin with, some power is lost, but for variables that were not normally distributed power may be improved by using the ranks (Conover and Imam, 1981; Kramer and Schmidhammer, 1992). Standard parametric significance tests (those based on the general linear model) may be used on the ranked variables. The most familiar example of this is Spearman's correlation, which is Pearson's correlation on rank-transformed variables. Multiple regression may also be used (Conover and Imam, 1981; Tabachnick and Fidell, 1989). As is always true for hypothesis testing with 
transformed data, significant results are interpreted differently (Tabachnick and Fidell, 1989). For example, a t-test on ranked data tests the hypothesis that medians, not means, differ (Kramer and Schmidthammer, 1992). I chose to use the rank transformation because the variance was expected to (and did) exceed the mean for most of the social behavior rate variables.

\section{Screening Data}

Univariate plots were examined for all variables. Normal probability plots were examined for any distributions that appeared non-normal. Transformations (discussed above) were chosen to minimize skew. Normal probability plots were examined again after transformation to check the utility of the transformation. Bivariate plots were examined for all combinations of predictor and response variables in all analyses.

\section{Multiple Regression Analyses}

Hypotheses (previous chapter; summarized on Table III-6) were tested using standard least-squares regression analyses on transformed variables. This statistical method was chosen to obtain the most desirable features of methods used by both zoo and laboratory biologists. Zoo biologists generally prefer non-parametric tests, such as the Kruskal-Wallis test, because they are robust to skew and heteroscedasticty--problems often inherent to behavioral data. Laboratory biologists generally employ parametric tests based on the general linear model, such as analysis of variance (ANOVA), because these methods permit consideration of multiple variables simultaneously. For example, "nuisance" variables in a laboratory study, such as temperature, can be statistically controlled for in a multivariate analysis. This cannot be done 
with existing non-parametric methods such as the Kruskal-Wallis test. I used the transformations of behavioral data, described above, to meet the assumptions of the linear model tests.

Table III-6. Summary of hypotheses tested.

\begin{tabular}{|c|c|c|c|}
\hline Hypothesis Number: & Predictor Variables: & Response Variables: & Sample Size (n): \\
\hline One & $\begin{array}{l}\text { Environment } \\
\text { (Table III-3) }\end{array}$ & Inactivity (Table III-4) & 62 animals \\
\hline Two & Inactivily & $\begin{array}{l}\text { Cohesion (proximity, } \\
\text { coactivity) }\end{array}$ & 28 adult pairs \\
\hline Three & Cohesion & $\begin{array}{l}\text { Affiliative-bonding } \\
\text { (affiliative behaviors: } \\
\text { Table III-5) }\end{array}$ & 28 adult pairs \\
\hline Four & Affiliative-bonding & $\begin{array}{l}\text { Initial sexual behaviors } \\
\text { (from Table III-5) }\end{array}$ & 28 adult pairs \\
\hline
\end{tabular}

Ordinal variables (ratings on Table III-3, rank-transformed behavior rates) were sometimes used, as was discussed above; at worst they decrease the power of a regression analysis, but do not bias the result against the null hypothesis (Conover and Imam, 1981; Cohen and Cohen, 1983). Regression models were chosen to test the hypotheses. The terms "predictor" and "response" variable are used in preference to "independent" and "dependent" variable, respectively, because my study is observational, not experimental. In addition to a desire for models that explained the greatest amount of variation in the response variable, the simplest models were preferred. "Nuisance" predictor variables, i.e., those not directly relevant to the particular hypothesis being considered, such as subject species or age, were entered manually one at a time into a regression equation to learn whether they had an effect on the response variable. Non-significant $(p>0.05)$ "nuisance" variables were manually removed from the model, while statistically significant "nuisance" variables were retained as covariates in equations with hypothesized 
predictor variables. Stepwise regression procedures were not used. The intent was to maximize the ratio of cases to predictor variables. Tabachnick and Fidell $(1989$, p. 129) assert that for multiple regression there should be twenty cases per predictor variable, and at least five. More are needed if the response variable "...is skewed, effect size is anticipated to be small, or substantial measurement error is expected from unreliable variables." All three of these problems may be intrinsic to the present research. For hypotheses two, three and four, concerning the behavior of females paired with a male, the number of cases was 28 (from 28 adult and subadult females; the number of adult males with these females was 12 in 12 groups). This translates to preferably one, and no more than five, predictor variables per regression model by Tabachnick and Fidell's criteria. Every reasonable attempt was made to test hypotheses using just one predictor variable in the regression equations, and all were with less than five.

\section{Statistical Procedures used for Visualization of Data}

Two statistical methods were used to portray graphically complex relationships within the data: cluster analysis and multi-dimensional scaling. I used average-linkage agglomerative hierarchical cluster analysis (Manly, 1986) to identify social behaviors used within female-male dyads. Cluster analysis can be done using rank-transformed data (Conover and Imam, 1981). Multidimensional scaling (MDS) (Manly, 1986) was used to form a "map" showing proximity relationships within groups. Multidimensional scaling has a long history of use by primatologists to describe spatial organization of primate groups (Corradino, 1990; Itoigawa, 1993, Terdal, 1993b). ! used monotonic instead of linear MDS to be conservative, as I was 
using the proportion of time a dyad spent within one meter of each other; proportions, as discussed above, have non-interval properties and so do not scale linearly. I used two-dimensional MDS because it is easier to interpret the results: a map is produced that resembles the typical way the animals in a group distribute themselves over the floor of the exhibit (Terdal, 1993b). The SYSTAT software was used for MDS (Wilkinson, 1993). 


\section{CHAPTER IV}

\section{RESULTS}

\section{SPECIES DIFFERENCES}

In the first chapter, I showed that mandrills have historically reproduced in zoos better than their congener the drill. In this study, I am using mandrills as a model for drills. My premise is that the historic difference in reproductive success between the two species is not attributable to any intrinsic difference between the two species, but rather to behavioral differences among individuals resulting from husbandry practices that differed among captive groups of both species in the past. I base this premise on the fact that some captive drill groups, notably at Zoo Hannover (Boër, 1987), have been as reproductively successful as any mandrill group.

Given this premise, I treat "species: mandrill or drill" as a "nuisance" variable in regression models used below to evaluate the four hypotheses. Prior to evaluating hypothesis one, which considers the effect of environmental predictor variables on activity, I examined the effect of species, sex, age and their interactions on the proportion of time spent in the three broad categories of behavioral states: social, non-social active, and inactive. The latter is simply the proportion of time not spent in either of the two "active" categories. More detailed activity budgets are presented later in this chapter. Table IV-1 lists p-value results for species and other "nuisance" predictor 
variables (sex, age, and two-way interactions of the three main effects) with the three "behavioral state" categories (Table III-4) as response variables. The proportion of time spent in social interactions (when visible) was very skewed, but the logit transformation normalized the distribution. The proportion of time spent non-socially active (when visible) was normally distributed without transformation. The angular transformation of the time spent inactive (when visible) corrected that distribution's moderate right skew. All three analyses are shown, even though any two are sufficient to account for all of the variation, because the three categories account for all of each animal's visible time.

Table IV-1. Results of least-squares regression (or ANCOVA) tests of species, sex, age and their two-way interactions on three categories of activity which sum to $100 \%$ of visible time for each animal. $\mathrm{N}=32$ drills and 30 mandrills.

\begin{tabular}{llll}
\hline Predictor & Social (logit) & Active, Non-Social & Inactive (angular) \\
\hline Species & $p>0.5$ & $p>0.1^{1}$ & $p=0.0808^{1}$ \\
Sex & $p>0.3$ & $p>0.9$ & $p>0.4$ \\
Age & $p<0.001$ (sign: - ) & $p<0.001$ (sign: - ) & $p<0.0001$ (sign: + ) \\
Species $\times$ Sex & $p>0.4$ & $p>0.4$ & $p>0.5$ \\
Species $\times$ Age & $p>0.4$ & $p>0.7$ & $p>0.9$ \\
Sex $\times$ Age & $p>0.7$ & $p>0.1^{2}$ & $p=0.0275^{2}$ \\
\hline
\end{tabular}

1 Drills tended to be a little more active than mandrills. ${ }^{2}$ There was a small tendency for age to reduce activity more in males than females; this was statistically significant for "inactivity."

These results indicate that mandrills and drills did not differ statistically significantly in activity. Indeed, the tendency was for drills to be more active than mandrills. This supports my premise that mandrills and drills can be treated collectively for analyses of the effect of environmental variables on activity. "Species" is considered below as a "nuisance variable" for response variables in tests of hypotheses two, three and four. In brief, however, there 
were no statistically significant species effects on any of the measures of cohesion, affiliativeness or sexual sequence iniating behaviors. Further, my subjective impression was that neither the form nor the function of the behaviors in the Mandrillus ethogram differed between the species.

\section{HYPOTHESES}

Figure IV-1 presents an overview of the four linked hypotheses. For each hypothesis, I first present descriptive statistics for the predictor and response variables. Then I show the results of the regression analyses in table form. Next, I have selectively produced figures to illustrate large effects. Post hoc analyses are described in the sections summarizing the results of each hypothesis test.

Hypothesis: 1 2

3

4

Environment $\rightarrow$ Activity $\rightarrow$ Cohesion $\rightarrow$ Affiliation $\rightarrow$ Breeding

Figure IV-1. Summary of hypotheses one through four. Arrows indicate the presumed direction of causality.

\section{Hypothesis One}

Statement of the hypothesis. Features of the captive environment which simulate aspects of the natural environment are hypothesized to reduce inactivity. "Inactivity" was chosen as an overall measure of the lack of natural "activity," either social interaction, or foraging, exploration and locomotion.

Predicter Variables. Table IV-2 describes the distribution of the variables used as regression predictors (from Table III-3) for 62 animals in the 14 groups for which at least 10 hours of data were obtained (Table III-1). 
Table IV-2. Hypothesis one predictor variables.

\begin{tabular}{lll}
\hline Variable: & Median: & Range (in 62 animals in 14 groups): \\
\hline Adult Females & 3 & $1-6$ \\
Rearing History & Mother & Wild $=6 ;$ Mother $=32 ;$ Hand $=6$; Unknown $=18$ \\
Area & $2.3\left(=200 \mathrm{~m}^{2}\right)$ & $1.3\left(=20 \mathrm{~m}^{2}\right)-3.5\left(=3030 \mathrm{~m}^{2}\right)$ \\
Mixed Species? & No & No $=50 ;$ Yes $=12($ in two groups) \\
Outside? & Yes & No $=24 ;$ Yes $=38$ \\
Climb & 3 & $1-5$ \\
Cover & 3.5 & $1-4$ \\
Objects & 3 & $1-5$ \\
Forage & 4 & $1-2,4-5($ none $=3)$ \\
Feedings & 1 & $1-2,4-5($ none $=3)$ \\
Style & 3 & $1-5$ \\
Visitors & 0.19 & $0-0.85(\mathrm{n}=50$, as not measured at Tulsa Zoo) \\
\hline
\end{tabular}

A few of these variables were correlated. The correlations between "climb" and "cover", and between "objects" and "forage", were especially strong (rho $=0.79$ for both), as was the correlation between "feedings" and "style" (0.76). The other correlations exceeding 0.50 were "climb" and "cover" with "visitors" (0.64 and 0.60, respectively), "objects" and "style" (0.61), and "climb" with "objects" (0.57).

Activity Budget. Tables IV-3, IV-4, IV-5 and IV-6 show the mean, median and range of the percent (= proportion $\times 100)$ of time spent, rounded to the nearest percent, in the four activity categories and their component states (from Table III-4). The total for each category is presented both raw, and adjusted for the time each animal was visible; the latter was used in analyses. 
Table IV-3. Percent of time in seven social states by 62 animals.

\begin{tabular}{llllllllll}
\hline State: & $\begin{array}{l}\text { Allo- } \\
\text { groom }\end{array}$ & $\begin{array}{l}\text { Receiv. } \\
\text { Groom }\end{array}$ & $\begin{array}{l}\text { Social } \\
\text { Play }\end{array}$ & $\begin{array}{l}\text { Other } \\
\text { Social }\end{array}$ & $\begin{array}{l}\text { Adjac. } \\
\text { Group }\end{array}$ & $\begin{array}{l}\text { Social, } \\
\text { Human }\end{array}$ & $\begin{array}{l}\text { Other } \\
\text { Spec. }\end{array}$ & $\begin{array}{l}\text { Any } \\
\text { Social }\end{array}$ & $\begin{array}{l}\text { Social, } \\
\text { Visible }\end{array}$ \\
\hline Mean & 3 & 3 & 1 & 9 & 0 & 0 & 0 & 16 & 19 \\
Median & 1 & 1 & 0 & 3 & 0 & 0 & 0 & 9 & 10 \\
Range & $0-17$ & $0-17$ & $0-17$ & $0-741$ & $0-1$ & $0-1$ & $0-3$ & $0-76$ & $0-86$ \\
\hline
\end{tabular}

1 This high score was from a nursing mother-neonate dyad at Zoo Hannover.

Table IV-4. Percent of time in three non-social active states by 62 animals.

\begin{tabular}{llllll}
\hline State: & Forage & Explore & Locomote & Any Active & Active, Visible \\
\hline Mean & 21 & 5 & 8 & 34 & 39 \\
Median & 20 & 2 & 8 & 33 & 37 \\
Range & $0-52$ & $0-37$ & $1-18$ & $6-75$ & $7-85$ \\
\hline
\end{tabular}

Table IV-5. Percent of time in four inactive states by 62 animals.

\begin{tabular}{lllllll}
\hline State: & Maintenance & Aberrant & Other & Stationary & Any Inactive & Inactive, Vis. \\
\hline Mean & 7 & 1 & 0 & 30 & 38 & 42 \\
Median & 6 & 0 & 0 & 29 & 37 & 42 \\
Range & $0-22$ & $0-7$ & $0-2$ & $2-80$ & $3-88$ & $3-89$ \\
\hline
\end{tabular}

Table IV-6. Percent of time in two not-visible states by 62 animals.

\begin{tabular}{llll}
\hline State: & In exhibit but Not Seen & Off-exhibit Voluntarily & Total Not Visible \\
\hline Mean & 5 & 7 & 12 \\
Median & 1 & 1 & 5 \\
Range & $0-37^{1}$ & $0-85^{2}$ & $0-85$ \\
\hline
\end{tabular}

1 This high percent is from the juvenile at Zoo Atlanta. ${ }^{2}$ This high percent is from an old female at Knoxville Zoo who was usually alone off-exhibit.

Response variable. The proportion of time inactive was used as the response variable. "Nuisance" predictor variables species and sex had no effect on inactivity, but, as indicated above (Table IV-1), age in years had an effect and explained about half of the variation among animals in the time 
spent inactive $\left(R^{2}[\times 100]=49\right)$. The distributions of both age and inactivity showed moderate right skews, but the regression residuals showed no skew, because the especially old animals were especially inactive. The regression residuals were normally distributed; therefore, the residual inactivity was used as the response variable in testing for an effect of the predictor variables on Table IV-2.

Table IV-7 summarizes the effect of the predictor variables on the response variable, inactivity. The columns for "Hypothesized Sign" and "Observed Sign" in this and following tables refer to the sign of the regression slope. A negative sign, for example, means that increasing values of the variable were associated with lower inactivity. The actual regression slopes are not shown because it is difficult to interpret slopes calculated from transformed or ranked variables. Instead, $\mathrm{R}^{2}(\times 100)$ is reported as a measure of the strength of an effect. It represents the percent of the variation in ageadjusted inactivity accounted for by the variable. For alpha $(p)$, I have rounded down if $p>0.10$ and up if $p<0.01$. For instances of "borderline" statistical significance $(0.10>p>0.01)$ I give the actual $p$ calculated by the JMP statistical software.

Summary. Hypothesis one was supported in part. As expected, ageadjusted inactivity was reduced by letting the animals outside, by providing manipulable objects and opportunities to forage, by feeding them more often and by keepers with an affiliative husbandry style. Figure IV-2 shows the relationship between forage rating and inactivity. Note that the biggest difference was between animals with minimal foraging opportunities and all others. Figure IV-3 shows the relationship between husbandry style rating and 
inactivity. The relationship is monotonic, but the most inactive animals were those cared for by the least affiliative keepers.

Table IV-7. Effect of environmental variables on age-adjusted inactivity for 62 animals in 14 groups.

\begin{tabular}{|c|c|c|c|c|}
\hline Predictors: & Hypothesized Sign: & Observed Sign: & $R^{2}(\times 100):$ & Two-tailed p: \\
\hline $\begin{array}{l}\text { Adult Females } \\
\text { Rearing History }\end{array}$ & $\begin{array}{l}\text { - } \\
\text { Wild = Mother } \\
\text { < Hand; Unknown } \\
\text { intermediate }\end{array}$ & $\begin{array}{l}\text { Wild } \leq \text { Mother } \\
\leq \text { Hand } \leq \text { Unknown }\end{array}$ & $\begin{array}{l}1.7 \\
6.0\end{array}$ & $\begin{array}{l}>0.3 \\
>0.3\end{array}$ \\
\hline Area & - & + & 0.3 & $>0.6$ \\
\hline Mixed Species? & $Y<N$ & $Y>N$ & 7.9 & 0.0263 \\
\hline Outside? & $Y<N$ & $Y<N$ & 7.5 & 0.0311 \\
\hline Climb & - & + & 0.6 & $>0.5$ \\
\hline Cover & - & - & 0.1 & $>0.8$ \\
\hline Objects & - & - & 19.6 & $<0.001$ \\
\hline Forage & - & - & 22.1 & $<0.001$ \\
\hline Feedings & - & - & 7.4 & 0.0322 \\
\hline Style & - & $\cdot$ & 18.6 & $<0.001$ \\
\hline Visitors $(n=50)$ & No Effect & - & 0.2 & $>0.7$ \\
\hline
\end{tabular}

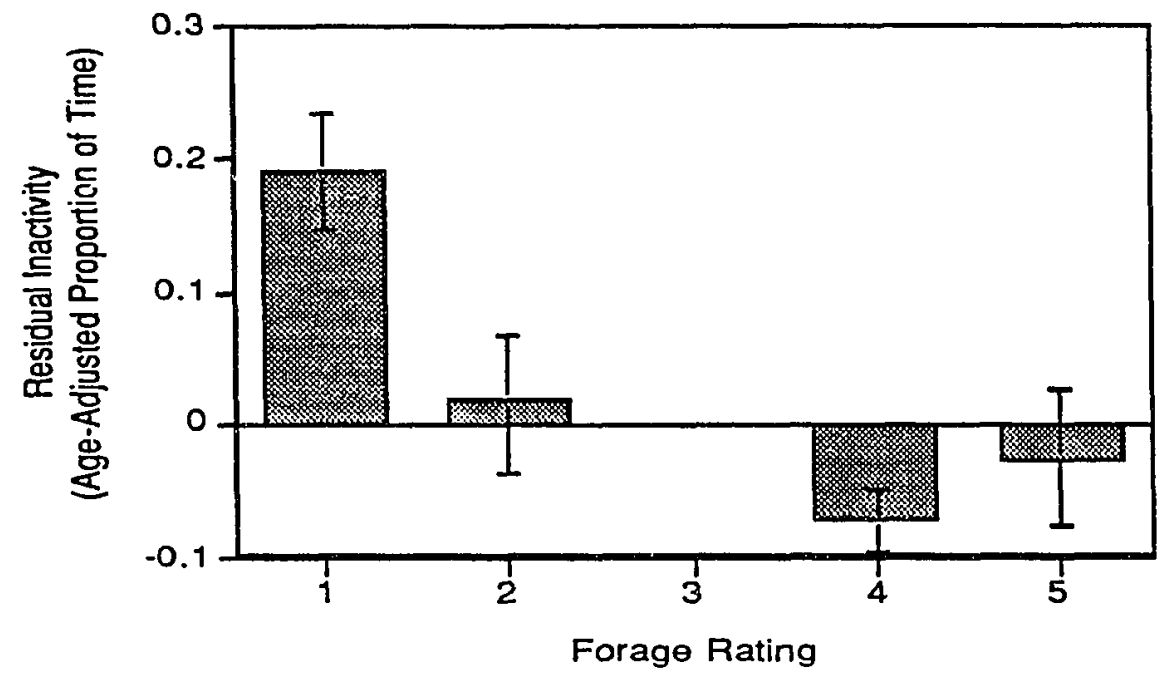

Figure IV-2. Effect of Forage rating on age-adjusted proportion of time spent Inactive by 62 Mandrillus in 14 captive groups. Mean and SEM are shown. 


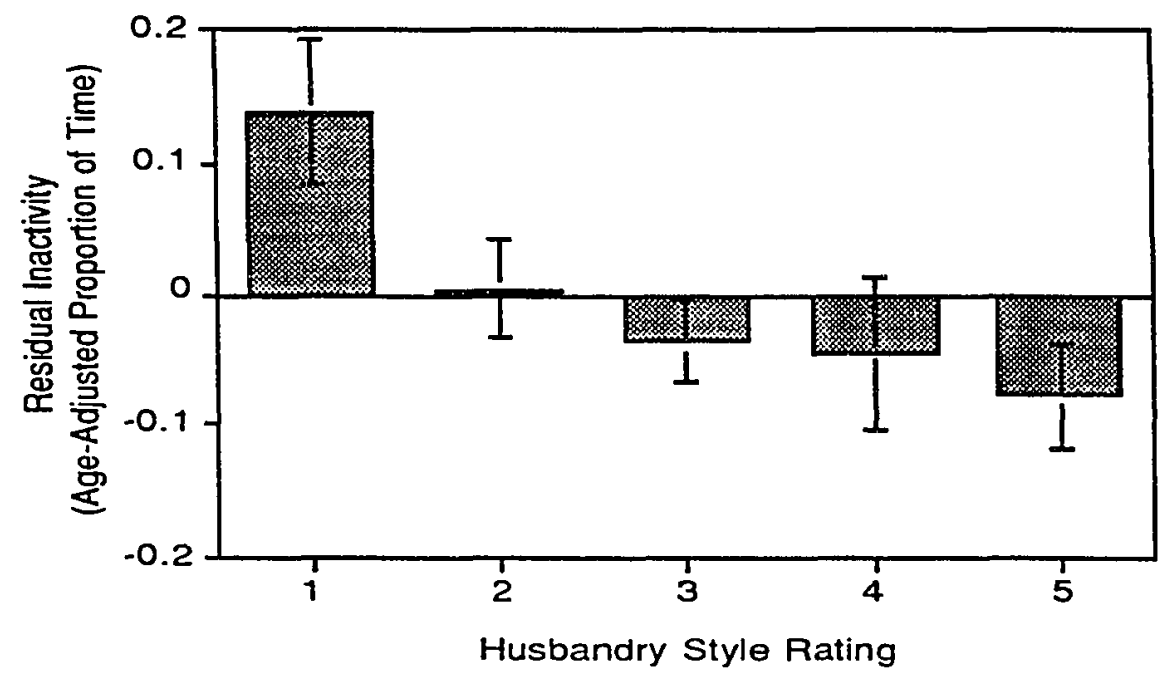

Figure IV-3. Effect of Husbandry Style rating on age-adjusted proportion of time spent Inactive by 62 Mandrillus in 14 captive groups. (Mean and SEM.)

The apparent lack of an effect of visitors on inactivity was also expected. While it is statistically difficult to argue in support of the null hypothesis (of no effect), the low $R^{2}$ obtained is in agreement with the hypothesis that there is no strong relationship between the proportion of time visitors are present and inactivity in general.

The deletory effect of mixed-species exhibits was surprising. This test was not particularly strong, however, as only two of the 14 groups were exhibited with other monkey species. The larger of these groups had mandrills who were often inactive. This same group also had low scores for objects, forage, feedings and style; I suggest that the animals there may have been inactive for that reason instead. Post hoc tests with both "mixed species?" and these other predictor variables showed that only the latter were significant predictors of inactivity in multiple regression analyses. The other mixedspecies group, at Zoo Atlanta, was much less inactive. 
Overall, rearing history explained just $6 \%$ of age-adjusted inactivity and was not a statistically significant predictor. Post hoc, I tested for an effect of rearing history on one particular component of inactivity: the proportion of time spent engaged in aberrant behaviors. This was zero in all wild-caught, and in all but one mother-reared animals, but was higher in hand-reared and unknown rearing history animals (mean percent of time $=2 \%$ and $1 \%$, respectively). This difference was statistically significant (Kruskal-Wallis test, $p$ $<0.001)$. Next, 1 determined which category of aberrant behaviors accounted for this difference by analyzing hourly rates of aberrant behavior events. Selfdirected aberrant behaviors were nearly non-existent in wild-caught and mother-reared animals, but were not uncommon in hand-reared and unknown rearing history animals (Figure IV-4). This difference was statistically significant (Kruskal-Wallis test, $p<0.01$ ). The four groups did not differ statistically in their rate of non-self directed aberrant behaviors.

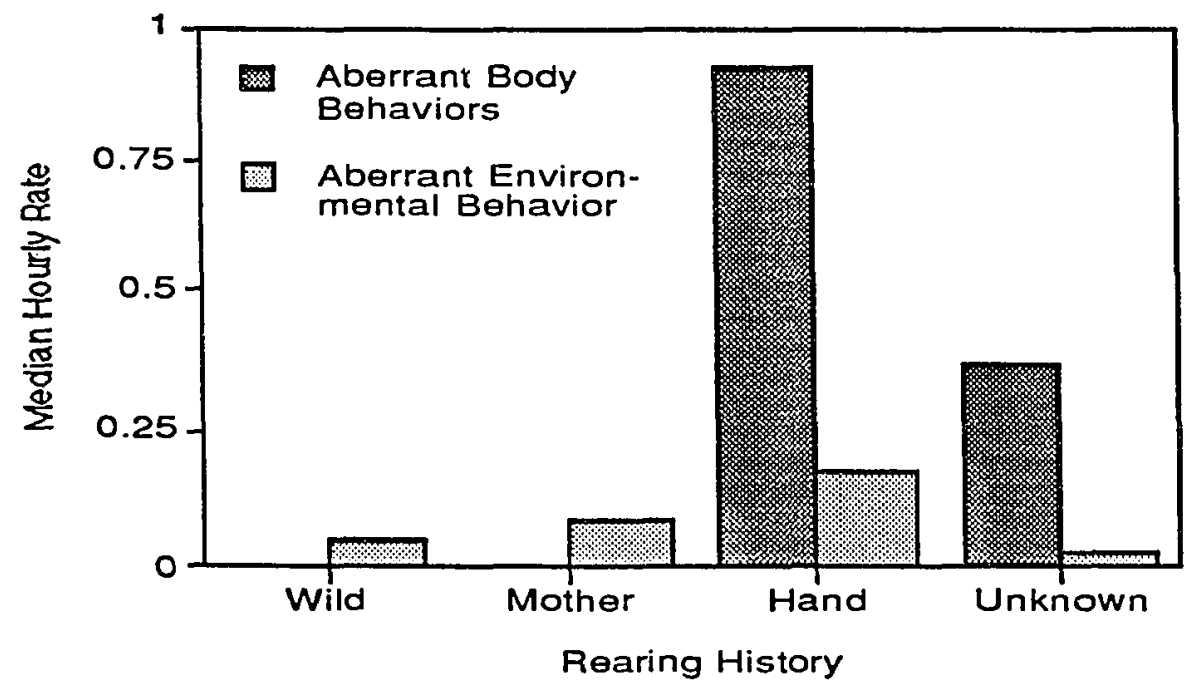

Figure IV-4. Effect of rearing history on expression of two categories of aberrant behavior events. The difference between groups was statistically significant only for rate of aberrant self-directed (bodily) behaviors. 
The other hypothesis one predictor variables, i.e., the number of adult females, the enclosure area, and opportunities to climb or take cover, were found to have little if any relationship to inactivity.

\section{Hypothesis Two}

Statement of the Hypothesis. Adult animals who are less inactive are hypothesized to be more likely to form cohesive dyads with opposite sex adults.

Predictor Variables. The proportion of time the female and male members of each adult pair were inactive (female inactivity and male inactivity) were the predictor variables. The 28 adult pairs considered for this and the following hypotheses included 28 different females housed with 12 males in 12 groups. Thus, most males were a part of more than one femalemale pair.

Response variables. The proportion of time the female and male members of each adult pair were within one meter of each other (proximity) and the kappa value for the estimate of the time they were engaged in the same category of activity (coactivity) were used as response variables.

The distribution of the proportion of time in proximity showed a strong right skew because a few dyads were in proximity much more often than were the rest. The mean, expressed as percent, was $7.9 \%$, while the median was less than half that: $3.5 \%$; range 0 to $37 \%$. The angular transformation did not correct all of the skew, but the logit transformation did (logit proportion of time in proximity $=-1.63$, median $=-1.52$, range -3.11 to -0.21 ; for the one dyad out of 28 where the raw proportion was 0 , which is technically $-\infty$ by the logit transformation, I substituted -3.11 , the next lowest value actually observed; 
this corresponds to a dyad in proximity $0.2 \%$ of the time). I used the logit transformation for proximity.

The kappa values used to measure coactivity were normally distributed without transformation (mean $=0.16$, median $=0.14$, range -0.02 to 0.47 ) Coactivity was significantly correlated with proximity $(r=0.57, p<0.01)$.

The "nuisance" predictor variables tested were species, female age and male age. None of these had a statistically significant effect on either response variable.

Tables IV -8 and IV -9 show the results for the response of proximity and coactivity (respectively) to female inactivity and male inactivity.

Table IV-8. Effect of inactivity by the female and male member of 28 adult pairs on proximity.

\begin{tabular}{lllll}
\hline Predictors: & Hypothesized Sign: & Observed Sign: & $\mathrm{R}^{2}(\times 100):$ & Two-tailed p: \\
\hline Female Inactivity & - & - & 20.2 & 0.0166 \\
Male Inactivity & - & - & 0.4 & $>0.7$ \\
\hline
\end{tabular}

Table IV-9. Effect of Inactivity by the Female and Male member of 28 adult pairs on Coactivity.

\begin{tabular}{lllll}
\hline Predictors: & Hypothesized Sign: & Observed Sign: & $R^{2}(x$ 100): & Two-tailed p: \\
\hline Female Inactivity & - & - & 4.1 & $>0.3$ \\
Male Inactivity & - & - & 6.8 & $>0.1$ \\
\hline
\end{tabular}

Summary. Hypothesis Two is supported in part. Inactivity did reduce cohesiveness, but the only strong and statistically significant effect was the negative effect of female inactivity on proximity (Figure IV-5). 


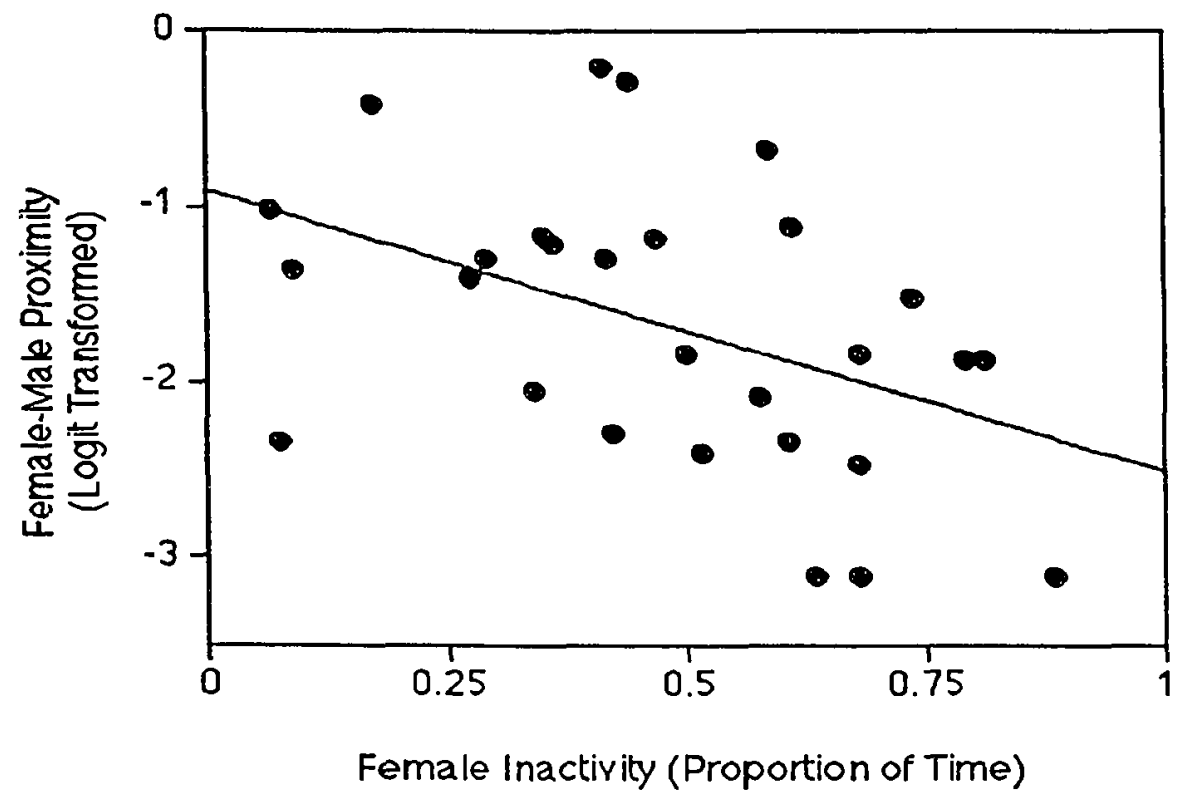

Figure IV-5. Effect of female inactivity (proportion of time) on female-male proximity ( $\leq 1$ meter) in 28 adult Mandrillus pairs in 12 captive groups.

In collecting the data on proximity, I noticed that in some groups highranking females actively prevented lower ranking females from approaching the male. Rank was determined in two ways: directionality of threats, and directionality of avoidance behaviors. For each group, matrices of these were constructed and dominance relations were determined in the usual way (Martin and Bateson, 1986). Tested post hoc, this effect was significant: if there were higher ranking females in the group, a female was less likely to be within one meter of the male $\left(R^{2}[x 100]=21.7, t=2.69,27\right.$ d.f., $\left.p=0.0124\right)$. When the above analysis of the effect of female inactivity on proximity was repeated with the presence of a higher ranking female as a regression covariate, I obtained similar results. 
Hypothesis Three

Statement of the Hypothesis. Cohesive pairs are hypothesized to show signs of affiliative bonding.

Predicter Variables. Proximity and coactivity, as used above, were the predictor variables.

Respense Variables. Several affiliative behaviors were recorded (Table IV-5). To help me choose which were appropriate measures of affiliativebonding in various dyads, I used cluster analysis of rank-transformed hourly rates of social behaviors used by at least $25 \%$ of the adult female-male dyads in the six groups with a history of successful reproduction. It was only for these groups that I had a priori indication that the animals were behaviorally competent. Figures IV-6 and IV-7 show the clusters obtained for females and males, respectively. The labels on the left summarize the content of the clusters to their right. The length of the lines is approximately proportional to the similarity between the behaviors in their use within dyads. In other words, if two behaviors are clustered closely, then both were used at high rates within the same dyads.

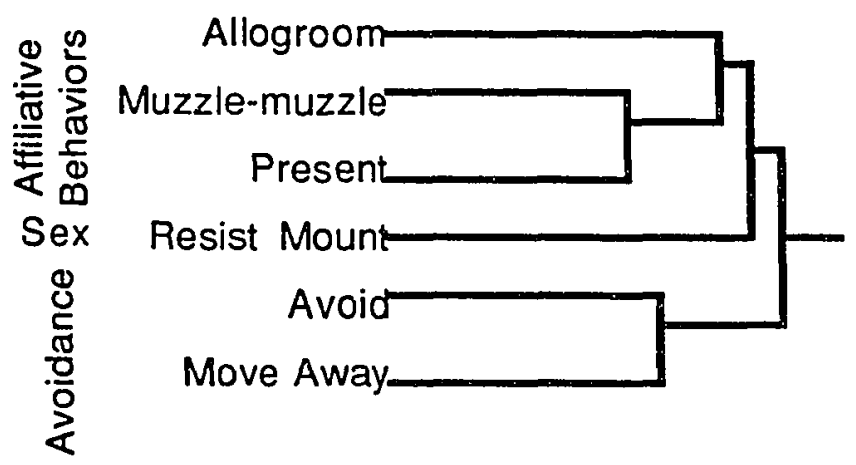

Figure IV-6. Clusters of adult female-to-male behaviors, based on ranked hourly rates in six groups with a history of reproduction. Only the six behaviors used in at least $25 \%$ of the dyads were considered. 


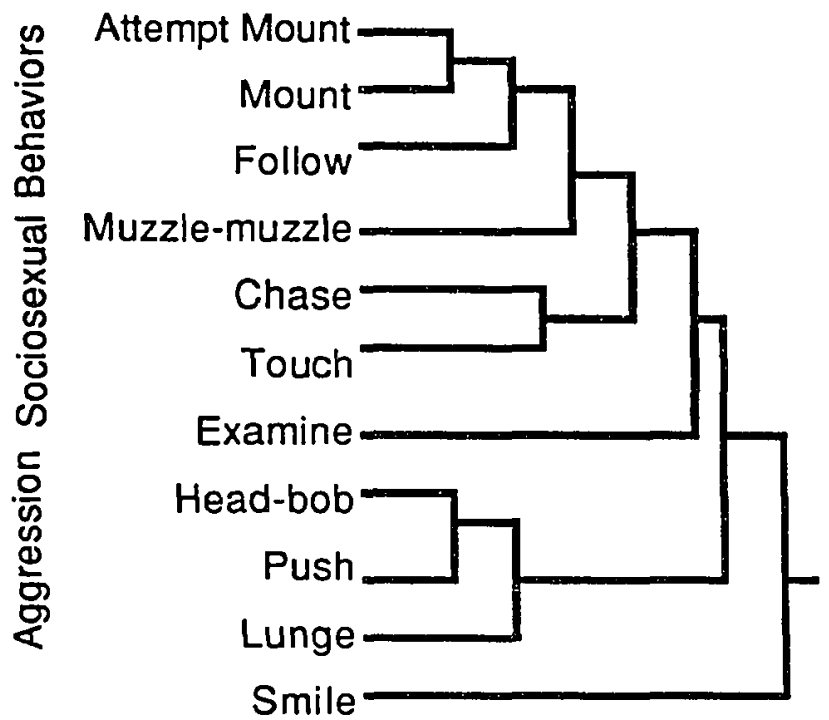

Figure IV-7. Clusters of adult male-to-female behaviors, based on ranked hourly rates in six groups with a history of reproduction. Only the 11 behaviors used in at least $25 \%$ of the dyads were considered.

From Figure IV $-6,1$ choose allogrooming and presenting to reflect affiliative-bonding. Although presenting the posterior was used both receptively and proceptively in sexual sequences (below), it was also used in non-sexual affiliative interactions. Typically, a female would present her posterior to a male as she approached him to groom, or simply to rest or feed near him. From Figure IV-7, I choose smiling as an affiliative behavior likely to be important in establishing and maintaining affiliative bonds. "Smile" was not clustered with either sociosexual or aggression behaviors because it was used by males in both types of interactions, although in different sequence. Males appeared to use smiling in affiliative or sexual contexts to indicate that an approach was "friendly." Also, males apparently used smiling to reconcile after a conflict with a female (data not shown). 
To summarize, I choose these three response variables: 1) female allogrooming of the male, 2) female posterior presenting to the male, and 3 ) male smiling to the female.

The distribution of hourly rates of Allogrooming was very skewed; mean $=0.4$, median $=0$, range $=0-4.0$. Even after the rank-transformation, this variable was skewed because about half of the pairs showed no allogrooming, and so shared the same rank.

Present posterior was not normaliy distributed, either: mean $=2.1$, median $=1.4$, range $=0.1-7.5$. The rank transformation of posterior presenting was approximately normally distributed, however.

The distribution of hourly rates of smiling was very skewed as well: mean $=1.4$, median $=0.3$, range $=0-19.7$. The rank transformation of smiling was also approximately normally distributed, however.

The "nuisance" predictor variables species, female age, and male age were considered. None of these were statistically significant for allogrooming and smiling, but female age had a significant negative effect on posterior presenting $\left(R^{2}[\times 100]=22.6 ; p=0.0106\right)$ and was used as a covariate predictor variable in regression equations with presenting.

Tables IV-10, IV-11 and IV-12 show the effect of proximity and coactivity on three indicators of affiliative bonding in the $\mathbf{2 8}$ adult pairs.

Table IV-10. Effect of two measures of cohesion in 28 adult pairs on female to male allogrooming.

\begin{tabular}{lllll}
\hline Predictors: & Hypothesized Sign: & Observed Sign: & $\mathrm{R}^{2}(\times 100):$ & Two-tailed p: \\
\hline Proximity & + & + & 44.7 & $<0.001$ \\
Coactivity & + & + & 25.9 & $<0.001$ \\
\hline
\end{tabular}


Table IV-11. Effect of two measures of cohesion in 28 adult pairs on female to male posterior present, with female age as covariate.

\begin{tabular}{lllll}
\hline Predictors: & Hypothesized Sign: & Observed Sign: & Added $\mathrm{P}^{2}(\times 100)$ & Two-tailed p: \\
\hline Proximity & + & + & 22.4 & $<0.001$ \\
Coactivity + & + & 23.2 & $<0.001$ \\
\hline
\end{tabular}

Table IV-12. Effect of two measures of cohesion in 28 adult pairs on male to female smiling.

\begin{tabular}{lllll}
\hline Predictors: & Hypothesized Sign: & Observed Sign: & $\mathrm{R}^{2}(\times 100):$ & Two-tailed $\mathrm{p}$ \\
\hline Proximity & + & + & 4.0 & $>0.3$ \\
Coactivity & + & + & 16.1 & 0.0342 \\
\hline
\end{tabular}

Summary. Hypothesis Three was supported. The primary indicator of affiliative bonds, female to male allogrooming, was strongly related to both measures of dyadic cohesion (Figures IV-8 and IV-9).

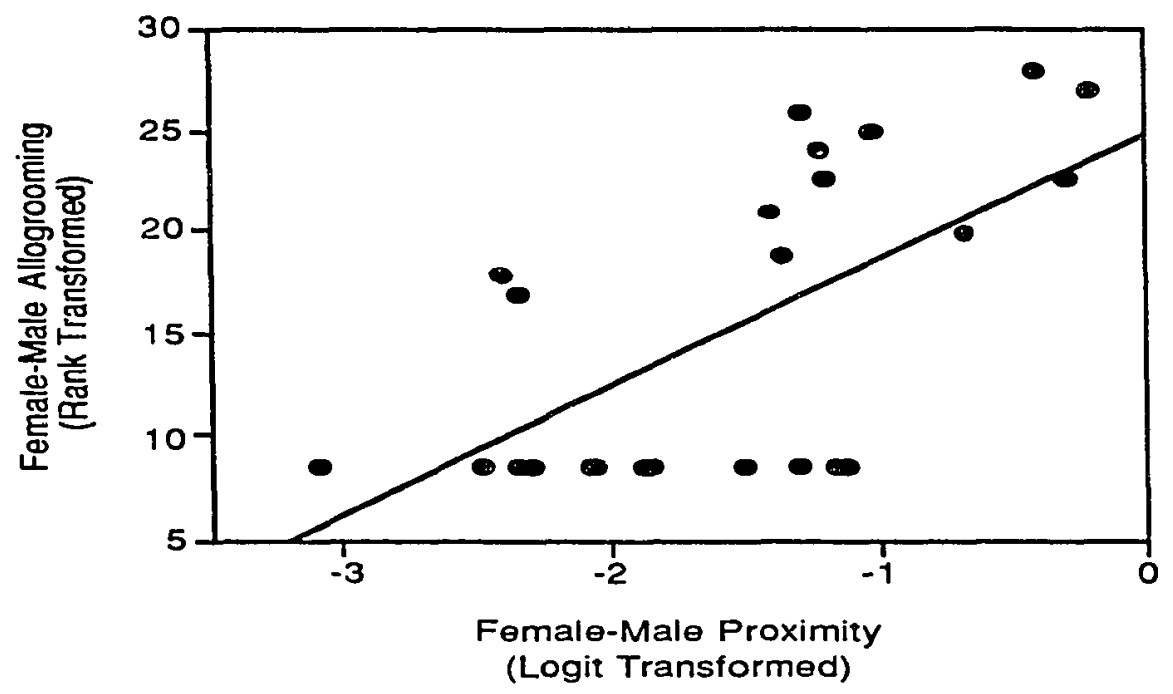

Figure IV-8. Effect of female-male proximity (logit transformation of proportion of time spent within one meter), a measure of cohesion, on a measure of female-male affiliative bonding (rank transformation of hourly rate of allogrooming) in 28 adult Mandrillus pairs in 12 captive groups. 


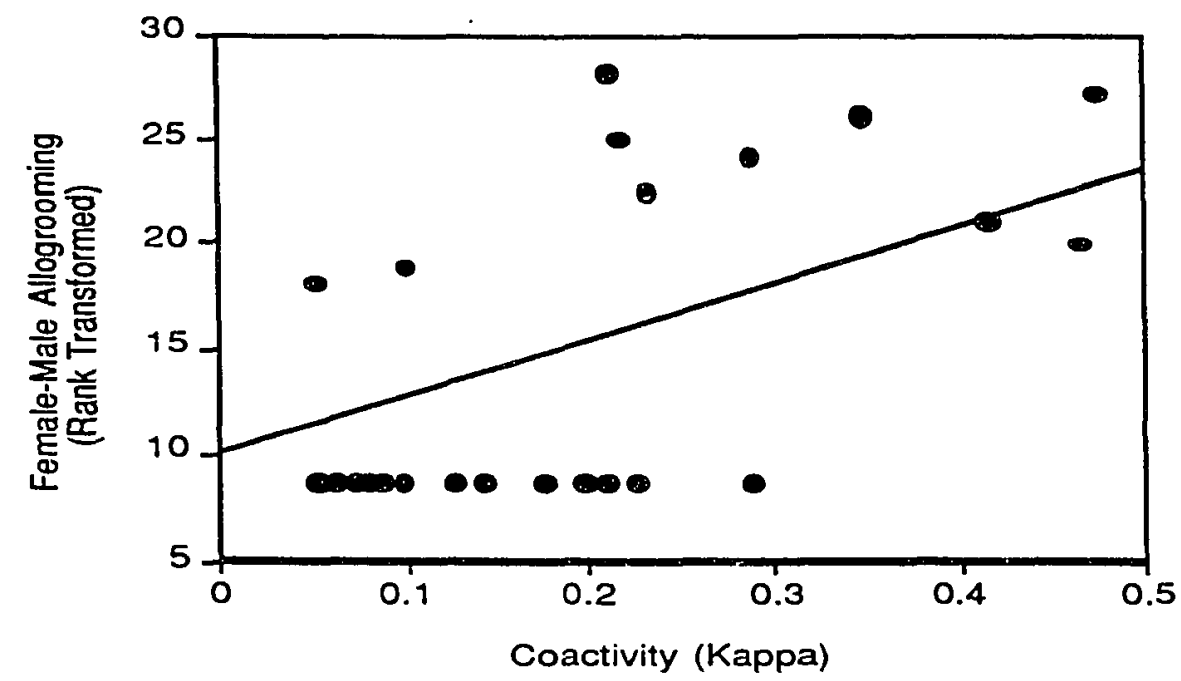

Figure IV-9. Effect of female-male coactivity (kappa coefficient of the proportion of the time spent in the same activity category), a measure of cohesion, on a measure of female-male affiliative bonding (rank transformation of hourly rate of allogrooming) in 28 adult Mandrillus pairs in 12 captive groups.

Post hoc, $\mathrm{i}$ tested the effect of the presence of higher ranking females on allogrooming. The regression was statistically significant (not shown). However, the effect of higher-ranking females on allogrooming rate disappeared when proximity was added to the regression equation. Rankrelated suppression of allogrooming appears to be solely an indirect result of the effect of rank on proximity discussed above.

I also tested post hoc for the effect of cohesion on a measure of females' "confidence" in their relationship to their males: the proportion of avoidance behaviors that were slow, i.e., move away at a walk $\div$ (move away + avoid at a run). ( postulated - incorrectly - that this would be higher in cohesive pairs, as the females would be less "fearful" of their male. Each female had a lower dominance rank than her male, whether dominance was 
measured by the directionality of threats or avoidance (data not shown). This variable was normally distributed: mean $=0.6$, median 0.7 , range $=0.2-1.0$ ). It was negatively related to the male's age $\left(R^{2}[\times 100]=15.0, p=0.0432\right)$. However, with male's age as a covariate in the regression equations, it was not predicted by either proximity or coactivity (both $R^{2}[x 100]<2.0, p>0.5$ ).

\section{Hypothesis Four}

Statement of the Hypothesis. Affiliatively-bonded dyads were hypothesized to show more sexual behavior.

Predictor Variables. Allogrooming was used as a measure of affiliative bonds, despite its skewed distribution even when rank-transformed, as it was an affiliative behavior that was not also a part of sexual sequences. Posterior presenting and smiling were also considered, although posterior presenting was a component of all sexual sequences, and smiling of many.

Respense Variable. Reproductive success, measured as the number of offspring produced per year of potential reproduction, was initially considered as a response variable. This was rejected, however, because of the many complications involved in determining the correct denominator. Most of the adult female mandrills were contracepted, generally with subcutaneous melengestrol acetate implants (MGA, an synthetic progestin), and had been for several years prior to my observations. (The detailed group descriptions in the appendix note which mandrills had MGA implants.) Also, Mandrillus has a lengthy period of lactational amennorhea during which they are apparently infertile (Boër, 1987; Feistner, 1992). Finally, the age of menarche and spermarche could be estimated only by applying the results of Wickings and Dixson (1992b) for CIRMF mandrills (Table III-2). 
Instead, sequence sampling of sexual interactions was used to describe the order in which various behaviors were used, culminating in intromission and ejaculation in a few instances (Figure IV-10). This was done to identify the behavior which initiated the sequence, and this behavior (male examination of female anogenital region) was used as the response variable for hypothesis four.

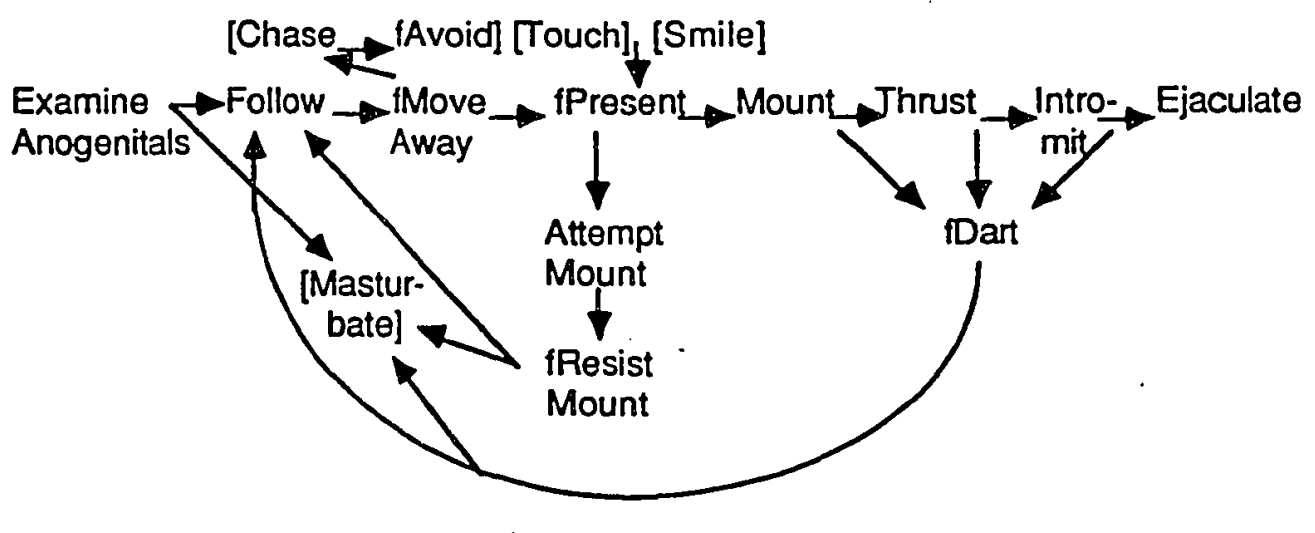

Figure IV-10. Sequence of sexual behaviors. The arrows indicate directionality (i.e., which behavior preceded the next). Behaviors marked with an " $f$ " are those performed by the female member of the dyad. Behaviors in [brackets] were alternatives seen in a few sequences by at least two dyads. Simple regressions indicate that ranked hourly rates of each non-bracketed behavior significantly predicted ranked rates of the following non-bracketed behavior (all $p<0.01$ except fPresent $>$ Mount, where $p=0.016$ ), except that ejaculation was seen in only 6 dyads so the regression of Intromit on Ejaculate was not performed. $\mathrm{N}=28$ dyads for all regressions. The main sequence across the middle (Examine to Ejaculate), with no "detours", rarely occurred (i.e., the males were multiple-mount ejaculators).

The response variable used, examination of female anogenital region was not distributed normally (mean $=0.5$, median $=0.2$, range $=0-1.8$ ), but the rank transformed variable was approximately normally distributed. 
"Nuisance" predictor variables considered for examining anogenitals were species, female age, male age and median female perineal swelling stage (Table IV-13). Species and female age were not significant predictors, but male age significantly reduced the rate of examining $\left(R^{2}[x 100]=26.6, p<\right.$ $0.01)$. Female swellings increased the rate of examining $\left(R^{2}[x 100]=20.8, p=\right.$ 0.015). Both were used together as covariates in the regression equations (both nuisance variables together, without examining: multiple $R^{2}[\times 100]=$ $36.4, p=0.021$ for male age and $p=0.0609$ for swellings).

Table IV-13. Female perineal swelling stages. Scored once for each observation period.

\begin{tabular}{ll} 
Stage: & Description of Perineum: \\
\hline 0 & At or below the level of the ischial callosities. Menses sometimes visible. \\
1 & Slightly above the ischial callosities. \\
2 & Well above the ischial callosities, but very wrinkled and not at all "Shiny." \\
3 & Well above the ischial callosities, but somewhat wrinkled and only a little "shiny." \\
4 & Well above the ischial callosities, taut and "shiny." \\
\hline
\end{tabular}

Table IV-14. Effect of three measures of affiliative bonding in 28 adult pairs on male examination of female anogenital region, a sexual sequence initiating behavior. Male Age and median female perineal Swelling stage were covariates.

\begin{tabular}{lllll}
\hline Predictors: & Hypothesized Sign: & Observed Sign: & Added $\mathrm{R}^{2}(\times 100):$ & Two-tailed $\mathrm{p}$ \\
\hline Allogrooming & + & + & 19.5 & $<0.01$ \\
Present & + & + & 28.2 & $<0.01$ \\
Smiling & + & + & 19.0 & $<0.01$ \\
\hline
\end{tabular}

Summary: Hypothesis Four was supported. Adult female-male dyads that showed more affiliative bonding were more likely to initiate sexual behavior, as indicated by male examination of the female's anogenital region (Figure IV-11). The anogenital exam behavior was usually the first of a 
sequence of behaviors that sometimes culminated in intromission and ejaculation.

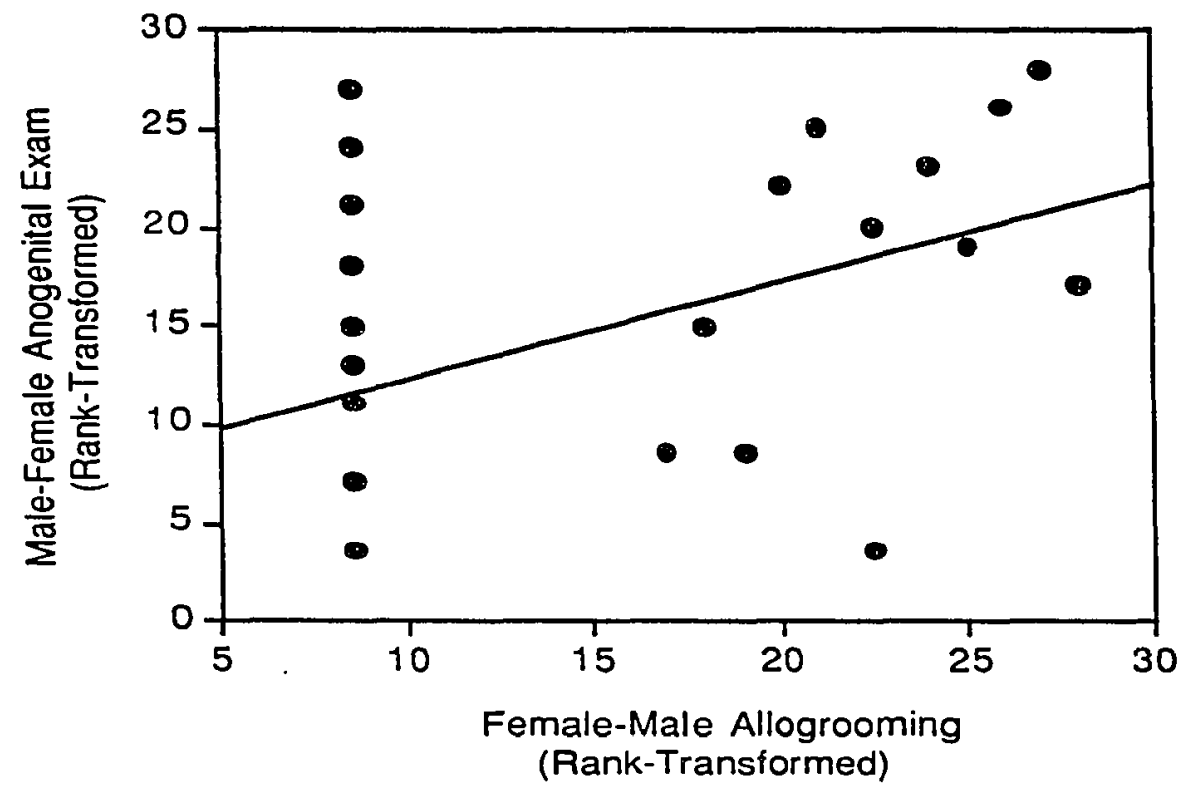

Figure IV-11. Effect of female-to-male allogrooming (rank transformed hourly rate), a measure of affiliative bonding, on male-to-female anogenital examination behavior (rank transformed hourly rate), a measure of sexual sequence initiations, in 28 adult Mandrillus pairs in 12 captive groups. Regression line shown is without the covariates (male age and female perineal swelling stage) used in hypothesis test.

Presenting of the posterior was sometimes used proceptively by females to initiate sexual sequences. Post hoc, posterior presenting was analyzed as a response variable with allogrooming and smiling, the remaining two indicators of affiliative bonds, as predictors. Female age was the "nuisance" covariate. Table IV-15 shows the result of this analysis. 
Table IV-15. Effect of two measures of affiliative bonds in 28 adult pairs on female presenting, a sexual sequence initiating behavior. Female age was the covariate in this post hoc test.

\begin{tabular}{lllll}
\hline Predictors: & Hypothesized Sign: & Observed Sign: & Added $\mathrm{R}^{2}(\times 100):$ & Two-tailed $\mathrm{p}:$ \\
\hline Allogrooming + & + & 21.0 & $<0.01$ \\
Smiling + & + & 19.3 & $<0.01$ \\
\hline
\end{tabular}

\section{Qverall Summary of Results}

No statistically significant effects of "species" on any response variable were found. No other behavioral differences between drills and mandrills were observed, suggesting that mandrills are a suitable model species for the more endangered drill.

Hypotheses one and two were partially supported, and hypotheses three and four were largely supported. Three features of captive environments were especially effective in reducing inactivity: manipulable objects, foraging opportunities, and an affiliative husbandry style. Less inactive adult females were more likely to be in proximity to adult males, an indicator of dyadic cohesion. Cohesive dyads showed more affiliative bonding, as indicated by allogrooming and other affiliative behaviors. Affiliatively-bonded dyads were more likely to initiate sexual interactions, which sometimes led to ejaculation. Figure IV-12 shows an example of these relations, using selected predictor/response variables and the "nuisance" variables associated with them. 
Hypotheses:

$\begin{array}{llll}\mathrm{H} 1 & \mathrm{H} 2 & \mathrm{H} 3 & \mathrm{H}\end{array}$

Objects,

Forage, $\rightarrow$ Activity

Style

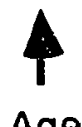

Age

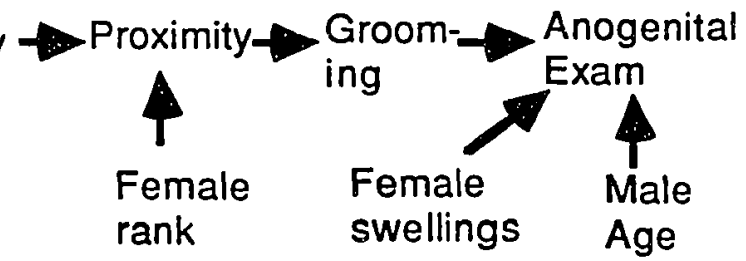

"Nuisance" variables

Figure IV-12. Summary of main results of hypothesis tests $(\mathrm{H} 1, \mathrm{H} 2, \mathrm{H} 3, \mathrm{H} 4)$. Arrows show statistically significant regression results. The final behavior shown, anogenital examining, was the first behavior in a sequence of sexual behaviors leading to ejaculation in some cases. 


\section{CHAPTER V}

\section{DISCUSSION OF RESULTS}

The hypotheses developed from a review of the literature on wild and semi-free-ranging Manarillus were supported. More enriched captive environments reduced inactivity. Adult females with reduced inactivity formed more cohesive dyads with adult males. The cohesive dyads showed evidence of affiliative bonding. The affiliatiated pairs were more likely to show sexual behaviors leading to copulation. Figure V-1 summarizes these results. This chapter elaborates on the results of the hypothesis tests presented in the previous chapter.

Hypothesis: 1

2

3

4

Environment $\rightarrow$ Activity $\rightarrow$ Cohesion $\rightarrow$ Affiliation $\rightarrow$ Breeding Figure V-1. Summary of results of the four hypothesis tests. All four hypotheses were supported in whole or in part.

\section{SPECIES DIFFERENCES}

Drills and mandrills did not differ in their activity budgets, nor was "species" a significant "nuisance" predictor variable for any of the other response variables. More subjectively, I did not notice any subtle behavioral distinctions between the two species in general, although there was 
considerable variation in behavior among individuals and groups. In the literature review chapter, however, I described the greater reproductive success captive mandrills have had historically, relative to captive drills. A resolution of this paradox is of great importance in the effort to identify solutions to the problem of poor drill reproduction.

\section{Species Differences in Captive Environments}

Can the greater reproductive success mandrills have had historically be attributed to mandrills being housed in "better" captive environments, i.e., environments having more of the features identified in the previous chapter as being effective at reducing inactivity? Table $V-1$ lists these environmental variables, and the hypothesized difference between the species (e.g., " $M>D$ " means that the feature is expected to be "better" in mandrill captive environments than in drill environments). Table $\mathrm{V}-1$ also lists the observed medians for the environmental variables in the two species; the observed direction of the difference is indicated ("<" or ">") between the columns for the mandrills and the drills. The $\mathrm{G}^{2}$ chi-square test was used for the dichotomous variable (access to the outside - yes or no - when I visited), and the KruskalWallis test was used for the ordinal variables. The "mixed species?" variable is not included in Table V-1 because only one group of each species were in mixed species exhibits ( $n=7$ of 30 mandrills, $n=5$ of 32 drills). 
Table V-1. Species differences in environmental features that might account for the species difference in reproductive success.

\begin{tabular}{|c|c|c|c|c|c|}
\hline $\begin{array}{l}\text { Environmental } \\
\text { Feature }\end{array}$ & $\begin{array}{l}\text { Hypothesized } \\
\text { Difference }\end{array}$ & $\begin{array}{l}\text { Mandrill Mediar } \\
(n=30)\end{array}$ & & $\begin{array}{l}\text { Drill Median } \\
(n=32)\end{array}$ & Statistical Test \\
\hline Outside? & $M>D$ & {$[$ Yes $=43 \%]$} & $<$ & [Yes $=69 \%]$ & $G^{2} ; p=0.0426$ \\
\hline Objects & $M>D$ & 1 & $<$ & 4.5 & $K-W: p<0.0001$ \\
\hline Forage & $M>D$ & 2 & $<$ & 4 & $K-W: p<0.0001$ \\
\hline Feedings & $M>D$ & 1 & $<$ & 2 & $K-W_{;} p<0.0001$ \\
\hline Style & $M>D$ & 3 & $<$ & 4 & $K-W: p<0.01$ \\
\hline
\end{tabular}

The results do not support the suggestion: the mandrill groups I observed were actually exhibited in environments that were generally less enriched than the drills groups I observed. While I observed essentially the entire captive drill population outside of the species' range in Africa, my mandrill sample was relatively smaller; I used data from approximately $13 \%$ of the North American captive mandrill population. While the mandrill sample was not chosen randomly, I do not think that the environments of the groups I visited were "inferior" to those of the average captive mandrill group. Most of the mandrill groups I studied had reproduced previously, as is true of most captive mandrill groups. Also, I have visited several other mandrill groups (Table III-1), so I am familiar with the range of mandrill environments in U.S. zoos. I attribute much of the greater enrichment of drill environments observed in this study to the recent efforts of the Drill Species Survival Plan to use environmental enrichment to enhance reproduction (Cox, 1989).

These recent efforts at environmental enrichment for drills did not lead drills to be more active than mandrills (Table IV-1), as would be expected based on the hypothesis one results (Table IV-7). The drills in my study were, on average, older than the mandrills in my study ( 32 drills: mean $=12.5$ years; 
30 mandrills: mean $=8.3$ years; $p=0.0222$ by $t$-test). It might be suspected that the "better" drill environments simply compensated for the greater age of the inhabitants. As Table IV-1 shows, age reduced both social and non-social categories of activity, in both species: the interaction terms were not significant. However, "age" was statistically controlled for in the regression analyses, so it is unlikely to explain the lack of the expected species difference.

Alternatively, the "better" environments drills were observed in during this study (Table $V-1$ ) may have served instead to compensate for possible long-term effects of any social or physical environmental deficits in the past. Information was not available on historic drill versus mandrill social and physical environments. If such information could be obtained, it would potentially be useful in resolving the paradox of captive mandrills' historically greater reproductive success. Even more environmental enrichment may be necessary in the future for captive drills to compensate for any possible longterm effects of environmental (social or physical) deficits in their past.

The next section discusses the results of the hypothesis tests, with an emphasis on hypothesis one. The following section describes two reproductively successful drill groups in detail, which had relatively enriched social and physical environments. In the final chapter, I propose a model which relates social environments during early rearing to contemporary environmental enrichment. This model is then used to develop a hypothesis to account for the two species' historic difference in reproductive success. 


\section{Hypothesis One}

The twelve environmental predictor variables tested in hypothesis one were chosen based on the literature review. I hypothesized that more functionally "naturalistic" environments would reduce inactivity: the animals would engage in various social and/or active behaviors.

Group Size. I chose the number of adult (including subadult) females as my measure of group size as this is a variable that managers can manipulate. None of the captive groups I studied had multiple adult males in the group when I visited them, although some of these groups have existed in zoos (e.g., Tulsa Zoo in the U.S.; Hartley and Bettinger, 1995), as well as at CIRMF (Feistner, 1990) and DRBC (E. Gadsby, letter, Sept. 1995) in Africa. The number of juveniles and infants is more difficult for managers to manipulate, although most zoos I visited with mandrills manipulated this downwards by contracepting females with MGA implants. The number of adult females had only a small, and not statistically significant, effect to reduce ageadjusted inactivity. Adult females essentially interacted socially only if they were mother-daughter pairs who had been housed together continuously. These cohesive pairs allogroomed at high rates (data not shown).

Adult mother-daughter pairs were rare in this study, however, because daughters were usually removed from their natal group at or before sexual maturity to prevent father-daughter matings. I suggest that it would be more natural, assuming that wild Mandrillus are matrifocal and matrilineal, to replace adult males when their daughters are scheduled for breeding. In one mandrill group where this was done, at the Brookfield Zoo, a mother 
(Sapphire) helped when her daughter (Jade) gave birth for the first time by holding the infant (Gunnite) while Jade recuperated from the delivery (per keeper's notes of the event). During my studies of the group, Gunnite received about equal allogrooming from his mother and grandmother when both two and four years old (data not shown). Fairbanks (1988) found that laboratory vervet monkey (Cercopithecus aethiops sabaeus) grandmothers help their daughters with infant caretaking, especially with their daughter's first offspring, and their presence reduces infant mortality. I suggest that maternal grandmothers might help reduce the high infant mortality in captive Mandrillus (especially drills)--if the mother-daughter pairs are kept together continuously. The Zoo Hannover drill group had a mother-daughter pair (Tschita and Hanna) that had been separated for most of Hanna's adult life, and they showed no indication of kinship bonds.

Rearing History had a somewhat larger effect on age-adjusted inactivity, but it was not statistically significant. The tendency was for wildcaught females to be the most active, followed by mother-reared animals; hand-reared animals tended to be a little more inactive. This result was in the hypothesized direction.

I suspect that "rearing history" failed to account for more of the variation among individuals in age-adjusted inactivity because the categories used were too broad. Wild-caught animals may have been captured as infants and kept in isolation for a long time, or they may have been captured when much older, and after any critical periods for the development of appropriate social and coping skills. In the case of mother-reared animals, they were considered mother-reared even if they were housed with their mothers only, with no peers. In other words, not all mother-reared animals were group-reared. 
Hand-reared animals may have been kept in isolation for months or years, or they may have been re-introduced as infants to groups with numerous peers to play with, and adults to observe, before critical periods in their development were completed. Finally, the "unknown" rearing history group was presumably a mixture of all three of these categories. I suspect that the "unknowns" tended to be animals who had been moved among institutions repeatedly, and that their records had been lost in the moves. The repeated moves may have been contributory to their apparent tendency for reduced activity. In the next chapter I develop a model relating early experience and later stressors. Moves between institutions might involve early separation from mothers, and/or moves might be "stressful" themselves.

A more intensive effort to better classify animals' early rearing history, e.g., the number of peers at various ages, maternal competence, the number of moves between institutions, and at what ages, will be necessary to clarify the relation between early rearing and adult behavior. The post hoc finding that rearing history affects the expression of aberrant self-directed behaviors, such as fur-pulling and self-biting, suggests that early rearing history is an important influence on behavior later in life for Mandrillus.

Spatial Relationshios: Area. Enclosure area was used to measure the opportunity for the animals to distribute themselves spatially in a natural way. 1 hypothesized that in larger exhibits, the animals would be able to choose whether and when to be in proximity to group members, and that this choice might result in their being less "stressed" (see discussion by Stricklin, 1995). The effect of area on inactivity was minimal, and had a slight tendency in the opposite direction than predicted. I suspect that this slight tendency for small enclosures to increase activity may have been a result of subordinate animals 
having to move out of the way of higher-ranking animals more often, but in any event the relationship observed was very weak.

Polyspecific Associations. There was a small but statistically significant negative effect of housing other monkeys with Mandrillus groups. As described in the previous chapter, however, this was not a particularly strong test as only two of the 14 groups studied were exhibited with other species. The smaller of these groups had active drills, while the animals in the larger of the two groups were often inactive. At the latter $z 00$, the mandrills were presumably inactive for other reasons: lack of manipulable objects or foraging opportunities; unaffiliative husbandry style. These mandrills interacted with the other monkeys sometimes, especially two juvenile males who played with the young guenons and attempted to copulate with female mangabeys. Occasionally, interspecies grooming was seen among certain mangabeys and mandrills as well. I suggest that the presence of other monkey species itself did not have a negative effect on Mandrillus in either group, and may have been beneficial for the juveniles. This suggestion needs to be evaluated with a focused study of the interactions between animals in polyspecific exhibits.

Habitat Structure: Outside, Climb Cover. Objects. The habitat structure predictor variables were whether the animals had the opportunity to be outside, opportunities to climb or take cover (collectively, structural complexity), and manipulable objects. (See Perkins, 1992, for a study of enclosure variable effects on activity in captive orangutans [Pongo pygmaeus]). Allowing the animals to go outside statistically significantly reduced inactivity, while the two structural complexity variables did not have a statistically significant effect. There was actually a small tendency for higher 
"climb" ratings to be associated with increased inactivity. I believe this was a result of the influence of two large groups at the extremes of both distributions. One group of generally inactive mandrills had the greatest opportunities for climbing: 20 large, artificial trees. Another large group of mandrills were very active, presumably because they had $400 \mathrm{~m}^{2}$ of deep straw to forage in, but had no climbing structures.

The extent and quality of manipulable objects had a large effect to reduce inactivity, as in Perkin's (1992) study of zoo orangutans (but not as in Line and Morgan's, 1991, study of laboratory rhesus macaques). In my study, this may have been due in part to the correlation between objects and opportunities to forage (rho $=0.79$ ). The correlation existed because many of the objects were associated with food: either sticks, which were part of browse, or paper or cardboard boxes that keepers hid food inside. Natural food items such as trees branches, and hidden food, such as seeds wrapped in paper, then placed in cardboard boxes, required more processing time than monkey chow and chopped fruits and vegetables placed on the floor (discussed below). The former also provided positive reinforcement for exploratory behaviors, which would be expected to lead to more exploratory behaviors over time.

Infants and juveniles appeared to be much more likely than adults to play with objects as non-food items ("toys"). Their playful manipulations were "rewarded" with results; for example, biting paper resulted in its tearing. This presumably helps young monkeys learn that their behaviors affect their environment in a predictable way. Opportunities for young mammals to learn contingencies between behaviors and outcomes are thought to improve their life-long ability to cope with stressors (Carlstead and Shepherdson, 1994). 
Foraging and Feeding. As expected, opportunities to forage had a large effect on inactivity reduction. An increased number of feedings had a small effect, which may have been solely a result of the correlation between the number of feedings and affiliative husbandry style (rho $=0.76$ ); the latter had a large effect (discussed below). An increased opportunity to forage, such as by scattering seeds in a thick layer of straw, provides for positive reinforcement of natural foraging behavior, which may occupy two-thirds of the animal's time in the wild (literature review chapter). Simply feeding the animals more often, by contrast, rewards the animals for no behavior in particular, and if the animals were inactive when fed may actually reinforce inactivity (see similar suggestion by Lacinak, 1995).

For the group which was fed the most often, at Zoo Hannover, the keepers provided enrichment foods that required some active behavioral response: whole eggs, seeds wrapped in paper or hidden in bamboo sections, whole (albeit killed) baby chicks, etc. This ensured that the reward (food) was contingent on an active, exploratory behavior by the animals. In the next section of this chapter, I describe the Zoo Hannover drills in detail, but briefly they were less often inactive than zoo drills generally, and have had the best record of drill breeding, by several males and females, and for many years. I suggest that this is in part a result of positive-reinforcement environmental enrichment by the Zoo Hannover keepers.

Humans: Keepers and Visitors. An affiliative keeper style had a large effect on reducing inactivity. This variable may not appear to be directly relatable to the situation in the wild, but research by Mitchell et al. (1991a) suggests that golden-bellied mangabeys (Cercocebus galeritus chrysogaster, recall that Cercocebus is the genus most closely related to Mandrillus ) in 
zoos behave towards their keepers as if they were familiar conspecifics. In my study, for groups with a husbandry style rating of "one," the keepers spent only a few minutes a day with the animals, did not talk to them in a pleasant tone of voice, and never groomed them. The relatively unaffiliative keepers occasionally raised their voices, or even (rarely) used the threat of hosing the animals with water (by showing them a hose, or turning the hose on), to obtain compliance in moving between enclosure areas. No appropriate social behaviors by the animals (threats, reconciliation by smiling, appeasement by presenting the posterior, allogroom solicitations) could affect the behavior of these unaffiliative "familiar conspecifics." I suggest that this lack of reinforcement for appropriately-used social behaviors might lead to a decrease in social activity.

Mellen (1991; Mellen et al., in press) found that an affiliative husbandry style increased reproductive success, and reduced pacing, in captive small cats (Felis sp.). Mellen suggests that an affiliative husbandry style is less stressful for captive cats, perhaps because it is more predictable. This interpretation is also consistent with the results I obtained, and does not contradict the "familiar conspecific" interpretation: both could be true for Mandrillus.

The proportion of time that visitors were present was not expected to affect inactivity, based on the few observations of wild Mandrillus suggesting that they learned responses to humans based on their relationship to them (literature review chapter). This was the statistical result obtained. Groups with visitors present more often had a very slight tendency, not approaching statistical significance, to be more active. Most Mandrillus appeared to ignore visitors: they rarely appeared to be visually attending to them, and most 
individual monkey's activity budgets were independent of whether visitors were present at each scan sample (data not shown). The slight tendency for a positive effect of visitors may have been because some drills thought to be sensitive to visitors were kept off-exhibit; these same drills tended to be inactive. At the upper end on the range of activity, the Zoo Atlanta drill exhibit also had the highest visitor proportion: about $85 \%$ of the observation time. 1 did not study visitor stay-time, but my perception was that visitors to the Zoo Atlanta drill exhibit stayed much longer than at most other Mandrillus exhibits because the monkeys were often active in their complex, natural-looking "habitat." Visitor stay-time also seemed to be high at Zoo Hannover, perhaps because chairs were provided for visitors to use while watching the monkeys.

The result that visitors had no major effect on Mandrillus behavior is very different from what Chamove et al. (1988) found for one zoo mandrill group, and from what Mitchell et al. (1991b) has described in Cercocebus mangabeys. More research is needed to determine what factors influence whether zoo monkeys are affected by visitors.

\section{Hypotheses Two. Three and Four}

These hypotheses evaluated the presumed chain of behaviors relating environment-related activity to sexual behavior. I analyzed various intermediate variables, such as cohesion, affiliation and sexual behaviors, and not simply reproductive success. This was done in part because of concern a priori that "nuisance" variables, such as age and sexual swellings, might affect these intermediate variables and thereby obfuscate any relation between environment and reproduction. 
Cohesion. The response variable for hypothesis two was the formation of cohesive adult female-male dyads, as measured by proximity (being within one meter) and coactivity (being engaged in the same category of behavior at the same time). Female and male inactivity was not strongly associated with coactivity, although there was a tendency in the predicted direction. Inactive females were less likely to be in proximity to males, but there was no association between male inactivity and proximity. My perception was that females were more responsible than males in determining proximity relations: females seemed to approach males to rest or engage in other behaviors nearby, while males did not appear to make a similar effort to be near females.

The observation that higher-ranking females prevented subordinates from approaching the male may explain the sex difference in the effect of inactivity on proximity. In unimale, multifemale groups, proximity to the male might be considered a scarce resource worth competing for. The male in every group monopolized concentrated preferred food items, and females in proximity to him could often share in the resource. Also, males used preferred resting sites, and again a female with a proximity relationship with him could share that resource. I also saw higher-ranking females interfere in mating attempts between the male and lower-ranking females. I hypothesize that in a multimale group, males would take an active interest in proximity to females, if only for mating and mate-guarding (an expression of male-male competition). In the unimale groups studied, it may not make any difference to a male whether or not he was near the females. Males may have had no motivation to maintain proximity to females. This suggestion should be evaluated by study of a multimale group. 
Affiliative and Sexual Behavior. Cohesive dyads were more likely to show affiliative behaviors, and to initiate sequences of sexual behavior. 1 observed that many of the animals that did not show signs of having developed social relationships appeared to be generally "passive and withdrawn." The final chapter will propose a model to account for a constellation of signs observed in the "passive and withdrawn," nonreproducing animals.

\section{Proposed Experiments}

The research described here is observational, not experimental, and so does not permit strong inference about causality. For example, in evaluating hypothesis one I have assumed that opportunities to forage would decrease inactivity. It is possible that the opposite is true: keepers may feel that inactive animals do not need opportunities to forage. I do not think that this interpretation is correct, but my research cannot distinguish between these alternative explanations. Figure V-2 illustrates the uncertainty about the direction of causality inherent in this observational study. This uncertainty about the direction of causality can only be resolved by experimental designs.

\footnotetext{
Assumed direction of causality:

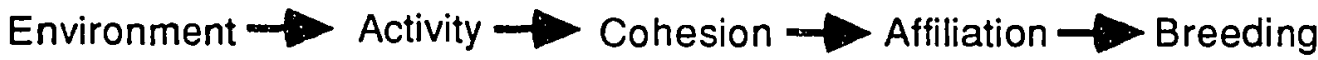

A possible alternative direction of causality:

\section{Environment} Activity
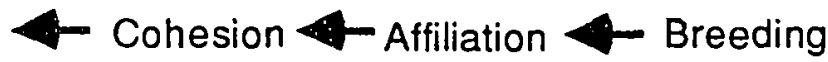

Figure V-2. The assumed direction of causality between the variables considered in the four hypotheses (top), and one alternative direction (below). Only an experimental study can distinguish among such alternative causal models. 
For an example of a suggested experiment, the activity budgets of individuals in a group--preferably several groups--could be compared before and after foraging opportunities (alone) are increased, and again following a return to the baseline condition. This is an A-B-A' design, where $A$ is the control condition and $B$ is the experimental treatment. If the treatment is beneficial, then activity would be expected to be greater in condition $B$ than $A$ or $A^{\prime}$. The $A^{\prime}$ phase is necessary to control for the effect of time. In a simple $A-B$ (pre-post) design, the possibility that there is some other factor which covaries with the beginning of treatment cannot be excluded. It is most informative to vary one factor at a time: $B$ should be increased foraging opportunities, for example, not forage and manipulable objects. This would permit the separate influence of two factors to be determined. In the present study, for example, the variables "forage" and "objects" are correlated and so their separate effects on inactivity cannot be determined.

I suggest that a quarterly Mandrillus Species Survival Plan (SSP) newsletter would be a suitable forum for the publication of these single-group experiments. If all researchers used the same recording methods (the Drill SSP ethogram), and reported their statistical methods and results, then metaanalyses could be performed to draw population-level conclusions (Sokal and Rohlf, 1995).

Environmental enrichment research, such as is proposed, has received the bulk of attention from behavioral zoo biologists attempting to facilitate reproduction in captive populations, presumably in part because captive environments are relatively easy to modify. The behavioral variables intermediate between environment and reproduction which I described-- 
cohesion, affiliation and initial sexual behaviors--are also potential targets for intervention to enhance reproduction. Cox (1987a) and Desmond et al. (1987), and Simerson (1995), described two projects which used positive reinforcement training to directly increase social activity in captive drills. It would be useful to know whether training to reinforce cohesion (proximity and coactivity), for example, would indirectly increase non-reinforced affiliative behaviors, such as allogrooming, posterior presenting, and "smiling." This would allow more "direct" intervention to assist a non-reproducing animal to breed. More research on the effect of using training to target intermediate behavioral variables is needed.

\section{TWO EXAMPLES OF REPRODUCTIVELY SUCCESSFUL DRILL GROUPS}

To illustrate how environmental and behavioral variables interrelate to produce a reproductively successful drill group, I describe below the group dynamics I observed at the only two groups of zoo drills reproducing regularly and with mother-rearing of offspring: those at Zoo Hannover and Zoo Atlanta.

\section{Environments}

The exhibits and husbandry for the drills at Zoo Hannover and Zoo Atlanta are described in the appendix. In brief, the two environments looked very different. The six environmental factors identified in Table IV-7 as important in reducing inactivity also differed between the groups. These six factors--mixed species, outside access, manipulable objects, forage, number of feedings, and affiliative keeper style--will be discussed below. 
Mixed Species. The Zoo Hannover drills were not housed with other monkeys, while the Zoo Atlanta drills were exhibited with guenons. At Zoo Atlanta, only the juvenile drill (Bioko) interacted often with the guenons: she played with the guenon juveniles. The drill infant (Max) sometimes joined in the play as well. Both drill parents observed these inter-species play sessions closely, and both mother (Inge) and father (Adonis) interceded on their offspring's behalf as soon as the play became rough, particularly if the drill infant was involved. I often saw Inge allogroom Adonis after these tense interspecies interactions were resolved.

It is also worth noting that the juvenile drill female, Bioko, at Zoo Atlanta seemed to attentively watch the guenon adults when they showed sexual or maternal behaviors. The juvenile male guenons mounted Bioko during play sessions, and she displayed normal Mandrillus female sexual behaviors during these interspecies sexual play sessions. In a large drill group, she would have had opportunities to play with conspecific peers, as I have seen mandrill juveniles do, but Bioko appeared to use the guenon juveniles as substitute peers. Based on these observations, I suggest that the guenons had a positive impact on the behavior of the Zoo Atlanta drill group.

Qutside. The Zoo Hannover drills had limited opportunities to go outside when I was there because of the cold weather; the temperature was usually around $0^{\circ} \mathrm{C}$. When they did have access, the outside exhibit was primarily used by subordinate animals to escape from animals threatening them. (They were not often followed into the freezing cold!) The fleeing animals could always re-enter one of the two interconnected inside rooms, and so did not suffer from prolonged exposure to the cold. The Zoo Atlanta drills were always outside during the day. They appeared to benefit from this 
primarily by having an interesting substrate for foraging (below). Also, the many live plants were played on and among by the two young drills, sometimes with the juvenile guenons.

Manipulable Objects. The keepers at Zoo Hannover provided new objects for the drills to investigate every morning. Sticks picked up on the zoo grounds were the most frequently offered items when I was there, and appeared to be very interesting to the drills. Older animals primarily treated them as possible food items, by stripping the bark off to eat. The young drills did this as well, but also played with the sticks. The Zoo Atlanta drills were not provided with objects on exhibit by their keepers, but they found many such items in their large, complex enclosure. Sticks and leaves that fell from trees within or adjacent to their enclosure were investigated as described above for the Zoo Hannover drills.

Eorage. The Zoo Hannover drills were provided with fresh straw and browse every morning. Small food items (corn, seeds) were scattered in the foraging materials. The Zoo Atlanta drills foraged throughout the floor of their enclosure. They often dug for food items in the soil, as was described for wild Mandrillus in the literature review chapter.

Feedings. The Zoo Hannover drill keepers provided food throughout the day, as is described in the appendix. Some of these feedings were of small quantities, intended primarily for behavioral enrichment. Examples I saw included seeds wrapped in paper or placed in sections of bamboo, raw or hard-boiled eggs, and (killed) baby chicks. If the animals were inactive before these feedings, they became active and investigated whatever the keeper had provided. The enrichment feedings were usually of food items that required an active behavioral response by the animals: they could not simply ingest the 
food, without processing. Often mild agonistic interactions occurred, but the animals reconciled afterwards with affiliative social behaviors. In this way, enrichment feedings indirectly increased social behavior for a period afterwards. The Zoo Atlanta drill keepers scattered food in the enclosure each morning before letting the monkeys out of the night-time holding area, and did not feed them again during the day. However, the enclosure was large and sufficiently structurally complicated that at least some food went undiscovered into the afternoon. This allowed the animals the choice of foraging throughout the day, with at least a chance of finding food. In conclusion, in both groups the feedings provided positive reinforcement primarily for active behavioral responses by the animals.

Husbandry Style. The Zoo Hannover drill keepers were very friendly to the drills. They hand-fed the animals occasionally. The keepers checked on the animals about every hour throughout the day, usually bringing with them some food item. They talked to the animals in a relaxed tone of voice whenever they visited them. Each interaction bout was short, about one minute. At Zoo Atlanta, the drill keepers checked on the animals less often but for longer periods. They did not feed them, but did talk to the animals. At both zoos, the drills did not appear anxious when the keepers approached.

Summary. The Zoo Hannover and Zoo Atlanta drill environments differed greatly in their structure. What they had in common was that they were complex and apparently interesting to the animals. At Zoo Hannover, this was achieved by keepers who modified the exhibit daily and used environmental enrichment techniques nearly hourly. At Zoo Atlanta, the drills benefited from a truly naturalistic exhibit. The animals received positive reinforcement for active 
behaviors. The next section will show the activity budgets for drills at these zoos, which reflect their enriched environments.

\section{Activity Budgets}

The social activity of drills in the two groups (Tables V-2 and V-3) was generally higher than average (Table V-3). Much of this reflected behavior within matrilines: mother-daughter allogrooming (Sue and Liza at Zoo Hannover; Inge and Bioko at Zoo Atlanta), and maternal care, especially nursing. Both males, Viktor and Adonis, were often groomed, however.

Table V-2. Percent of time in seven social states by non-infants at Zoo Hannover.

\begin{tabular}{llllllllll}
\hline Name: & $\begin{array}{l}\text { Allo- } \\
\text { groom }\end{array}$ & $\begin{array}{l}\text { Receive } \\
\text { Groom }\end{array}$ & $\begin{array}{l}\text { Social } \\
\text { Play }\end{array}$ & $\begin{array}{l}\text { Other } \\
\text { Social }\end{array}$ & $\begin{array}{l}\text { Adjac. } \\
\text { Group }\end{array}$ & $\begin{array}{l}\text { Social, } \\
\text { Human }\end{array}$ & $\begin{array}{l}\text { Other } \\
\text { Species }\end{array}$ & $\begin{array}{l}\text { Any } \\
\text { Social }\end{array}$ & Vocial, \\
\hline Viktor & 0 & 13 & 0 & 6 & NA* & 1 & NA 1 & 19 & 19 \\
Hanna & 14 & 2 & 0 & 27 & NA & 0 & NA & 44 & 45 \\
Liza & 7 & 1 & 1 & 5 & NA & 0 & NA & 14 & 16 \\
Sue & 2 & 5 & 0 & 692 & NA & 0 & NA & 76 & 86 \\
Tschita & 1 & 0 & 0 & 1 & NA & 0 & NA & 2 & 3 \\
\hline
\end{tabular}

1 Not Applicable: there was no adjacent Mandrillus group at Zoo Hannover, nor other monkeys housed with the drills. ${ }^{2}$ Sue nursed neonate Daphne most of the time.

Table V-3. Percent of time in seven social states by non-infants at Zoo Atlanta.

\begin{tabular}{llllllllll}
\hline Name: & $\begin{array}{l}\text { Allo- } \\
\text { groom }\end{array}$ & $\begin{array}{l}\text { Receive } \\
\text { Groom }\end{array}$ & $\begin{array}{l}\text { Social } \\
\text { Play }\end{array}$ & $\begin{array}{l}\text { Other } \\
\text { Social }\end{array}$ & $\begin{array}{l}\text { Adjac. } \\
\text { Group }\end{array}$ & $\begin{array}{l}\text { Social, } \\
\text { Human }\end{array}$ & $\begin{array}{l}\text { Other } \\
\text { Species }\end{array}$ & $\begin{array}{l}\text { Any } \\
\text { Social }\end{array}$ & $\begin{array}{l}\text { Social, } \\
\text { Visible }\end{array}$ \\
\hline Adonis & 0 & 6 & 0 & 3 & NA 1 & 0 & 0 & 9 & 12 \\
Inge & 10 & 5 & 1 & 8 & NA & 0 & 0 & 24 & 33 \\
Bioko & 7 & 3 & 8 & 1 & NA & 0 & 3 & 21 & 33 \\
Peart & 2 & 5 & 0 & 3 & NA & 0 & 0 & 10 & 12 \\
\hline
\end{tabular}

1 Not Applicable: there was no adjacent Mandrillus group at Zoo Atlanta. 
Non-social activity in the Hannover and Atlanta drill groups made up a somewhat larger than average part of the activity budget (compare Tables V-4 and V-5 to Table IV-4). This is important, as these drills were also more social (above). In other words, their greater social activity did not come at the expense of non-social activity (or vice versa): the drills in these two groups were active both socially and non-socially. Interestingly, drills in both groups spent about $25 \%$ of their visible time foraging even though they were in very different environments. Sue at Zoo Hannover was excluded from these calculations, as she foraged while nursing.

Table V-4. Percent of time in three non-social active states by non-infants at Zoo Hannover.

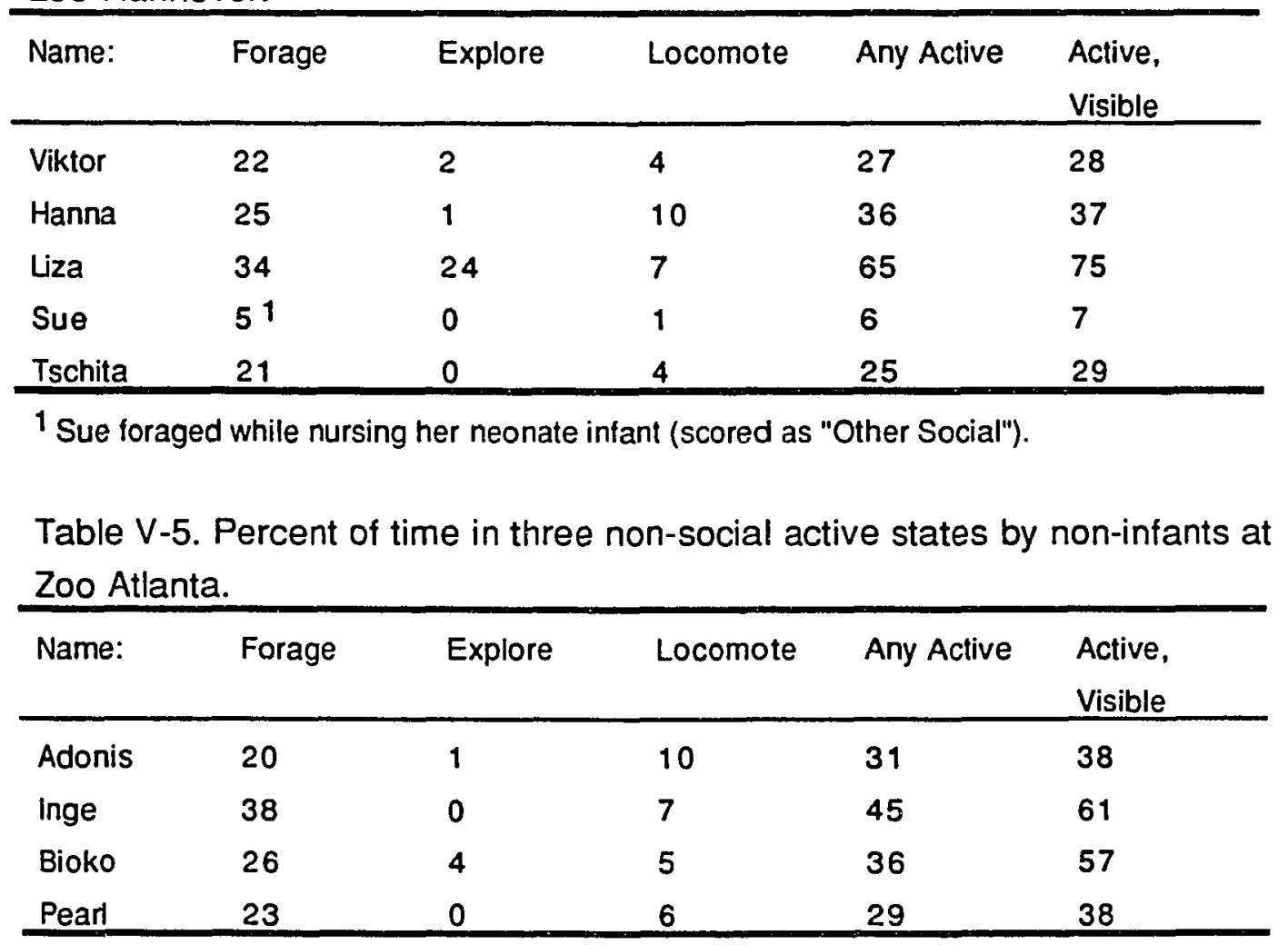


Most of the Hannover and Atlanta drills were inactive much less often than average (compare Tables V- 6 and V-7 to Table IV-5). The exceptions were the adult males and the females without offspring. This appeared to be a consequence of the group-level coactivity. The animals usually foraged as a group. After foraging bouts, matrilineal kin would come together and groom each other while infants nursed. This social activity excluded the adult males and the females without offspring, who self-groomed, rested and watched.

Table V-6. Percent of time in four inactive states by non-infants at Zoo Hannover.

\begin{tabular}{|c|c|c|c|c|c|c|}
\hline Name: & Maintenance & Aberrant & Other & Stationany & Any Inactive & Inactive, Vis. \\
\hline Viktor & 10 & 0 & 1 & 41 & 52 & 53 \\
\hline Hanna & 1 & 0 & 0 & 16 & 17 & 18 \\
\hline Liza & 2 & 0 & 0 & 6 & 8 & 9 \\
\hline Sue & 0 & 0 & 0 & 7 & 7 & 8 \\
\hline Tschita & 3 & 0 & 0 & 56 & 59 & 68 \\
\hline
\end{tabular}

Table V-7. Percent of time in four inactive states by non-infants at Zoo Atlanta.

\begin{tabular}{lllllll}
\hline Name: & Maintenance & Aberrant & Other & Stationary & Any Inactive & Inactive, Vis. \\
\hline Adonis & 6 & 0 & 1 & 33 & 41 & 50 \\
Inge & 1 & 0 & 0 & 4 & 5 & 7 \\
Bioko & 3 & 0 & 0 & 3 & 6 & 10 \\
Pearl & 12 & 0 & 0 & 27 & 39 & 50 \\
\hline
\end{tabular}

Tables $V-6$ and $V-7$, showing the percent of time when they were not visible, are included here for completeness. At Zoo Hannover, subordinate animals sometimes avoided dominant animals Viktor and Hanna by going outside or into the side room. At Zoo Hannover, and in most groups elsewhere, animals were "not visible" when they were in small areas of their enclosures where they were unlikely to have had opportunities to forage or 
engage in other active behaviors. I suspect that most animals' "not visible" time was spent either in passive social behaviors, such as allogrooming, nursing or huddling together, or inactive.

At Zoo Atlanta, however, the animals were frequently "not visible" when on the far side of their large enclosure because of the many shrubs. I suspect that the Zoo Atlanta drills spent most of their "not visible" time foraging, as that is what they were usually doing there when I observed them in that part of the enclosure between data collection periods. It is possible that the Zoo Atlanta drills actually spent as much as $50 \%$ of their total exhibit time foraging, if it is assumed that most of their "in exhibit but not seen" time was spent foraging amongst the shrubs on the far side of the enclosure. Many interactions with the guenon monkeys occurred there, too, as the guenons tended to use that end of the enclosure, where the drills spent less time. The preferred resting sites used by the Zoo Atlanta drills were clearly visible from my observation location, so I suspect that little of their "not visible" time was spent inactive.

Table V-8. Percent of time in two not-visible states by non-infants at Zoo Hannover.

\begin{tabular}{llll}
\hline Name: & $\begin{array}{l}\text { In exhibit but Not } \\
\text { Seen }\end{array}$ & $\begin{array}{l}\text { Off-exhibit } \\
\text { Voluntarily }\end{array}$ & Total Not Visible \\
\hline Viktor & 0 & 2 & 2 \\
Hanna & 1 & 2 & 3 \\
Liza & 2 & 10 & 13 \\
Sue & 2 & 10 & 12 \\
Tschita & 0 & 14 & 14 \\
\hline
\end{tabular}


Table V-9. Percent of time in two not-visible states by non-infants at Zoo Atlanta.

\begin{tabular}{llll}
\hline Name: & $\begin{array}{l}\text { In exhibit but Not } \\
\text { Seen }\end{array}$ & $\begin{array}{l}\text { Off-exhibit } \\
\text { Voluntarily }\end{array}$ & Total Not Visible \\
\hline Adonis & 19 & NA 1 & 19 \\
Inge & 26 & NA & 26 \\
Bioko & 37 & NA & 37 \\
Pearl & 23 & NA & 23 \\
\hline
\end{tabular}

1 Not applicable: Zoo Atlanta drills could not leave their exhibit.

\section{Cohession and Affiliative Bonding}

The preceding discussion concerned my first hypothesis, by showing how aspects of captive drills' environments affect their activity. Drills in the Zoo Hannover and Zoo Atlanta groups tended to be less inactive than captive Mandrillus elsewhere, especially the females. As shown in the previous chapter (hypothesis two), females who were less inactive were more likely to be in proximity to their adult male, unless prevented from this by a higherranking female. This was seen in the Hannover and Atlanta drill groups. At Zoo Hannover, the percentage of time females spent in proximity to adult male Viktor, listed in order of female rank, were: Hanna, 31\%; Liza, $6 \%$; Sue, $1 \%$; Tschita, 1\%. For the Zoo Atlanta adult female drills, proximity to adult male Adonis was Inge, $12 \%$ and Pearl, $2 \%$. In both groups, the highest ranking females, Hanna and Inge, were in proximity to the male more often than the median for all females with no higher-ranking females in their group: median = $9 \%, n=13$. This was particularly true for Zoo Hannover's Hanna (31\%), but was also true for Inge $(12 \%)$ in the large $\left(975 \mathrm{~m}^{2}\right)$ Zoo Atlanta enclosure, where chance levels of proximity were much lower than for most of the other groups. 
Hypothesis three stated that cohesive dyads were expected to show behaviors relating to affiliative bonding. Figures $V-3$ and $V-4$ illustrate this in the Zoo Hannover and Zoo Atlanta drill groups. Spatiai relations were analyzed from matrices of the proportion of time each dyad was in proximity using two-dimensional monotonic multidimensional scaling (MDS). Infants were included in these analyses, but for simplicity are not shown on these figures because they occupied approximately the same "place" on MDS maps as their mothers. Six-month-old Max at Zoo Atlanta was located between Inge and Bioko, because he was nursed by his mother and played with his sister.

Overlaid on Figures V-3 and V-4 are sociograms showing allogrooming relations in these groups. The males, Viktor at Hannover, Adonis at Atlanta, are indicated in bold, and young females, three-year old Liza at Hannover and two-year-old Bioko at Atlanta, are marked with italics. Both young females tended to be in proximity to their mothers.

\section{Sexual Behavior}

As a consequence of their past reproductive success, four of the female drills in the Zoo Hannover and Zoo Atlanta groups were in post-partum or lactational amenorrhea when I visited. This apparently explains the low level of sexual behavior seen, especially at Zoo Hannover where none of the four females were showing normal adult sexual swellings (see group descriptions in the appendix). Adult male Viktor did examine the female's anogenital regions when they presented to him. His principle other sexual behavior was masturbation. 


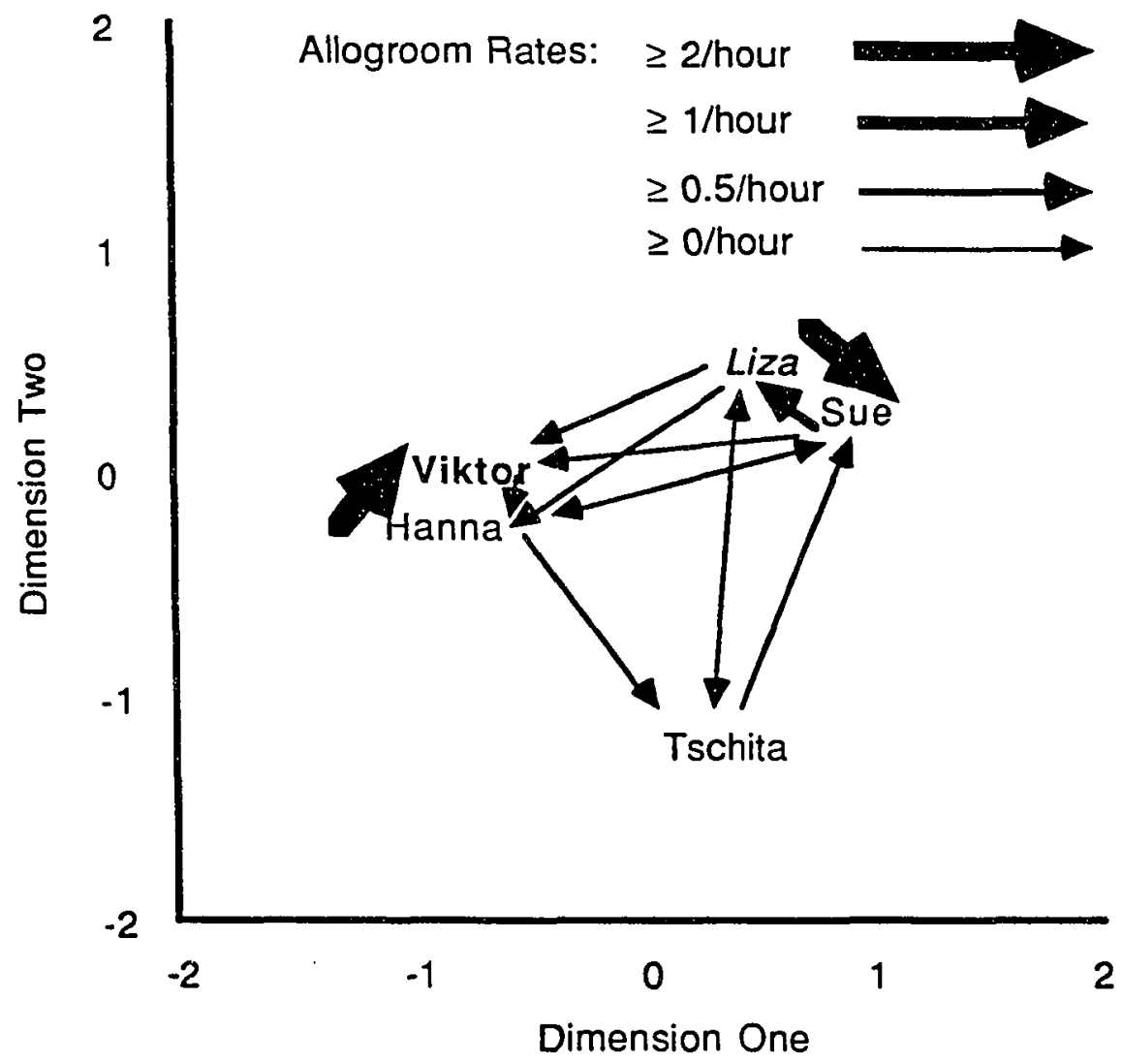

Figure V-3. Monotonic multidimensional scaling of proximity relations in the Zoo Hannover drill group. Adult male is in bold; subadult female is in italics. Arrows show the direction and frequency of allogrooming between adults.

Adult female Inge at Zoo Atlanta was also in lactational amenorrhea, but the other adult female. Pearl, had a perineal swelling when I was there. Pearl behaved somewhat proceptively to Adonis, by approaching him and presenting her posterior. Adult male Adonis showed a great deal of sexual interest in Pearl. Adonis and Pearl followed the sequence shown in Figure IV10, but Pearl always "darted" when Adonis attempted intromission. Pearl was hand-reared, and she probably did not have peer experience, either. After several copulation attempts with Pearl, Adonis would approach Inge and 


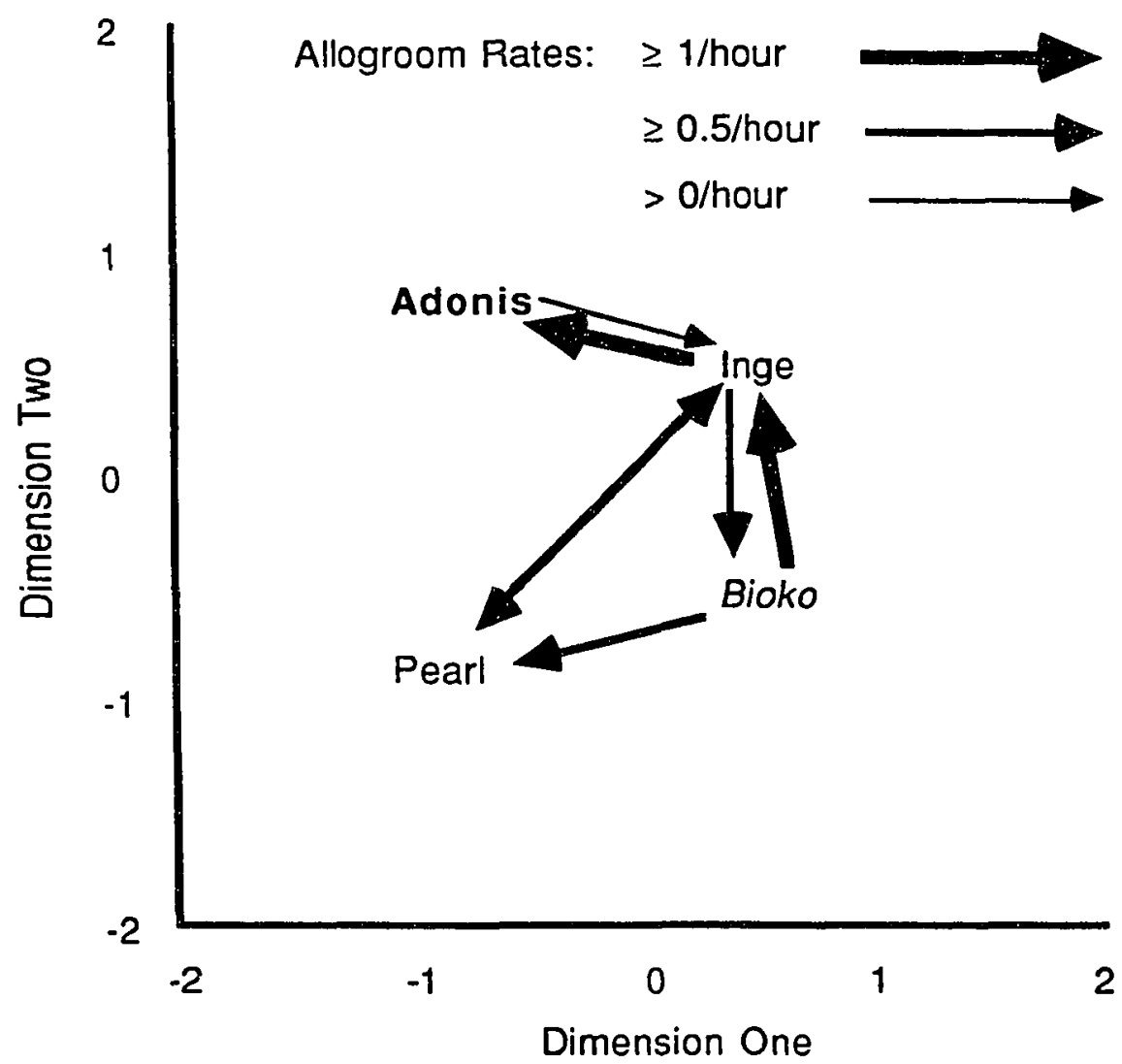

Figure V-4. Monotonic multidimensional scaling of proximity relations in the Zoo Atlanta drill group. Adult male is in bold; juvenile female is in italics. Arrows show the direction and frequency of allogrooming between non-infant.

examine her anogenital region, which was always perineal swelling stage "zero" when I was there. Adonis sometimes masturbated next.

Interestingly, the Zoo Atlanta male infant (Max) appeared to "copy" many of his father's sexual behaviors. Max would approach Pearl, smile, and touch her; when she presented, he would mount her, standing on her lower back, and thrust--without intromission--his erect penis. 1 assume that this reflects a normal process by which young Mandrillus learn adult sexual behaviors. As mentioned above, the juvenile female drill (Bioko) engaged in 
sexual play with the juvenile male guenons. I suggest that historically, many young drills may not have had similar opportunities for observational learning of, and practice with, various adult social behaviors. (Jouventin et al., 1977, have demonstrated the captive mandrill's capacity for observational learning.) This suggestion is developed further in the final chapter. 


\section{CHAPTER VI}

\section{A PROPOSED MODEL TO EXPLAIN THE RESULTS}

In the results chapter, I described the apparent lack of overall behavioral differences between mandrills and drills. This finding was perhaps unexpected, given the historic difference in reproductive success between mandrills and drills which was described in the literature review chapter. In the previous chapter, I described captive environments and behavior in two reproductively successful drill groups. Next I will describe a behavioral pattern l observed in many of the reproductively unsuccessful drills.

\section{A CONSTELLATION OF SIGNS}

For a few of the drills who had not reproduced, there were ready explanations for their apparent infertility. One young male drill, at Saarbrucken Zoo, copulated frequently with two females; presumably reproduction will occur when spermache commences. Frequent copulation was also observed in the Zoo Wuppertal drill group, but the female who had been paired with the male the longest had a chronically non-detumescing perineum. The detailed group descriptions in the appendix list four drill females I observed with this condition. It has been suggested that females with chronically nondetumescing perineums are infertile (G. Olbricht, pers. comm., Feb. 1995), 
perhaps because of abnormalities in the progesterone phase of the female cycle. This suggestion needs to be evaluated with physiological research. Most of the other non-reproducing drills showed a distinct pattern of abnormal behavior. Table VI-1 lists the constellation of signs seen in these animals. In brief, they appeared to be lethargic or passive, and withdrawn from social activity. Not every "passive and withdrawn" non-reproducing drill showed all six of the signs in this constellation, but in general these signs cooccurred in certain individuals. I refer to this condition as "Passive and Withdrawn Syndrome" (PAWS) because this name corresponds to my hypothesis one response variable (age-adjusted inactivity), but Table VI-1 lists other signs which are also a part of this syndrome.

Table VI-1. The constellation of signs observed in many non-reproducing captive drills (Passive and Withdrawn Syndrome: PAWS). Not every "PAWS" animal had all seven signs, but all had at least five.

Description of Sign:

1) Sleeping during the day

2) Decreased motor activity, relative to other animals of similar age

3) Decreased social activity, relative to other animals of similar age

4) Alone--often more than 5 meters from group members, if enclosure size allowed

5) Aberrant bodily behaviors, such as fur-pulling and self-biting

6) Obesity--weight well above the ranges of body weights reported for the provisioned mandrills at CIRMF (10 - 15 kg in adult females, $30-35 \mathrm{~kg}$ in adult males)

7) Diminished proceptive and/or receptive sexual behavior, but not diminished masturbation by males

\section{Theory in Zoo Biology Revisited}

As described in the literature review chapter, zoo biology theory is premised on the idea that captive environments should functionally simulate essential characteristics of the natural environment. Hediger's (1964) criterion 
for evaluating the success of captive environments was reproduction: if reproduction occurred, the captive environment must have had the necessary components of the environment in which that species evolved.

Zoo biology theory is weaker when it comes to describing the proximal mechanisms by which environment relates to reproduction. One model zoo biologists employ is based on "chronic stress" (reviewed by Carlstead and Shepherdson, 1994; see Byrne and Suomi, 1991, for a non-zoo example). While I do not deny that chronic stress can be detrimental to animals, I suggest that many zoo biologists are using "stress" in an overly general sense. Earlier in this century, physician-researcher Hans Selye developed a "General Adaptation Theory" to explain how chronic non-specific stress could cause almost any disease (reviewed and critiqued by Goldstein, 1995). "Among other things, (Selye's) theory provided a ready explanation for how any distressing experience could lead to virtually any disease state" (Goldstein, 1995, p. 13). Selye's theory has fallen from favor among biomedical scientists in part because it was so general as to be of little use in specific cases (Goldstein, 1995). However, chronic hypercortisolemia, which is a definite and specific response to excessive chronic stress, is not known to cause the constellation of signs listed in Table Vl-1 (Hadley, 1988). I conclude from this that "stress," in and of itself, is not a sufficient explanation for the lack of reproduction in the PAWS drills I observed. In other words, the "chronic stress model" is not very useful in interpreting the behavioral pattern observed. A more useful model would have two key properties: 1) it would specifically predict the co-occurrence of the signs I observed in the PAWS drills; and 2) it would suggest specific treatments for PAWS. 


\section{Iowards a New Model}

The results of the test of my first hypothesis, that aspects of the environment affect activity in captive Mandrillus, point to a possible explanation for the "passive and withdrawn" appearance that is more specific to the constellation of signs (Table VI-1) than is a Selyean general stress model. "Inactivity" was negatively related to the amount of environmental enrichment: manipulable objects and foraging opportunities. Both of these forms of enrichment provide positive reinforcement for active behaviors initiated by the animals, which is expected to increase the amount of activity over time via learning processes (see review of the biology of learning in Kupferman, 1991). The frequency of self-injurious behaviors was related to early rearing history. Laboratory studies of the effect of different early rearing environments on behavior and neurodevelopment in macaques and other Cercopithecines are reviewed below. An ideal explanatory model would relate both of these factors - positive reinforcement and early rearing history in one explanation for the constellation of signs observed in the drills with PAWS. In the remainder of this chapter, I will develop a model to explain the constellation of signs, using positive reinforcement and early rearing history as the primary etiological factors. The proposed model is based on analogy to human clinical depression. Human clinical depression will be described below following a discussion of the idea of using humans as a model species for understanding the behavior of non-human primates. 
Sackett (1991, p. 35) has developed what he calls "The human model of psychological well-being in primates." $\mathrm{He}$ first reviews the two principle goals of developing comparative models of physical or psychological health: 1) to aid in research on causal processes in the species of primary concern, and 2) to aid in identifying therapies that might be useful in the species of primary concern. Sackett then considers several defiritions and indices of human well-being, and identifies those that rely on observable behavior as relevant to non-human primates. He then lists influences on human well-being that might be relevant to non-human primates. Among these influences are personality factors. Sackett suggests that primates who show active social and exploratory behaviors would be presumed to have high well-being. Nonhuman primates who appear "depressed" and withdrawn from natural species-specific activities, and who show behaviors similar to those classified as neurotic in humans, would be presumed to have low psychological wellbeing under this model.

\section{Bationale for Using Humans as a Model Species for a Non-Human Primate}

Aspects of human "well-being" have been studied extensively in numerous well-funded biomedical laboratories around the world. Many of the studies on human health have used carefully developed non-human primate models to permit detailed investigation of proximal mechanisms, and to evaluate of specific therapies in related species. Biomedical researchers using rhesus macaque models often cite studies pointing to the many similarities between humans and Cercopithecids, such as by noting, "...rhesus 
share more than $90 \%$ of their genetic material with humans and, as a consequence of genetic homology, are strikingly similar in neuroanatomy, physiology and organized social behavior" (Champoux et al., 1995, p. 7). I suggest that zoo biologists should take advantage of the extensive biomedical literature on human "well-being" because much of the knowledge may be generalizable to other mammalian species. $I$ expect that this would be especially true in cases where animal models have been relied upon for much of the data on human conditions. Logically, if a non-human animal can be a model for humans, the opposite must be true unless a non-Darwinian scala naturae is assumed.

Zoo biologists will realistically never have research budgets close to what biomedical scientists have been given, but they can thriftily utilize much of the voluminous biomedical literature. A potentially useful, if unconventional, question for zoo biologists to ask themselves when confronted with an unknown condition in a captive primate population is, "What would this condition be called if these were humans?" An electronic search of the biomedical literature will reveal whether a non-human primate model has been developed for the analogous human condition. If so, then this literature may suggest a possible pathogenetic process and/or an effective treatment. This is the process I used a posteriori in an attempt to find an explanation for the "passive and withdrawn" appearance in many of the non-reproducing drills I observed.

This procedure, of using the biomedical literature for zoo biological purposes, is not intrinsically anthropomorphic. Anthropomorphism is merely the attribution of human mental states to non-human animals, which is not useful. Drawing parallels between human and non-human animal 
physiological states is not anthropomorphic, and may be useful. Given two caveats, 1) that the human model is a simplification, as all models are, and 2) that my research is observational, not a series of experiments to test predictions drawn from the human model, I propose that human depressive disorders can be used as a model psychopathology to assist in interpreting the behaviors seen in PAWS drills. I review here some models of human depression which suggest that depressive disorders are not necessarily intrinsically human.

\section{HUMAN DEPRESSIVE DISORDERS}

Among the early models of human depression was that of Sigmund Freud, whose conception of the disorder did not allow for the possibility that children could be depressed (Kazdin, 1988). The recognition by psychologists that children did become depressed led to the development of models for depression that were broad enough to include children of all ages, that is to say, people without an adult human's sophisticated cognitive abilities (Kazdin, 1988). These more inclusive models were developed to explain depression in children, but I suggest that these models are broad enough that they can be invoked to explain analogous disorders in non-human primates, possibly including PAWS.

Kazdin (1988) reviews the models of depression etiology and pathogenesis developed to explain the occurrence of depression in children as well as adults. In summarizing his review, I have replaced the word "person" with "individual." Behavioral models assert that depression results from the reduction of positive reinforcement from the environment: the 
individual's behaviors are not rewarded, or even result in aversive consequences. These behaviors are consequently shown less often, and the individual becomes "passive and withdrawn," a behavioral sign of human depression. A related conceptualization is that individuals with poorly developed social skills fail to obtain positive reinforcement from interactions with others. Depressed people show diminished rates of social interaction. Cognitive models of depression are closely related to the behavioral models, differing only in emphasis on internal mental states versus observable behaviors. The "learned helplessness model" was based on analogy to laboratory rodents, which stopped showing escape behaviors after learning that they could not escape electric shocks, even when later given the opportunity to escape. Another cognitive model suggests that depression occurs in individuals with deficits in interindividual problem-solving skills when they are faced with stressful social problems. Socioenvironmental models of depression emphasize the accumulated impact of stressful events during an individual's life. Biological models focus on neurochemical and neuroendocrinological abnormalities, while genetic models of depression are based on inheritance patterns observed for the disorder. Kazdin (1988, p. 169) emphasizes that "the models overlap greatly."

I wish to emphasize that none of the models reviewed by Kazdin (1988) are necessarily anthropocentric. Indeed, an additional model of depression is that it is a normal, adaptive response to adverse environments (Klerman, 1987). This view of depression emphasizes that, "Although depression is a ubiquitous human experience, it is not a uniquely human condition. Most mammals, and especially primates, have the capacity to become depressed" (Klerman, 1987, p. 5, emphasis added). An earlier version of this model 
referred to depression as an adaptive "conservation-withdrawal response to chronic stress," but this interpretation was abandoned when it became apparent that chronic hypercortisolemia often accompanied depression (Klerman, 1987). Cortisol mobilizes bodily energy reserves (Hadley, 1988), which would not be expected if depression is an adaptive "conservation" response.

Some work on an integrated "biobehavioral model" has been completed and is described by Kazdin (1989; see also Kandel, 1991, and Paykel, 1992). This integrated model includes two key factors in depression susceptibility: early rearing environment and "stress," including among other adverse states or events a lack of positive reinforcement for behaviors. (Genetic predisposition is thought to be influential as well.) According to this model, individuals with a deficient early rearing environment have altered neurodevelopment such that their neurochemistry is particularly sensitive to adverse events throughout their life. These adverse events, including a loss of positive reinforcement for behaviors, decrease noradrenergic and serotonergic function in the limbic system of the brain of these individuals who had abnormal neurodevelopment. It is the altered neurochermistry in the hypothalamus (part of the limbic system) of these clinically depressed individuals which causes the various physiological signs, via the hypothalamus-pituitary-endocrine gland axes. These signs are strikingly similar to those listed previously on Table VI-1, the "constellation of signs" I observed in the passive and withdrawn, non-reproducing drills.

Differences between PAWS and human clinical depression (Kazdin, 1988; Paykel, 1992) include a high incidence of night-time insomnia in clinically depressed humans, in addition to sleepiness during the day. I did not 
observe Mandrillus at night, so I do not have comparable data on this sign. Also, clinically depressed humans may have anorexia or obesity, or neither. I did not observe any "anorexic" animals; not all appeared obese, however. Finally, clinically depressed humans report dysphoria; this cannot be considered in animal models for obvious reasons. (Note: biomedical scientists who use non-human primate models in their research on human depression occasionally use the term "depression" in reference to monkeys showing signs similar to those observed in humans diagnosed as clinically depressed. Dysphoria, or reports of sad feelings, is strongly associated with human depression. Dysphoria and depression are not synonyms, however. Human "depression" refers to a large assemblage of signs and symptoms. Dysphoria is among these, but dysphoria alone is not "depression." Despite this technical distinction, I prefer not to use "depression" to refer to non-human primates because of the term's association with dysphoria, which is not usefully applied to non-human animals.)

However, striking parallels between PAWS and clinical human depression are seen, even in the details of PAWS (Table VI-1). Reynolds et al. (1988) described the pattern of decreased sexual behavior in clinically depressed humans, as well as the lack of a reduction in masturbation by clinically depressed men. Also, Jenike (1990) described hair-pulling (trichotillomania) and other self-injurious behaviors as being associated with clinical depression in humans, and as responding to similar treatments.

Figure VI-1 describes an etiological model for PAWS, using early rearing environment and recent environmental enrichment ("positive reinforcement") as putative contributing factors. Based on the analogy with the biobehavioral model for human clinical depression, PAWS would be expected 
to result from reduced norepinepherine and serotonin functioning in the hypothalamus. The next section reviews experiments on early rearing techniques for laboratory cercopithecids, and describes altered neurodevelopment of noradrenergic and serotonergic systems in monkeys reared in less-complex or more stressful environments. I suggest that this forms the neurobiological substrate for the later development of PAWS in Mandrillus in "stressful" environments, where "stressful" specifically means a lack of positive reinforcement for behaviors, and/or a lack of "control" over aspects of the environment (see discussion of the relationship between "control" and psychological well-being in laboratory macaques by Line et al., 1991).

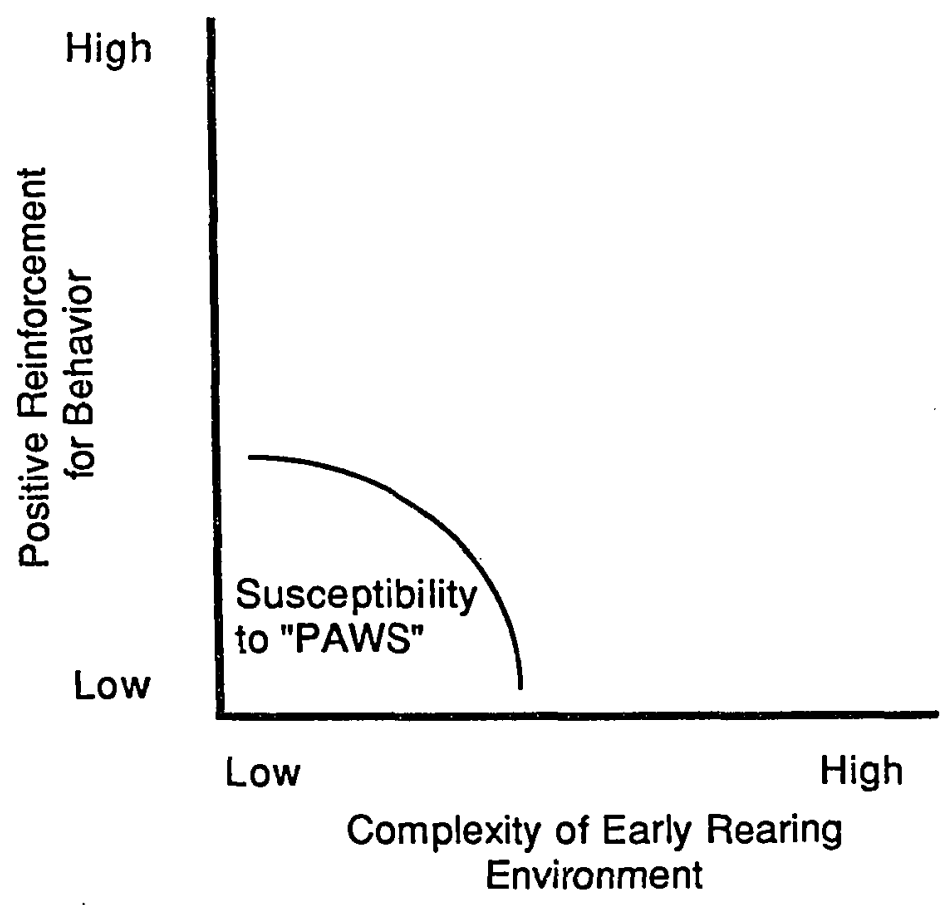

Figure VI-1. Illustration of a proposed etiological model for the "Passive and Withdrawn Syndrome" (PAWS) described for many non-reproducing drills. The model is based on biobehavioral models for human clinical depression. 
EFFECT OF EARLY REARING ENVIRONMENT ON BEHAVIOR AND

NEURODEVELOPMENT IN LABORATORY MACAQUES

Harlow and Harlow (1962) reviewed their early experiments on the effects of social deprivation in laboratory rhesus macaques. Normal development of various social behaviors (play, agonism, affiliation, sex and maternal care) was dependent on the presence of peers to play with. Appropriate maternal care alone was not sufficient: motherless monkeys who could play with other infants developed somewhat more normally than did those reared only with their mother.

The effects of a deprived developmental environment typically persist into adulthood (Harlow and Harlow, 1962; Fittinghoff et al., 1974), even with long-term efforts at rehabilitation with conspecifics (Cummins and Suomi, 1976). Interestingly, a large, complex, outside environment helped rehabilitate a group of motherless, peer-reared rhesus macaque juveniles, who as adults behaved much like wild conspecifics (Suomi, 1986; Novak et al., 1994; O'Neill-Wagner, 1994).

With the important exception of the latter group of rehabilitated peeronly monkeys, both peer-only and mother-only females give inadequate maternal care to their own offspring (Champoux et al., 1992). Their usual response to the birth of their infants is to ignore or abuse them (Ruppenthal and Sackett, 1979). Note that this is like what has been reported for drills (Cox, 1989).

Male monkeys raised in socially deprived environments rarely become fathers because they do not exhibit normal sexual behavior. Masturbation is the principal sexual behavior instead. (Fittinghoff et al., 1974). Note that this is 
also like what has been reported for drill males (Cox, 1987a, b; this study, data not shown).

The affective consequence of deprived social environments for infant monkeys is "despair," which is described as being apparently homologous to human depression (Suomi, 1983; Velluci, 1990). Neurobiological developmental effects related to "despair" or "depression" are found in socially deprived monkey infants (Kraemer et al., 1991). There may also be cognitive deficits associated with early social restriction in monkeys (Gluck, 1979).

There is evidence that social environments more complex than just mother and peers are beneficial for monkey social development. Suomi (1974) found that rhesus macaques reared with unrelated adult males and females as well as their fathers, mothers, siblings and peers showed more appropriate social behavior as adults than did monkeys reared with their mother and peers but no other animals. They were more active and became dominant to the mother-peer monkeys, who were comparatively "lethargic" and "timid."

This result led to the idea that social environments for young macaques in laboratories can be arranged along a continuum of increasing social complexity (Erwin and Deni, 1979):
1) Isolation
2) Mother-only
3) Peer-only
4) Mothers and Peers
5) Nuclear Family
6) "Harem" Groups
7) Large Multimale, Multifemale Groups. 
Erwin and Deni (1979) recommended the latter two social

environments for laboratory macaque breeding programs. The latter two rearing environments ( 6 and 7) would also appear appropriate for Mandrillus, based on my review of their groupings in the wild in the literature review chapter. However, many "mother-reared" drills may have been reared in groups with few, if any, peers. This may contribute to an increased susceptibility to PAWS. This suggestion is developed further in the following section.

Early experiences much less extreme than isolation can have large, long lasting effects as well. Stress experienced by a mother can permanently affect her offspring's neurological and social development. Andrews et al. (1993) and Rosenblum and Andrews (1994) described experiments with bonnet macaques (Macaca radiata) in which group-living mothers of three-tosix-month-old infants were fed either in a low foraging demand captive environment, or in a variable foraging demand situation. In the latter environment, the food delivery method varied unpredictably to the animals; the animals were not food deprived. This unpredictability appeared to be stressful to the mothers. The infants of these "stressed" mothers showed evidence of "insecure attachment" and even "depression," like what has been described for motherless monkeys, even though they were mother-reared in a harem-type group with peers. When these infants became adults, they were more timid, less social and more likely to be subordinate than were the infants reared in the environment that was less stressful to the mothers. There were also permanent effects on central serotonergic and noradrenergic systems (Rosenblum et al., 1994). 
As described above, serotonergic and noradrenergic pathways are also involved in human clinical depression, and in macaque models of human depression (reviewed by Vellucci, 1990). Serotonergic pathways also appear to be key in determining social relations in laboratory cercopithecines (reviewed by Vellucci, 1990); recall that social relationships are central to models of human clinical depression. In one study, antidepressant drugs known to increase serotonergic activity indirectly enhanced status acquisition by helping male vervet monkeys (Cercopithecus aethiops) establish affiliative relationships (proximity, allogrooming) with females, who then aided them in dominance struggles (Raleigh et al., 1991). The effect was reversed in a controlled, balanced, cross-over experimental design by drugs that reduced serotonergic activity: the males became less affiliative with females, and in turn received less aid from them. The antidepressants used were tryptophan, the precursor compound to serotonin, and fluoxetine, a selective serotonin reuptake inhibitor (SSRI). Raleigh et al. (1991) did not find behavioral response differences between the two serotonergic drugs at the doses used, suggesting that either could be used for drug treatment in monkeys. In the next section of this chapter, I propose an experimental trial of antidepressant drugs for PAWS Mandrillus. Following this, I describe how the model developed to explain PAWS can be used to explain the historic difference in reproductive success between mandrills and drills.

\section{A PROPOSED EXPERIMENT TO EVALUATE THE SUGGESTED MODEL}

The hypothesis that passivity and social withdrawal in captive Mandrillus is similar to human clinical depression could be tested by 
combining environmental enrichment with psychopharmaceuticals effective in treating human clinical depression. When humans are clinically depressed, they are treated with a combination of behavior therapy and anti-depressant medicines. Selective serotonin re-uptake inhibitors are widely used to treat depressed humans (Paykel, 1992). Selective serotonin reuptake inhibitors are also effective in treating compulsive behaviors often associated with depression, such as hair-pulling (Jenike, 1990). If the model I am proposing is correct, the combination of enriched environments, that is, those that provide a positive reinforcement for natural, active behaviors, and SSRI, would be more effective at reducing inactivity than enrichment alone. If a depressive disorder is not involved, the addition of SSRI would not be expected to provide any additional change in behavior over enrichment alone.

I suggest the following experimental design for an investigative treatment of monkeys who appear to be both "passive and withdrawn" and show aberrant, self-injurious behavior (PAWS; Table VI-1): A - B - C - B' - A', where $A$ is the baseline condition, $B$ is the addition of enrichment and a placebo, $C$ is enrichment continued with the addition of SSRI, B' is enrichment continued, but with the placebo substituted for $S S R I$, and $A^{\prime}$ is a replicate of the original baseline condition. The depression model predicts that the activity in condition $C>B \approx B^{\prime}>A \approx A^{\prime}$; the null hypothesis for this test is that $C=B \approx$ $B^{\prime}>A \approx A^{\prime}$. If $B=A$, then the test result that $C=B=A$ would not support the null hypothesis that SSRI is not effective, as in humans anti-depressant drugs are usually thought to be effective only in combination with effective behavior therapy (Kazdin, 1989). A finding that B' > B would suggest long-term effects of SSRI after it is discontinued, which would be the ideal result. 
I would recommend only using Mandrillus outside of breeding

programs--genetically over-represented mandrills, or reproductively senescent drills or mandrills--for such an experimental treatment with SSRI, both because of the experimental nature of the trial, and because SSRI are reported to reduce sexual function (libido, orgasm) in some humans (Paykel, 1992). These side effects may be reversible with the noradrenergic agonist yohimbine (Jacobsen, 1992), although yohimbine may not function in cercopithecines as it does in humans (Chambers and Phoenix, 1989). Alternatively, tryptophan could be used instead of an SSRI, based on Raleigh et al.'s (1991) finding described above of no social behavioral difference between tryptophan and fluoxetine in vervet monkeys. Finally, it is important to stress that I am proposing a small, experimental investigation of the effect of human anti-depressant drugs only in combination with effective environmental enrichment. not long-term drug therapy alone, which I would not predict to be useful.

\section{A HISTORIC-DEMOGRAPHIC HYPOTHESIS FOR THE SPECIES DIFFERENCE IN CAPTIVE MANDRILLUS REPRODUCTIVE SUCCESS}

In the literature review chapter, I presented demographic evidence that mandrills have been more successful than drills in zoos historically. My results, however, suggest that recently drills have been housed in more enriched captive environments (Table V-1). The drills, however, were no more active than the mandrills (Table IV-1). The two species appeared to me to share an identical repertoire of behaviors, and these behaviors seemed to be 
used in the same way by both species. Therefore, the data collected for this study do not explain the historic species difference in reproductive success.

I can propose a possible historical-demographic explanation, however, by using the PAWS model just developed. I suggest that because drills are less colorful than mandrills, zoos in the past made less effort to acquire large (i.e., multifemale) groups. Schaaf (1990) suggested that historically, drills were often housed in pairs: one adult male, one adult female. According to my hypothesis, the wild-caught pairs may have reproduced, but any offspring born grew up in a socially impoverished environment: no peers, and at best a sibling, to play with; few adults to observe. This uncomplex early rearing environment would resemble those Erwin and Deni (1979) considered unsuitable for successful laboratory macaque breeding, above. In addition, infant and juvenile males would have had no females with which they could engage in normal sexual play (I observed that mothers vigorously rejected their son's mount attempts.) As reviewed above, socially impoverished early rearing environments in laboratories produce monkeys who are comparatively "lethargic and timid" as adults, even if they were technically "mother-reared." These first-generation captive-born drills would be expected, based on the model I developed, to be more susceptible to developing PAWS as adults, and so they would be less likely to develop cohesive, affiliated adult dyads who initiated sequences of sexual behavior.

Additionally under this historic-demographic hypothesis, drill females who did become pregnant would be expected to have been at increased risk to fail to show appropriate maternal care, because they did not have experience with infants when they were juveniles. I observed that juvenile females closely observed maternal behavior and sought out infants with which 
to interact. Also, mothers with PAWS might be prone to infant abuse and neglect, as has been suggested for clinically depressed human mothers (Culp et al., 1989; Lee and Gotlib, 1989; Gaudin et al., 1993; see also Taylor et al., 1990).

Mandrills, being more colorful, may have been more likely to be exhibited in large, multifemale groups under this historical-demographic hypothesis. Mandrill infants and juveniles would therefore have been more likely to mature in a complex social group that included peers of both sexes and different ages. This would give them an opportunity to develop normal social skills; recall that social skill deficits are central to theories of human clinical depression (the model for PAWS). Additionally, females who were not competent mothers would have had an opportunity to observe normal maternal care by cage-mates. Littlewood and Smith (1979) describe a case at the Metro Washington Park Zoo in which a hand-reared adult female mandrill was abusive and neglectful of her first four offspring. When another mandrill female gave birth, and was a competent mother, the hand-reared female was "very attentive" to the other female's infant, and was a competent mother to her next infant and to several since then. A similar process occurred in the Potter Park Zoological Garden mandrill group (G. Brady, pers. comm., Sept. 1992). 1 suggest that drill females have not been given similar opportunities for observational learning of normal maternal behaviors.

Finally, some mandrills in the past presumably were housed in small groups, and so may have been as susceptible to PAWS as have many drills. If the offspring of these small-group mandrills did not reproduce very often, however, the captive mandrill population as a whole would not have been jeopardized. This is simply because there would have been so many other 
mandrills born in other groups available for reproduction. In other words, the mandrill population may historically have been buffered from the consequences of reproductive failure in some proportion of the population by its demographic advantage: there have always been many more mandrills than drills in captivity. The historical-demographic hypothesis could be evaluated by a retrospective study using the mandrill studbook, which is both larger and more complete than the drill studbook. My hypothesis predicts that mother-reared mandrills reared in a one-male, one-female social environment with no peers would be less likely than those reared in a complex social group to reproduce as adults and to rear their infants if female.

The present population of zoo mandrills may be disproportionately composed of the desendants of those mandrills who were historically housed in relatively large, complex social groups. A similar demographic phenomena is underway in the captive drill population. An increasing proportion of the world's captive drill population was born at Zoo Hannover, which provides the largest group size and most socially complex early rearing environment for drills outside of Africa. By one estimate, Zoo Hannover is the origin for half of the world's drills living outside of Africa (R. Wolf, unpubl. data). I suggest that zoos desiring to breed Mandrillus for sustained captive propagation should maintain their animals in socially as well as physically complex and enriched environments. 


\section{CONCLUSION}

I began this dissertation with the story of Nshum, the inactive drill-man in Ekoi folklore. Nshum clearly had social skill deficits, and received only negative reinforcement from his interpersonal relationships. Depressed Nshum was not cohesive with his group-members, and did not form affiliativebonds with anyone. His psychological well-being was poor, and he expired in captivity prematurely. Zoo keepers and managers must not be "Nshum" themselves if Mandrillus are to do better in our towns. This is what I suggest keepers and managers consider:

1) increase the opportunities for the animals to receive positive reinforcement for their active behaviors, such as by providing manipulable objects and foraging opportunities;

2) form affiliative relationships with the animals by spending time talking to them, grooming them, and with positive reinforcement training;

3) develop more truly naturalistic social and physical environments for the animals to live in, based on knowledge of how they live in the wild;

4) educate visitors about the animals, how they live in the wild, and why they are vulnerable to extinction; and,

5) support in situ conservation programs, such as the Drill Rehabilitation and Breeding Center. 


\section{REFERENCES}

Abbott, D. H. (1993). Social conflict and reproductive suppression in marmoset and tamarin monkeys. In Mason, W. A., \& Mendoza, S. P. (Eds.), Primate Social Conflict. (pp. 331-372). Albany: State University of New York Press.

Abegglen, J.-J. (1984). On socialization in Hamadryas baboons. London: Bucknell University Press.

Altmann, J. (1974). Observational study of behavior: sampling methods. Behaviour, 49, 227-267.

Anadu, P. A. (1987). Prospects for conservation of forest primates in Nigeria. Primate Conservation, 8, 154-159.

Andrews, M. W., Sunderland, G., \& Rosenblum, L. A. (1993). Impact of foraging demands on conflict within mother-infant dyads. In Mason, $W$. A., \& Mendoza, S. P. (Eds.), Primate Social Conflict. (pp. 229-252). Albany: State University of New York Press.

Anonymous. (1994). Meet the drill. International Primate Protection League News, 21, 3-6.

Areola, O. (1987). The political reality of conservation in Nigeria. In Anderson, D., \& Grove, R. (Eds.), Sonservation in Africa: peeple. policies and practice. (pp. 277-292). Cambridge: Cambridge University Press.

Baker, A., \& Lacy, R. (1992). Birth and development of a sooty mangabey (Cercocebus torquatus) $x$ mandrill (Papio sphinx) hybrid. Paper presented at the 14th Congress of the International Primatological Society, Strasbourg.

Baker, A. (1994). Variation in the parental care systems of mammals and the impact on zoo breeding programs. Zoo Biology, 13, 413-421.

Balasch, J., Sabater-Pi, J., \& Padrosa, T. (1974). Perceptual learning ability in Mandrillus sphinx and Cercopithecus nicitans. Revisita Espanola de Fisjoiogica, 30, 15-20. 
Ballou, J. D., \& Lacy, R. C. (1995). Identifying genetically important individuals for management of genetic variation in pedigreed populations. In Ballou, J. D., Gilpin, M., \& Foose, T. J. (Eds.), Population Management for Survival and Recovery. (pp. 76-111). New York: Columbia University Press.

Beck, B. B., \& Castro, M. I. (1994). Environments for endangered species. In Gibbons, E. F., Wyers, E. J., Waters, E., \& Menzel, E. W. (Eds.), Naturalistic environments in captvity for animal behavior research. (pp. 259-270). Albany: State University of New York Press.

Bercovitch, F. B., \& Goy, R. W. (1990). The socioendocrinology of reproductive development and reproductive success in macaques. In Ziegler, T. E., \& Bercovitch, F. B. (Eds.), Socioendecrinolegy of primate reproduction. (pp. 59-93). New York: Wiley-Liss.

Bercovitch, F. B. (1995). Female cooperation, consortship maintenance, and male mating success in savanna baboons. Animal Behaviour, 50, 137149.

Bettinger, T., Wallis, J., \& Morris, A. (1995). Reproductive parameters of mandrills at the Tulsa Zoo. Zoo Biology, 14, 115-121.

Blom, A., Alers, M. P. T., Feistner, A. T. C., Barnes, R. F. W., \& Barnes, K. L. (1992). Primates in Gabon - current status and distribution. Qnyx, 26. 223-234.

Boër, M. (1987). Beobachtungen zur fortpflanzung und zum verhalten des drill (Mandrillus leucophaeus Ritgen, 1825) im Zoo Hannover. Zeitschrift fur Saugetierkunde, 52, 265-281.

Boër, M., \& Sommer, V. (1992). Evidence for sexually selected infanticide in captive Cercopithecus mitis, Cercocebus torquatus and Mandrillus leucophaeus. Primates, 33, 557-563.

Boysen, J. (1991). A simple case of trickery. International Wildlife May-June, 30-34.

Bronson, F. H. (1989). Mammalian reproductive biology. Chicago: University of Chicago Press.

Byrne, G. D., \& Suomi, S. J. (1991). Effects of woodchips and buried food on behavior patterns and psychological well-being of captive rhesus monkeys. American Journal of Primatolegy, 23, 141-151.

Carlstead, K., \& Sheperdson, D. (1994). Effects of environmental enrichment on reproduction. Zoo Biology, 13, 447-458. 
Carman, M. (1979). The gestation and rearing periods of the mandrill at the London Zoo. International Zoo Yearbook, 19, 159-160.

Chambers, K. C., \& Phoenix, C. H. (1989). Apomorphine, deprenyl, and yohimbine fail to increase sexual behavior in rhesus males. Behavioral Neuroscience, 103, 816-823.

Chamove, A. S., Hosey, G. R., \& Schaetzel, P. (1988). Visitors excite primates in zoos. Zoo Biology, Z, 359-369.

Champoux, M., Byrne, E., DeLizio, R., \& Suomi, S. J. (1992). Motherless mothers revisited: rhesus maternal behavior and rearing history. Primates, 33, 251-255.

Champoux, M., Boyce, W. T., \& Suomi, S. J. (1995). Biobehavioral comparisons between adopted and nonadopted rhesus monkey infants. Developmental and Behavioral Pediatrics, 16, 6-13.

Chang, T. R. (1991). Social behavior and activity budgets of captive mandrills (Mandrillus sphin $x$ ): a comparison of a traditional exhibit and an ecologically representative habitat. Georgia Institute of Technology, Atlanta: Unpublished Master's Thesis.

Cohen, J., \& Cohen, P. (1983). Applied multiple regression/correlation analysis for the behavioral science, second edition. Hillsdale: Lawrence Erlbaum.

Conover, W. J., \& Imam, R. L. (1981). Rank transformations as a bridge between parametric and non-parametric statistics. American Statistician 35, 124-129.

Cooper, R., Feistner, A., Evans, S., Tsujimoto, H., \& Hayami, M. (1989). A lack of sexual transmission of a simian immunodeficiency agent in a semifree-ranging group of mandrills. AIDS, 3, 764.

Corradino, C. (1990). Proximity structure in a colony of Japanese macaques (Macaca fuscata): an application of multidimensional scaling. Primates. 31 351-362.

Cousins, D. (1979). The status of Mandrillus in British Zoological collections, with notes on conservation. International Zoo News, 26, 8-14.

Cox, C. (1987a). Social behavior and reproductive status of drills (Mandrillus leucophaeus). American Association of Zoological Parks and Aquaria Regional Conference Proceedings, 321-328. 
Cox, C. (1987b). Increasing the likelihood of reproduction among drills. American Association of Zoological Parks and Aquaria Annual Conference Proceedings, 425-434.

Cox, C. (1989). Drill (Mandrillus leucophaeus) SSP Masterplan. Unpublished report.

Cox, C., \& Hearn, G. (1989). Standardized methodology for observing drill behavior in zoos (Version 2.2). Unpublished manuscript.

Cox, C. R., \& duBois, T. T. (1992). Comparison of different types of behavioral enrichment on the activity and social behavior of drill baboons. American Association of Zoological Parks and Aquaria Annual Cenference Proceedings, 557.

Culp, R. E., Culp, A. M., Soulis, J., \& Letts, D. (1989). Self-esteem and depression in abusive, neglecting, and nonmaltreating mothers. Infant Mental Health Journal, 10, 243-251.

Cummins, M. S., \& Suomi, S. J. (1976). Long-term effects of social rehabilitation in rhesus monkeys. Primates, 17, 43-51.

Darwin, C. (1871). The Descent of Man, and Selection in Relation to Sex. London: Murray.

Darwin, C. (1872). The Expression of Emotions in Man and Animals. London: Murray.

Davis, J. A. (1976). The ascent of mandrill. Animal Kingdom, 79, 4-11.

Desmond, T., \& Laule, G. (1994). Use of positive reinforcement training in the management of species for reproduction. Z00 Biology, 13, 471-477.

Desmond, T., Laule, G., \& McNary, J. (1987). Training to enhance socialization and reproduction in drills. American Association of Zoological Parks and Aquaria Annual Proceedings, 435-441.

Disotell, T. R. (1994). Generic level relationships of the Papionini (Cercopithecoidea). American Journal of Physical Anthropology, 24, 47-57.

Disotell, T. R., Honeycutt, R. L., \& Ruvolo, M. (1992). Mitochondrial DNA phylogeny of the old-world monkey tribe Papionini. Molecular Biology and Evolution, 2, 1-13. 
Dixson, A. F., \& Lloyd, S. A. C. (1988). The hormonal and hypothalamic control of primate sexual behaviour. In Smith, G. R., \& Hearn, J. P. (Eds.), Reproduction and disease in captive and wild animals. (pp. 81-117). Oxford: Clarendon Press.

Dixson, A. F., Bossi, T., \& Wickings, E. J. (1993). Male dominance and genetically determined reproductive success in the mandrill (Mandrillus sphinx). Primates, 34, 525-532.

duBois, T. (1992). An exhibit for drills: from drab to dazzling. The Shape of Enrichment, 1, 1-3.

Dunbar, R., \& Dunbar, P. (1975). Social dynamics of gelada baboons. Basel: S. Karger.

Dunbar, R. I. M. (1984). Reproductive decisions: an economic analysis of gelada baboon social strategies. Princeton: Princeton University Press.

Durrell, G. (1953). The Overloaded Ark, London: Faber and Faber.

Emory, G. R. (1975a). Comparison of spatial and orientational relationships as manifestations of divergent modes of social organization in captive groups of Mandrillus sphinx and Theropithecus gelada. Folia Primtalogica, 24, 293-314.

Emory, G. R. (1975b). The patterns of interaction between the young males and group members in captive groups of Mandrillus sphinx and Theropithecus gelada. Primates, 16, 317-334.

Emory, G. R. (1976b). Attention structure as a determinant of social organization in the mandrill (Mandrillus sphinx) and gelada (Theropithecus gelada). In Chance, M. R., \& Larson, R. R. (Eds.), The Social Structure of Attention. (pp. 29-49). London: John Wiley and Sons.

Emory, G. R. (1976a). Aspects of attention, orientation, and status hierarchy in mandrills (Mandrillus sphinx) and gelada baboons (Theropithecus gelada). Behaviour, 59, 70-87.

Erwin, J., \& Deni, R. (1979). Strangers in a strange land: abnormal behaviors of abnormal environments? In Erwin, J., Maple, T. L., \& Mitchell, G. (Eds.), Captivity and Behavior. (pp. 1-28). New York: Van Nostrand Reinhold.

Fairbanks, L. A. (1988). Vervet monkey grandmothers: interactions with infant offspring. International Journal of Primatology, 9, 425-441. 
Feistner, A. T. C. (1988). Reproductive parameters in a semifree-ranging group of mandrills. In de Mello, M.T. (Ed.), Baboons: Selected Proceedings of the 12th Congress of the International Primatological Society Meeting. (pp.77-88). Brasilia, Brazil: University of Brasilia Press.

Feistner, A. T. C. (1990). The Behaviour of a social group of mandrills, Mandrillus sphinx. Primate Eye, 40, 25-26.

Feistner, A. T. C. (1991). Scent marking in mandrills, Mandrillus sphinx. Folia Primatoligca, 57, 42-47.

Feistner, A. T. C. (1992). Aspects of reproduction of female mandrills Mandrillus sphinx. International Zoo Yearbook, 31, 170-178.

Feistner, A. T. C., Cooper, R. W., \& Evans, S. (1992). The establishment and reproduction of a group of semifree-ranging mandrills. Zoo Biology, 11, 385-395.

Fleagle, J. G. (1988). Primate Adaptation and Evolution. San Diego: Academic Press.

Fleiss, J. L. (1981). Statistical Methods for Rates and Proportions. New York: John Wiley and Sons.

Forthman, D., \& Elder, S. (1992). Activity in hand-reared and mother-reared pairs of captive drills Papio leucophaeus. American Journal of Primatology, 27, 28.

Forthman, D. L., Chang, T. R., \& Elder, S. D. (1994). Behavioral comparison of captive drills (Papio leucophaeus) and mandrills (Papio sphinx). In Roeder, J. J., Thierry, B., Anderson, J. R., \& Herrenschmidt, N. (Eds.), Current Primatology Volume 11: Social Development. Learning and Behaviour. (pp. 193-198). Strasbourg: Université Louis Pasteur.

Fried, J., \& Whitehouse, M. (1992). A pre-post occupancy comparison of activity budgets and habitat utilization in a group of captive mandrills (Mandrillus sphinx). American Journal of Primatology, 27, 28-29.

Frittinghof, N. A., Lindburg, D. G., Gomber, J., \& Mitchell, G. (1974). Consistency and variability in the behavior of mature, isolation-reared, male rhesus macaques. Primates, 15, 111-139.

Gadsby, E. L. (1990). The status and distribution of the drill. Mandrillus leucophaeus in Nigeria. Unpublished report.

Gadsby, E. L. (1992). Drill survey in Cameroon. Oryx, 26, 177-178. 
Gadsby, E. L., \& Jenkins Jr, P. D. (1991). Report on wild life and hunting in the proposed Etinde Forest Reserve Limbe Botanic Garden and Rainforest Genetic Conservation Project. Unpublished report.

Gadsby, E. L., Jenkins Jr, P. D., \& Feistner, A. T. C. (1994). Coordinating conservation for the drill (Mandrillus leucophaeus): endangered in forest and zoo. In Olney, P. J. S., Mace, G. M., \& Feistner, A. T. C. (Eds.), Creative Conservation: Interactive management of wild and captive animals. (pp. 439-454). London: Chapman and Hall.

Gadsby, E. L., \& Jenkins Jr, P. D. (1995). Radio interview. Portland: KBOO $90.3 \mathrm{FM}$.

Gartlan, J. S. (1970). Preliminary notes on the ecology and behavior of the drill, Mandrillus leucophaeus RITGEN, 1824. In Napier, J. R., \& Napier, P. H. (Eds.), old World Monkeys: Evolution. Systematics and Behavior. (pp. 445-480). New York: Academic Press.

Gaudin, J. M., Polansky, N. A., Kilpatrick, A. A., \& Shilton, P. (1993). Loneliness, depression, stress, and social supports in neglectful families. American Journal of Orthopsychiatry, 63, 597-605.

Gluck, J. P. (1979). The intellectual consequences of early social restriction in rhesus monkeys (Macaca mulatta). In Ruppenthal, G. C. Nurseny Care of Nonhuman Primates. (pp. 253-267). New York: Plenum Press.

Goldstein, D. S. (1995). Stress, catecholamines and cardiovascular disease. New York: Oxford University Press.

Gonzalez-Kirchner, J. P. (1990). Some data on the ecology of the drill (Papio leucophaeus $L$ in the south of the island of Bioko (Republic of Equatorial Guinea). Madrid, Spain: Unpublished manuscript.

Gould, K. G., \& Schaaf, C. D. (1994). Comparative semen parameters of the drill and mandrill. In Anderson, J. R., Roedder, J. J., Thierry, B., \& Herrenschmidt, N. (Eds.), Current Primatology Volume III: Behavioral Neuroscience. Physiology and Reproduction. (pp. 169-174). Strasbourg, France: Université Louis Pasteur.

Groombridge, B. (Ed.) (1993). 1994 IUCN Red List of Threatened Species. Gland, Switzerland: International Union for the Conservation of Nature.

Hadidan, J., \& Bernstein, I. S. (1979). Female reproductive cycles and birth data from an old-world monkey colony. Primates, 20, 429-442.

Hadley, M. E. (1988). Endocrinology. Englewood Cliffs, NJ: Prentice Hall. 
Hamilton, D. B., \& Widner, K. (1994). Effects of environmental enrichment on social and aberrant behaviors in drill baboons (Mandrillus leucophaeus). Paper presented to the annual meeting of the American Association of Zoo Keepers.

Hammen, C., Adrian, C., Gordon, D., Burge, D., Jaaenicke, C., \& Hiroto, D. (1987). Children of depressed mothers: maternal strain and symptom predictors of dysfunction. Journal of Abnormal Psychology, 96, 190198.

Harlow, H. F., \& Harlow, M. K. (1962). Social deprivation in monkeys. Scientific American, 207, 136-145.

Harrison, M. J. S. (1988). The mandrill in Gabon's rain forest-ecology, distribution and status. Oryx, 22, 218-228.

Hartley, D., \& Bettinger, T. (1995). Aggression associated with changes in the dominance hierarchy of the mandrill troop at the Tulsa Zoo. Paper presented to the regional conference of the American Zoo and Aquarium Association.

Hearn, G. W., Weikel, E. C., \& Schaaf, C. D. (1988). A preliminary ethogram and study of social behavior in captive drills, Mandrillus leucophaeus. Primate Report, 19, 11-17.

Hearn, G. W., \& McColgan, J. (1992). Influence of cage design and companionship on behavior in drill baboons. American Association of Zoological Parks and Aquaria Annual Conference Proceedings, 558.

Hediger, H. (1964). Wild animals in captivity. New York: Dover.

Hill, W. C. O. (1970). Primates: Comparative Anatomy and Taxonomy VIll. Cynopithecinae: Papio. Mandrillus. Theropithecus. New York: Wiley.

Holthus, L. B., Delson, E., Napier, P. H., \& Meester, J. (1977). Comments on the request to determine the generic names of the baboon and the mandrill. Bulletin of Zoolegical Nomenclature, 33, 148-149.

Horwich, R. H. (1974). Regressive periods in primate behavioral development with reference to other mammals. Primates, 15, 141-149.

Hoshino, J., Mori, A., Kudo, H., \& Kawai, M. (1984). Preliminary report on the grouping of mandrills (Mandrillus sphinx) in Cameroon. Primates, 25, 295-307.

Hoshino, J. (1985). Feeding ecology of mandrills (Mandrillus sphinx) in Campo Animal Reserve, Cameroon. Primates, 26, 248-273. 
Hutchins, M., Hancocks, D., \& Crockett, C. (1984). Naturalistic solutions to the behavioral problems of captive animals. Zoologische Garten, 54, 28-42.

Inagaki, H., \& Yamashita, T. (1994). An investigation of intergeneric relations among Papionini monkeys based on fine hair medulla structures. Primates, 35, 499-503.

Itoigawa, M. (1993). Social conflict in adult male relationships in a freeranging group of Japanese monkeys. In Mason, W. A., \& Mendoza, S. P. (Eds.), Primate Social Conflict. (pp. 145-169). Albany: State University of New York Press.

Jacobsen, F. M. (1992). Fluoxetine-induced sexual dysfunction and an open trial of yohimbine. Journal of Clinical Psychiatrx, 53, 119-122.

Jenike, M. A. (1990). Illness related to obsessive-complusive disorder. In Jenike, M. A., Baer, L., \& Minichiello, W. E. (Eds.), Obsessivecomplusive Disorders: Thoery and Management. (pp. 39-60). Chicago: Year Book Medical Publishers.

Johns, A. G., \& Johns, B. G. (1995). Tropical forest primates and logging: longterm coexistence? Qryx, 29, 205-211.

Jolly, C. J. (1970). The large African monkeys as an adaptive array. In Napier, J. R. \& Napier, P. H. (Eds.), Old World Monkevs: Evolution. Systematics and Behavior. (pp. 139-174). New York: Academic Press.

Jouventin, P. (1975a). Observations sur la socio-ecologie du mandrill. 느 Tierre et la Vie, $29,493-532$.

Jouventin, P. (1975b). Les Roles des colorations du mandrill (Mandrillus sphinx). Zeitschrift fuer Tierpsychologie, 39, 455-462.

Jouventin, P., Pasteur, G., \& Cambefort, J. P. (1977). Observational learning of baboons and avoidance of mimics: exploratory tests. Evolution, 31 . 214-218.

Kandel, E. R. (1991). Disorders of mood: depression, mania, and anxiety disorders. In Kandel, E. R., Schwartz, J. H., \& Jessell, T. M. Principles of Neuroscience. (pp. 869-883). New York: Elsevier.

Kazdin, A. E. (1988). Childhood depression. In Mash, E. J., \& Terdal, L. G. Behavioral Assessment of Childhood Disorders. (pp. 157-195). New York: Guilford Press.

Kazdin, A. E. (1989). Childhood depression. In Mash, E. J., \& Barkley, R. A. Treatment of Childood Disorders. (pp. 135-166). New York: Guilford Press. 
Klerman, G. L. (1987). The nature of depression: mood, symptom, disorder. In Marsella, A. J., Hirschfield, R. M. A., \& Katz, M. M. (Eds.), The Measurement of Depression. (pp. 3-19). New York: Guilford Press.

Kraemer, G. W., Ebert, M. H., Schmidt, D. E., \& McKinney, W. T. (1991). Strangers in a strange land: a psychobiological study of infant monkeys before and after seperation from real or inanimate mothers. Child Development, 62, 548-566.

Kramer, M., \& Schimdhammer, J. (1992). The chi-squared statistic in ethology: use and misuse. Animal Behavior, 44, 833-841.

Kudo, H., \& Mitani, M. (1985). New record of predatory behavior by the mandrill in Cameroon. Primates, 26, 161-167.

Kudo, $\mathrm{H}$. (1987). The study of vocal communication of wild mandrills in Cameroon in relation to their social structure. Primates, 28, 289-308.

Kummer, H. (1968). Social organization of Hamadryas baboons. Chicago: University of Chicago Press.

Kupferman, I. (1991). Learning and memory. In Kandel, E. R., Schwartz, J. H., \& Jessell, T. M. Principles of Neiroscience. (pp. 997-1008). New York: Elsevier.

Lacinak, T. (1995). When is enrichment the most effective? Paper presented to the annual conference of the American Zoo and Aquarium Association.

Lahm, S. A. (1985). Mandrill ecology and the status of Gabon's rainforests. Primate Conservation, 6, 32-33.

Lahm, S. A. (1986). Diet and habitat preference of Mandrillus sphinx in Gabon: implications of foraging strategy. American Journal of Primatology, 11, 9-26.

LaRue, M. D. (1995). Mandrill (Mandrillus sphinx) Regional Studbook: Canada. United States and Mexice. Topeka, Kansas: Topeka Zoological Park.

Lee, C. M., \& Gotlib, I. H. (1989). Clinical status and emotional adjustment of children of depressed mothers. American Journal of Psychiatry, 146, 478-483.

Lee, P. C., Thornback, J., \& Bennett, E. L. (1988). Threatened Primates of Africa. Gland, Switzerland: International Union for the Conservation of Nature. 
Leithoff, K. (1990). Study of play and aggressive behaviors in mandrills as related to sex, age, rank and dyad pair formation. Milwaukee County Zoo, Milwaukee, Wisconsin: Unpublished manuscript.

Lindburg, D. G., \& Fitch-Snyder, H. (1994). Use of behavior to evaluate reproductive problems in captive mammals. Zoo Biology, 13, 433-445.

Line, S. W., Markowitz, H., Morgan, K. N., \& Strong, S. (1991). Effects of cage size and environmental enrichment on behavioral and physiological responses by rhesus macaques to the stress of daily events. In Novak, M. A., \& Petto, A. J. (Eds.), Through the looking glass: issues of psychological well-being in captive nonhuman primates. (pp. 160-179). Washington, D.C.: American Psychological Association.

Line, S. W., \& Morgan, K. N. (1991). The effects of two novel objects on the behavior of singly caged adult thesus macaques. Laboratory Animal Science, 41, 365-369.

Linke, K. (1990). Beobachtungen zur fortpflanzungsbiologie von mandrills und zur jungtierentwicklung eines mandrills im Zoologischen Garten Rostock. Zoologische Garten, 60, 285-296.

Littlewood, A., \& Smith, J. (1979). Breeding and hand-rearing mandrills Mandrillus sphinx at the Portland Zoo. International Zoo Yearbook, 19, 161-165.

Manly, B. F. J. (1986). Multivariate Statistical Methods. London: Chapman and Hall.

Maple, T. L., \& Finlay, T. W. (1989). Applied primatology in the modern zoo. Zoo Biologr Supplement, 1, 101-116.

Markowitz, H. (1982). Behavioral enrichment in the zoo. New York: Van Hostrand Reinhold.

Martin, P., \& Bateson, P. B. (1986). Measuring behaviour: an introductory guide. Cambridge: Cambridge University Press.

Martin, R. D. (1990). Primate origins and evolution: a phylogenetic reconstruction. Princeton: Princeton University Press.

McMillan, G. C. (1991). The effect of environmental manipulation on drill baboon social behavior. Paper presented at the regional meeting of the American Association of Zoological Parks and Aquaria.

Mellen, J. (1991). Factors influencing reproductive success in small captive exotic felids (Felis spp.): a multiple regression analysis. Zoo Biology, 10. $95-110$. 
Mellen, J. D. (1994). Survey and interzoo studies used to address husbandry problems in some zoo vertebrates. Zee Biology, 13, 459-470.

Mellen, J., \& Littlewood, A. (1978). Reintroducing an infant mandrill. Animal Keepers' Forum, $\mathbf{5}$, 9-10.

Mellen, J. D., Littlewood, A. P., \& Barrow, B. (1978). Husbandry, development and communication of captive mandrills (Mandrillus sphinx). Paper presented at the annual meeting of the American Association of Zoological Parks and Aquaria.

Mellen, J. D., Littlewood, A. P., Barrow, B. C., \& Stevens, V. J. (1981). Individual and social behavior in a captive troop of mandrills (Mandrillus sphinx). Primates, 22, 206-220.

Mellen, J. D., Hayes, M. P., \& Sheperdson, D. J. (in prep.). Captive environments for small felids. In Sheperdson, D. J., Mellen, J. D., \& Hutchins, M. (Eds.). Environmental Enrichment for Captive Animals. Washington, D. C.: Smithsonian Institution Press.

Mitani, M. (1991). Niche overlap and polyspecific associations among sympatric Cercopithecids in the Campo Animal Reserve, southwestern Cameroon. Primates, 32, 137-151.

Mitani, M. (1990). A note on the present situation of the Primate fauna found from south-eastern Cameroon to northern Congo. Primates, 31, 625633.

Mitchell, G., Obradovich, S. D., Herring, F. H., Dowd, B., \& Tromborg, C. (1991a). Threats to observers, keepers, visitors and others by zoo mangabeys (Cercocebus galeritus chrysogaster). Primates, 32, 515522.

Mitchell, G., Herring, F., Obradovich, S., Tromborg, C., Dowd, B., Neville, L. E., \& Field, L. (1991b). Effects of visitors and cage changes on the behaviors of mangabeys. Zoe Biology, 10, 417-423.

Mittermeier, R. A. (1987). Effects of hunting on rain forest primates. In Marsh, C. W., \& Mittermeier, R. A. (Eds.), Primate Conservation in the Tropical Rain Forest. (pp. 109-146). New York: Alan R. Liss.

Norris, J. (1988). Diet and foraging behavior of semi-free ranging mandrills in an enclosed Gabonais forest. Primates, 29, 449-463.

O'Neill-Wagner, P. L. (1994). Expression of species-specific behavior in rhesus monkeys. Lab Animal, $\underline{23}, 40-44$. 
Oates, J. F. (1986). Action plan for African Primate conservation: 1986-1990. International Union for the Conservation of Nature/Species Survival Commission Primate Specialist Group.

Oates, J. F. (1994). Africa's primates in 1992: conservation issues and options. American Journal of Primatology, 34, 61-71.

Oates, J. F. (1995). The dangers of conservation by rural development - a case-study from the forests of Nigeria. $\underline{\text { ryx }}, \underline{29}, 115-122$.

Oates, J. F., Gartlan, J. S., \& Struhsaker, T. T. (1987). A framework for African rain forest Primate Conservation. In Marsh, C. W., \& Mittermeier, R. A. (Eds.), Primate Censervation in the Tropical Rain Forest. (pp. 321-327). New York: Alan R. Liss.

Painter, J. N., Crozier, R. H., \& Westerman, M. (1993). Molecular identification of a Mandrillus hybrid using mitochondrial DNA. Zoe Biolegy, 12, 359365.

Paykel, E. S. (1992). Handbook of Affective Disorders. New York: Guilford Press.

Perkins, L. A. (1992). Variables that influence the activity of captive orangutans. Zoo Biology, 11, 177-186.

Portal, M. M., \& Asa, C. S. (1995). Effects of chronic melengestrol acetate contraceptive treatment on perineal tumescence, body weight, and sociosexual behavior of Hamadryas baboons (Papio hamadryas). Biology, 14, 251-259.

Raleigh, M. J., McGuire, M. T., Brammer, G. L., Pollack, D. B., \& Yuwiler, A. (1991). Serotonergic mechanisms promote dominance acquisition in adult male vervet monkeys. Brain Research, 559, 181-190.

Ralls, K., \& Ballou, J. (1982). Effects of inbreeding on infant mortality in captive primates. International Journal of Primatology, 3, 491-505.

Reynolds, C. F., Frank, E., Thase, M. E., \& Houck, P. R. (1988). Assessment of sexual function in depressed, impotent, and healthy men: factor analysis of a brief sexual function questionaire for men. Psychiatry Research, 24, 231-250.

Rosenblum, L. A., \& Andrews, M. W. (1994). Influences of environmental demand on maternal behavior and infant development. Acta Pædiatrica Supplement, 397, 57-63. 
Rosenblum, L. A., Coplan, J. D., Friedman, S., Bassoff, T., Gorman, J. M., \& Andrews, M. W. (1994). Adverse early experience affect noradrenergic and serotonergic functioning in adult primates. Biological Psychiatry, 35, 221-227.

Ruppenthal, G. C., \& Sackett, G. P. (1979). Experimental and husbandry procedures: their impact on development. In Ruppenthal, G. C. (Eds.), Nursery Care of nonhuman Primates. (pp. 269-284). New York: Plenum Press.

Sabater Pi, J. (1972). Contributions to the ecology of Mandrillus sphinx Linnaeus 1758 of Rio Muni (Republic of Equatorial Guinea). Folia Primatologica, 17, 304-319.

Sackett, G. P. (1991). The human model of psychological well-being in primates. In Novak, M. A., \& Petto, A. J. (Eds.), Through the looking glass: issues of psychological well-being in captive nonhuman primates. (pp. 35-42). Washington, D.C.: American Psychological Association.

Sapolsky, R. M. (1993). The physiology of dominance in stable versus unstable social hierarchies. In Mason, W. A., \& Mendoza, S. P. (Eds.), Primate Social Conflict. (pp. 171-204). Albany: State University of New York Press.

SAS (1994). JMP Statistical Software for the Macintosh (Version 3.1) Cary, North Carolina: SAS Institute.

Schaaf, C. D. (1990). Status of the drill (Mandrillus leucophaeus) in captivity and in the wild. American Association of Zoological Parks and Aquaria 1920 Regional Proceedings, 414-420.

Schaaf, C. D., Butynski, T. W., \& Hearn, G. W. (1990). The drill (Mandrillus leucophaeus) and other Primates in the Gran Caldera Volcanica de Luba: results of a survey conducted March 7-22, 1990. Unpublished manuscript.

Simerson, J. (1995). The use of operant conditioning to facilitate the introduction of drill baboons (Papio leucophaeus). Paper presentated at the annual conference of the American Zoo and Aquarium Association.

Small, M. F. (1992). Female choice in mating. American Scientist, 80, 142151.

Smuts, B. B. (1985). Sex and friendship in baboons. Hawthorne: Aldine de Gruyter. 
Smuts, B. B., Cheney, D. L., Seyfarth, R. M., Wrangham, R. W., \& Strusaker, T. T. (1987). Primate Societies. Chicago: University of Chicago Press.

Snowdon, C. T. (1989). The criteria for successful captive propagation of endangered primates. Zoo Biology Supplement, 1, 149-161.

Snowdon, C. T. (1991). Naturalistic environments and psychological wellbeing. In Novak, M. A., \& Petto, A. J. (Eds.), Through the looking glass: issues of psychological well-being in captive nonhuman primates. (pp. 103-115). Washington, D.C.: American Psychological Association.

Snowdon, C. T. (1994). The significance of naturalistic environments for primate behavioral research. In Gibbons, E. F., Wyers, E. J., Waters, E., \& Menzel; E. W. (Eds.), Naturalistic environments in captvity for animal behavior research. (pp. 217-235). Albany: State University of New York Press.

Sokal, R. R., \& Rohlf, F. J. (1995). Biometry. New York: W.H. Freeman.

Stammbach, E. (1987). Desert, forest and montane baboons: multilevel societies. In Smuts, B. B., Cheney, D. L., Seyfarth, R. M., Wrangham, R. W., \& Struhsaker, T. T. (Eds.), Primate Societies. (pp. 112-120). Chicago: University of Chicago Press.

Stricklin, W. R. (1995). Space as environmental enrichment. Lab Animal, 24, 24-29.

Suomi, S. J. (1974). Social interactions of monkeys reared in a nuclear family environment versus monkeys reared with mothers and peers. Primates, 15, 311-320.

Suomi, S. J. (1983). Models of depression in primates. Psycholegical Medicine, 13, 465-468.

Suomi, S. J. (1986). Behavioral aspects of successful reproduction in primates. In Berniscke, K. (ED.), Primates; the Road to Self-sustaining Populations. (pp. 331-340). New York: Springer-Verlag.

Tabachnick, B. G., \& Fidell, L. S. (1989). Using multivariate statistics. HarperCollins.

Talbot, P. A. (1912). In the shadow of the bush. London: Heinemann.

Taylor, J., Underwood, C., Thomas, L., \& Zhang, X. (1990). Effects of maternal dysphoria on materna! exchange dispositions. Jeurnal of Psychology. 124, 685-697. 
Terdal, E. S. O. (1993a). One room or two? Implications of exhibit design for captive mandrills. Paper presented at the First Conference on Environmental Enrichment, Portland, Oregon.

Terdal, E. S. O. (1993b). Variation in social behavior between adult mandrill dyads. Paper presented at the annual meeting of the Animal Behavior Society, Davis, California.

Terdal, E. S. O. (1994). Dominance hierarchies in captive mandrill groups. Paper presented at the annual meeting of the Animal Behavior society, Seattle, Washington.

Thompson, S. D. (1993). Zoo research and conservation: beyond sperm and eggs towards the science of animal management. Zoe Biology, 12. 155-159.

Tutin, C. E. G., \& Fernandez, M. (1987). Gabon: a fragile sanctuary. Primate Conservation, $8,160-161$.

van der Kuyl, A. C., Kuiken, C. L., Dekker, J. T., \& Goldsmit, J. (1995).

Phylogeny of African monkeys based upon mitochondrial 12S rRNA sequences. Journal of Molecular Evolution, 40, 173-180.

Vellucci, S. V. (1991). Primate social behavior - anxiety or depression? Pharmacological Therapeutics, 47, 167-180.

Verbeek, P. (1989a). Observation of a captive group of Mandrillus sphinx. Lowry Park Zoo, Tampa: unpublished manuscript.

Verbeek, P. (1989b). Preliminary report on the behavior of mothers and infants within a captive group of Mandrillus sphinx. Lowry Park Zoo, Tampa: unpublished manuscript.

Vincent, F. (1973). Utilisation spontanee d'outils chez le mandrill (Primate). Mammalia, 37, 277-280.

Walker, H. M., \& Lev, J. (1953). Statistical inference. New York: Henry Holt.

Weissman, M. M., Prisoff, B. A., Gammon, G. D., Merikangas, K. R., Leckman, J. F., \& Kidd, K. K. (1984). Psychopathology in the children (ages 6 - 18) of depressed and normal parents. Journal of the American Academy of Child Psychiatry, 23, 78-84.

Wickings, E. J., \& Dixson, A. F. (1992a). Testicular function, secondary sexual development, and social status in male mandrills (Mandrillus sphinx). Physiology and Behavior, 52, 909-916. 
Wickings, E. J., \& Dixson, A. F. (1992b). Development from birth to sexual maturity in a semi-free-ranging colony of mandrills (Mandrillus sphinx) in Gabon. Journal of Reproduction and Fertility 95, 129-138.

Wickings, E. J., \& Dixson, A. F. (1992c). Application of DNA fingerprinting to familial studies of Gabonese primates. In Martin, R. D.; Dixson, A. F., \& Wickings, E. (Eds.) Paternity in Primates: Tests and Theories. (pp. 113130). Basel: S. Karger.

Wickings, E. J., \& Bossi, T., \& Dixson, A. F. (1993). Reproductive success in the mandrill, Mandrillus sphinx: correlations of male dominance and mating success with paternity, as determined by DNA fingerprinting. Journal of Zeolegy (Londen) 231, 563-574. 


\section{APPENDIX}

\section{DESCRIPTION OF MANDRILLUS GROUPS STUDIED}


The information below in text and tables came from several sources. The Drill Species Survival Plan (SSP) Masterplan (Cox, 1989) and the Drill and Mandrill Studbooks (Cox, 1989, and unpubl. 1995 drill studbook data; LaRue, 1995) were used to obtain age and studbook numbers. To the studbook numbers, I have added a preceding " $\mathrm{D}$ " to indicate that the animal was a drill, and used " $M$ " for mandrills. Not all drills acquired since 1989 have studbook numbers, nor did the mandrills in Germany have studbook numbers. Cox (1989) also has drill rearing histories to the level of "wild-caught," "parentreared," "hand-reared," and "unknown." Rearing histories of drills born since 1989, and for all mandrills, were from International Species Inventory System (ISIS) records obtained at each zoo. Data on the reproductive history of each animal was from Cox (1989; also, unpubl. 1995 drill studbook data) for drills and LaRue (1995) for mandrills. Additional information was obtained from interviews with keepers about the animals in their care. At some zoos, I was offered access to files kept by keepers on each animal, which gave me more detailed information about an animal's history. The keepers also gave me "behind the scenes" tours of the animals' holding areas. They let me observe their daily husbandry routines and answered my questions. Enclosure measurements were from keepers, previously published reports on that group or (in a few cases) my own estimates based on pacing estimates of enclosure dimensions. 


\section{DRILL GROUPS}

I viewed 42 (16 males, 26 females) drills in 17 "groups" (including solitary animals) at 9 zoos in the U.S. and Germany. This was the entire studbook population for the two countries, and the vast majority of all drills in captivity outside of their range in Africa.

\section{Los Angeles Zoo (Los Angeles. CA. USA)}

The Los Angeles Zoo maintained its three male and three female drills in 3 groups called North, South and Off (Table A-1). All three groups were offexhibit, but visitors could be seen from the North and South enclosures, which were adjacent to each other.

North Group. The North enclosure housed a hand-reared, juvenile male (Lyle) with adult female Melissa. Melissa had a hysterectomy before coming to the Los Angeles Zoo, but still showed perineal swelling cycles and so presumably had intact ovaries. Melissa's cycles were unusual in that her perineal swelling did not detumesce: it merely became larger and tauter cyclically. This pattern was seen in a few other non-reproductive adult drill females (below).

The North enclosure was $120 \mathrm{~m}^{2}$ (enclosure areas were estimated to the nearest $10 \mathrm{~m}^{2}$ ); it was outdoors with a natural dirt floor and enclosed with chain-link fencing. There were several ledges (one with a heat-lamp), logs and ropes. The floor had some plants and a pool of water. This and the South enclosure (below) are described more fully by duBois (1992). Small wild birds and mammals entered and left the enclosure through the fencing. The adjacent South enclosure drills (described below) were visible from most 
Table A-1. Drills at Los Angeles Zoo in October, 1994.

\begin{tabular}{|c|c|c|c|c|c|}
\hline House name & Age & Sex & Studbook & Rearing & Reproduction notes \\
\hline Melissa & 20 & $\mathrm{~F}$ & D 281 & Unknown & $\begin{array}{l}\text { No uterus. Has a non-detumescing } \\
\text { perineum. }\end{array}$ \\
\hline Lyle & 2 & $M$ & D 345 & Hand & Juvenile. \\
\hline Kurt & 10 & M & D 266 & Mother & Sired Lyle in 1992 (dam deceased). \\
\hline Becky & 15 & $\mathbf{F}$ & D 286 & Mother & $\begin{array}{l}\text { Last reproduced in 1984. Has a } \\
\text { non-detumescing perineum. }\end{array}$ \\
\hline Sam & 23 & $\mathbf{M}$ & D 279 & Unknown & Last sired (Becky) in 1979. \\
\hline Leona & 14 & $\mathrm{~F}$ & D 282 & Unknown & $\begin{array}{l}\text { Never reproduced. Hysterectomy } \\
\text { in March, } 1994 .\end{array}$ \\
\hline
\end{tabular}

places within the North enclosure. The drills had access most of the time to a small room off-exhibit, called the "loft." The loft lacked the structural features of the outdoor enclosure (ledges, natural substrate) but was out of the view of visitors and observers. The keeper came two times daily to feed the drills. Feeding was done either through the fencing or by opening the enclosure door and depositing chopped fruit, vegetables and monkey chow from a bucket onto the enclosure floor. The latter method was usually used while the drills were locked in the loft and the keeper cleaned the outdoor enclosure. The keeper also brought browse cut for the drills from a variety of shrubs grown at the zoo for enrichment.

South Group. The South enclosure housed adult male Kurt and adult female Becky. Both were mother reared: Kunt at Zoo Hannover (Hannover, Germany) by Sonja (now at Saarbrucken Zoo [Saarbrucken, Germany], below) and Becky at Los Angeles by Nadine (now at Knoxville Zoo [Knoxville, TN, USA], below) and were paired here for breeding, but Becky had not become pregnant. Becky had a very large, permanent, perineal swelling similar to Melissa's (above) that did not detumesce cyclically. Kurt sired Lyle 
and another infant (deceased) with another female (since deceased), and so he was presumably fertile.

The $100 \mathrm{~m}^{2}$ South enclosure was very similar to the North enclosure described above. The South enclosure drills did not regularly have access to the loft. Instead, the keeper shifted Kurt into the loft after locking the North drills into their outdoor enclosure and before entering the south enclosure (with Becky) for cleaning. Kurt received some food in the loft while more food was placed in the South enclosure. Kurt was shifted back into the South enclosure after about five minutes.

Off Group. The Off enclosure was located behind the holding pens for birds used in the "Bird Show" and so was completely off-exhibit. Adult male Sam and adult female Leona were housed there. Leona had a hysterectomy and ovariectomy in March, 1994 because of severe endometriosis.

Sam and Leona were housed in a $60 \mathrm{~m}^{2}$ outdoor enclosure made with chain-link fencing. The substrate was natural dirt in the largest of the three rooms and concrete in the smaller two. There was a log pile in the center of the exhibit and numerous log ledges along the walls. One of the ledges had a heat lamp. The keepers actively trained the drills for husbandry purposes: moving to a target, sitting still on a scale, entering a transport box, others (see Desmond and Laule, 1987).

\section{San Diego Zoe and Wild Animal Park (San Diege, CA, USA)}

The San Diego Zoo and Wild Animal Park collectively held three male and six female adult drills in five enclosures at three locations. All were adult and had not reproduced. Detailed behavioral observations were only made 
on the one male, three female group at the Center for Reproduction of Endangered Species (CRES) facility at the Wild Animal Park.

Center for the Reproduction of Endangered Species. The CRES drill group included adult male Mike and adult females Amethyst, Ruby and Opal (Table A-2). Amethyst and Ruby were acquired from a zoo in Cairo, Egypt and were presumed wild-caught. Opal was born at the Audubon Zoo in Louisiana to Teal (now at Knoxville Zoo) and was hand-reared. She was a full-sib to Pearl at Zoo Atlanta (Atlanta, GA, USA) (below). Amethyst stopped showing perineal swelling cycles in 1992 and was presumably post-menopausal. Ruby and Opal continued to show regular, normal-looking swelling cycles.

Table A-3. Drills at the Center for the Reproduction of Endangered Species, San Diego, in October, 1994.

\begin{tabular}{|c|c|c|c|c|c|}
\hline House name & Age & Sex & Sludbook & Rearing & Reproduction notes \\
\hline Michael & 11 & $M$ & D 304 & Unknown & Has not reproduced. \\
\hline Amethyst & 24 & $F$ & D 319 & Wild? & $\begin{array}{l}\text { Has not reproduced. Last cycled in } \\
1992 \text { (presumed post- } \\
\text { menopausal). }\end{array}$ \\
\hline Ruby & 22 & $F$ & D 320 & Wild? & Has not reproduced. Cycles. \\
\hline Opal & 14 & $\mathbf{F}$ & D 291 & Hand & Has not reproduced. Cycles. \\
\hline
\end{tabular}

The CRES drills were housed in a very large $\left(3030 \mathrm{~m}^{2}\right)$ outdoor corral. Corrugated sheet metal walls, five meters high and sloping slightly inwards, formed a circle in which grew tall $(50 \mathrm{~cm})$ grass and several cottonwood trees. Three sun shelters were provided, made of corrugated sheet metal squares $(\sim 2 \mathrm{~m} \times 2 \mathrm{~m})$ elevated on steel poles. A log was placed below each shelter as a perch. Only one of these logs permitted the drill resting on it to be even one meter above the ground. (The trees were not easily climbed by the drills as they did not have horizontal branches.) Typically, the drills had access to 
water in a small room adjacent to the corral. The drills were fed twice daily. During both the morning and afternoon feedings a keeper dropped food from an observation tower into the corral, then went to the other side of the corral and placed food and browse through a section of the corral formed of chainlink fencing. I made observations of the drills' behavior from the observation tower using $9 \times 25$ binoculars.

San Diege Zoo. The San Diego Zoo's "Monkey House" had one male and three female drills off-exhibit in two enclosures. Adult male Loon was housed alone. Loon was diabetic and has received the most extensive training of any drill to allow management of his medical condition. He responded to 70 verbal instructions and permitted daily blood sampling and insulin injections (pers. obs. of training session). Two adult females were housed nearby: Susie and her daughter Jill. Susie, born in 1957, is likely the oldest living Mandrillus of either species and her daughter (born in 1965) is also one of the oldest. Both are post-menopausal.

The San Diego Zoo's "Research Pad" housed adult male Ace adjacent to adult female Rosie. Ace was the adult male housed with Amethyst, Ruby and Opal at the CRES facility before he was replaced by Mike. The switch was made because Ace did not show normal sexual behavior (H. Fitch-Snyder, pers. comm.) Rosie is a hand-reared drill formerly at the Philadelphia Zoo. Both Ace and Rosie were participants in a husbandry training program (Simerson, 1995).

\section{Knoxville Zoe (Knoxville. TN. USA)}

The Knoxville Zoo drill group included adult male Bart with adult females Teal and Nadine (Table A-3). Bart was mother-reared at Zoo 
Hannover. Teal and Nadine have had offspring by other males before being moved to Knoxville to form a group with adult male Ace (now at San Diego Zoo Research Pad, above). When breeding did not occur with Ace, Bart was obtained from Burger's Zoo (Arnhem, The Netherlands). These three drills were housed with Myrtle, an adult female mandrill. All three female Mandrillus showed swelling cycles, but Nadine's perineum did not fully detumesce: it resembled that of her daughter, Becky, and Melissa (both at Los Angeles Zoo, above).

Table A-3. Drills and a mandrill at Knoxville Zoo, November, 1994.

\begin{tabular}{llllll}
\hline House name & Age & Sex & Studbook & Rearing & Reproduction notes \\
\hline Bart & 14 & M & D 247 & Mother & Has not reproduced. \\
Teal & 26 & F & D 274 & Unknown & $\begin{array}{l}\text { Last reproduced in 1982 (Pearl, at } \\
\text { Atlanta); also Opal in 1979 (CRES) }\end{array}$ \\
Nadine & 21 & F & D 280 & Unknown & $\begin{array}{l}\text { Reproduced in 1979 (Becky, Los } \\
\text { Angeles). Perineum non- } \\
\end{array}$ \\
Myrtle & 16 & F & M 267 & Unknown & $\begin{array}{l}\text { detumescing. } \\
\text { Has not reproduced. }\end{array}$ \\
\hline
\end{tabular}

The Knoxville Mandrillus group is exhibited outdoors in a traditional concrete bear-grotto-type exhibit. It is $190 \mathrm{~m}^{2}$, with a dry moated front. The drills are prevented from using the moat by an electrified fence. The $10 \mathrm{~m}^{2}$ pool was filled with soil and planted as enrichment (Hamilton et al., 1994). A log structure to permit climbing and offer visual barriers both intra-group and from the visitors was also constructed (McMillan, 1991). The drills have access to a small off-exhibit area with ledges, water and monkey chow ad libitum. The animals are brought into the holding area late each afternoon for a feeding while the exhibit is hosed for cleaning. If the weather is cold the drills are kept 
inside overnight before being let back outside. The animals also are fed once on exhibit during the day by a keeper who tosses food to them.

\section{Zoo Atlanta (Atlanta, GA USA)}

The Atlanta drill group (Table A-4) included subadult (7 years old) male Adonis, adult female Inge with juvenile daughter Bioko and infant son Max, and adult female Pearl. Adonis was mother-reared at Zoo Hannover (by Sonja, now at the Saarbrucken Zoo) and Inge at the Wilhelma Zoological Gardens (Stuttgart, Germany). Pearl was hand-reared at the Audubon Zoo (New Orleans, LA, USA) because her mother (Teal, above at Knoxville Zoo) did not care for her in the first day postpartum.

Table A-4. Drills at Zoo Atlanta in November, 1994.

\begin{tabular}{llllll}
\hline House name & Age & Sex & Studbook & Rearing & Reproduction notes \\
\hline Adonis & 7 & M & D 295 & Mother & Sired Bioko and Max. \\
Inge & 8 & F & D 293 & Mother & Dam to Bioko and Max. \\
Bioko & 2 & F & D 315 & Mother & Juvenile. \\
Max & 0 & M & D 422 & Mother & Infant. \\
Peart & 12 & F & D 292 & Hand & Has not reproduced. \\
\hline
\end{tabular}

The Atlanta drills were exhibited during the day in a large $\left(975 \mathrm{~m}^{2}\right)$ outdoor enclosure with five mona monkeys (Cercopithecus mona). The substrate was natural soil with grass and many shrubs and some live trees. The center of the exhibit had two large (13 meter) artificial tree trunks with numerous "branches" and "vines." The sides and ceiling were of wire mesh. Water was supplied by two "lixit" taps near the entrances to the mona and drill holding areas. The exhibit is described in detail by Chang (1991), who studied the behavior of a mandrill group housed in it with the monas before the drills 
were substituted for the mandrills (see also Forthman et al. 1994). The monkeys were not given access to holding areas during the day. Visitors watched the monkeys from two places. One was an elevated building with large glass windows looking down on the area near the entrances to the holding area. The other viewing area was a raised platform on the far side of the enclosure set two meters back from the mesh. I collected data from the elevated building, through the window. I used $9 \times 25$ binoculars to make observations when the drills were on the far side of the enclosure.

\section{Zee Wuppertal (Wuppertal. Germany)}

Zoo Wuppertal held one male and four female drills, the male and two females on exhibit in the Affenhaus and two females in separate cages in the Zoo's animal hospital. All five had been put together in June, 1994. One female was removed because of injuries in October and another in December. I only recorded observations of the group on exhibit (Table A-5).

Adult male Roland was housed with adult females Francoise and Heike. Roland and Francoise had been housed together since 1986, while Heike was one of three females introduced the previous summer. Francoise had the same unusual perineal tumescence described for Melissa and Becky at the Los Angeles Zoo, and Nadine at Knoxville: it did not detumesce cyclically. Heike has normal cycles. None of these three drills have reproduced.

The drills were housed in a small $\left(20 \mathrm{~m}^{2}\right)$ indoor exhibit with a glass front and concrete floor and walls. There was a back ledge plus two smalier ledges in the rear side corners. The drills had access during warm-weather 
months to an outdoor enclosure $\left(60 \mathrm{~m}^{2}\right)$ with a concrete floor and bars for walls and ceiling. It also had several logs for climbing. During the colder

Table A-5. Drills on exhibit at Zoo Wuppertal in February, 1995.

\begin{tabular}{llllll}
\hline House name & Age & Sex & Studbook & Rearing & Reproduction notes \\
\hline Roland & 10 & M & D 267 & Unknown & Has not reproduced. \\
Francoise & 18 & F & D 268 & Wild & Has not reproduced. Has a non- \\
& & & & & $\begin{array}{l}\text { detumescing perineum. } \\
\text { Heike }\end{array}$ \\
\hline
\end{tabular}

months the drills were outside for about one hour each morning while the keeper cleaned the inside enclosure. Straw or browse is usually placed on the floor after the cleaning to encourage foraging behavior. Food is scattered on the floor in the straw or browse. A second feeding is done in the afternoon: the keeper briefly opens the door to the enclosure and tosses in food. Tea (black or herbal) is available for the drills to drink from a shallow pan on the floor. (It is customary for monkeys in German zoos to be given tea instead of water to drink.)

\section{Zoo Hannover (Hannover. Germany)}

Zoo Hannover has had the longest and best record for captive breeding of drills of any zoo. For this reason the group, exhibit, and husbandry are described in detail.

Juveniles are removed from the group and sent to other zoos for breeding (Boër, 1987; also described the history and husbandry of this group). When I was there, two juvenile males were housed together off-exhibit, away from the breeding group on exhibit in the Affenhaus. Only the Affenhaus group was studied systematically. 
Adult male Viktor had been moved to Hannover and introduced to the three adult females and one subadult female in May, 1994. The juvenile males were removed from the group before the introduction. Viktor had not reproduced previously when housed with four adult females at the Saarbrucken Zoo (Saarbrucken, Germany) (below). The three adult females at Hannover had all reproduced with two previous males (Alexander and Bioko, both deceased). Breeding began soon after Viktor's introduction at Hannover and births followed: a stillbirth to Tschita in December of 1994, a live birth of a male (house name: Valentine) to Hanna in January of 1995 and a live birth of a female (house name: Daphne) to Sue, also in January of 1995 (and on the first day of my data collection at Hannover). Altogether the group had one male and four female adults (including subadult female Liza) plus a male and a female infant (Table A-6). None of the females were showing perineal cycles during most of my visit, although Tschita began her first postpartum swelling while I was there. Subadult Liza was experiencing her second adolescent swelling. Hanna and Sue were lactating.

Table A-6. Drills on exhibit at Zoo Hannover in January, 1995.

\begin{tabular}{|c|c|c|c|c|c|}
\hline House name & Age & Sex & Studbook & Rearing & Reproduction notes \\
\hline Viktor & 12 & $M$ & D 259 & Unknown & $\begin{array}{l}\text { First } 3 \text { offspring were with Hanna, } \\
\text { Sue and Tschita (stillborn). }\end{array}$ \\
\hline Hanna & 11 & $\mathrm{~F}$ & D 256 & Mother & 8 offspring, including Valentine. \\
\hline Valentine & 0 & $M$ & D none & Mother & Born shortly before my visit. \\
\hline Sue & 13 & $\mathrm{~F}$ & D 255 & Mother & $\begin{array}{l}6 \text { offspring, including Liza and } \\
\text { Daphne. }\end{array}$ \\
\hline Liza & 3 & $F$ & $D$ none & Mother & $\begin{array}{l}\text { Has not reproduced. First cycle one } \\
\text { month prior to my visit. }\end{array}$ \\
\hline Daphne & 0 & $\mathrm{~F}$ & $D$ none & Mother & Born during my visit \\
\hline Tschita & 20 & $F$ & D 252 & Wild & 14 offspring. \\
\hline
\end{tabular}


The Hannover drills were observed in the indoor half of their exhibit. It was $23 \mathrm{~m}^{2}$, with a glass front and concrete floor and walls. There were logs for climbing and ledges on the side and rear walls. The drills had access to a small side-room $\left(4 \mathrm{~m}^{2}\right)$ off-exhibit. There were two openings to an outside exhibit: from a ledge at the back of the indoor exhibit and from the small side -room. This allowed the drills to circle through their three "rooms." The $25 \mathrm{~m}^{2}$ outdoor enclosure had a natural soil substrate with a few live plants, glass walls and bars for a ceiling. There were many logs for climbing both on the ground and suspended from the ceiling with chains. When I was in Hannover the weather was very cold (about $0^{\circ} \mathrm{C}$ ) and so the drills rarely went outside, even when given the opportunity. The drills were given access outside unless the temperature was below $-5^{\circ} \mathrm{C}$, or if almost freezing when there was a neonate (about one week post-partum, as was true of "Daphne" during much of my visit). I categorized this group as "inside" for my analyses for this reason. The drills were shifted outside, or to an adjacent enclosure (if the guenon monkeys whose enclosure it was were shifted outside), each morning while the indoor exhibit was cleaned. After a very thorough cleaning, the keepers spread fresh straw or browse on the floor of the inside exhibit to encourage foraging. Food was scattered in the straw. The drills received one more large feeding and a few small feedings (for enrichment) during the day. The Hannover drills were fed a great variety of foods, although any one feeding may have just one food type (or as many as ten). The feedings that occurred during the day (when the drills were in the exhibit) were done either by briefly opening the door to their exhibit and tossing the items in or by pushing food items under the bars at the rear (keeper-side) of the exhibit. The keepers tried to spread the food items over a large area. Some of the food was placed in the 
side-room to give animals a choice about where to eat: subordinate animals could eat away from dominant animals. Sometimes the keepers hand-fed the drills, especially low-ranking animals or lactating mothers who might need extra nutrition.

\section{Wilhelma Zoological Gardens (Stuttgart. Germany)}

The Wilhelma Zoo had one male and one female juvenile-subadult drills who were not studied systematically. Four-year old male Gobi was mother-reared by Tschita at Zoo Hannover (above). Three-year old female Bubi was hand-reared at Barcelona Zoo (Barcelona, Spain). The two were paired in Stuttgart in 1992. They were housed in a $30 \mathrm{~m}^{2}$ outdoor exhibit with a concrete floor and back wall, and barred front and ceiling. The exhibit had several log climbing structures and many novel manipulable objects for enrichment. Human clothes were amongst the novel objects the drills preferred. Leaves and straw were provided to encourage foraging. The drills were fed on a schedule six times each day, including hand-feedings. Their diet was the most varied of any zoo I have visited.

\section{Saarbrucken Zoo (Saarbrucken. Germany)}

The Saarbrucken Zoo had one male and three female drills (Table A-7) housed next to one male and two female mandrills (below). Subadult (4.5 years old) male Adam was with adult females Gail, Sonja and Little Bit. The Saarbrucken drill group had undergone several changes prior to my visit. Adult female Adelheit was removed from the Saarbrucken group in October of 1993 and moved to Zoo Wuppertal (above). Adult male Viktor was moved to Hannover in May of 1994 (above) and replaced by two young males. The other subadult male with Adam (house name: "Fritz") was moved to a zoo in 
Sofia, Bulgaria in December of 1994 because Fritz showed abnormal sexual behavior (primarily excessive masturbation) while preventing Adam from attempting to mount the females. Finally, adult female "Freckles" was euthanized for health reasons in January, 1995.

Table A-7. Drills at Saarbrucken Zoo in February, 1995.

\begin{tabular}{llllll}
\hline House name & Age & Sex & Studbook & Rearing & Reproduction notes \\
\hline Adam & 4.5 & M & D 310 & Mother & Has not reproduced. \\
Gail & 12 & F & D 303 & Wild? & Has not reproduced? \\
Sonja & 20 & F & D 249 & Wild & 6 offspring. \\
Little Bit & 21 & F & D 245 & Hand & Has not reproduced. \\
\hline
\end{tabular}

The Saarbrucken drill enclosure consisted of two inside rooms (13 and $4 \mathrm{~m}^{2}$ ) and a larger outdoor enclosure $\left(60 \mathrm{~m}^{2}\right)$. The indoor rooms were glass fronted with tile floors and walls. The floor of the larger indoor room was covered with a deep layer of straw and had two log climbing structures. Seeds were scattered in the straw to encourage foraging. The smaller indoor room was located in between the larger indoor room and the outdoor enclosure. It had food scattered on the floor and two ledges. The outdoor enclosure had a natural soil substrate and several log climbing structures and ledges. The walls and ceiling were made of rebar. The drills had access to the outside enclosure 24 hours a day, in all weather. The keepers routinely went into the enclosure with the drills for feeding, cleaning and to modify the enclosure. Keepers fed the drills about four times each day, varying amounts, and sometimes hand-fed the drills. 


\section{MANDRILL GROUPS}

I observed 53 ( 19 male and 33 female) mandrills in 12 groups at 10 zoos, one in Germany and nine in the U.S (Table III-1).

\section{Saarbrucken Z00}

Saarbrucken Zoo had one male and two female mandrills (Table A-8) housed adjacent to the four drills described above. Adult male Stanley was with adult female Heide and the young female Angelica. Angelica's age was not known. She was purchased without accompanying records from the Duisberg, Germany zoo as a presumed hand-reared juvenile in February, 1994. The keepers estimate that she was three years old at the time of my visit, 3.5 at most, but Angelica appeared to me to be about 2.5 years of age: about the same as juvenile females Bioko at Zoo Atlanta (above) and Jalissa at the Lincoln Park Zoo (Chicago, IL, USA) (below) in size and behavior. The keepers report that she had had a few small perineal swellings in the previous months, which is consistent with either estimate of her age. I have classified her as a juvenile female in my analyses. Stanley and Heide have been together since 1992 and have not reproduced.

Table A-8. Mandrills at Saarbrucken Zoo in February, 1995.

\begin{tabular}{llllll}
\hline House name & Age & Sex & Studbook & Rearing & Reproduction notes \\
\hline Stan & 9 & M & M none & Mother & Has not reproduced. \\
Heide & $\sim 6$ & $F$ & M none & Mother? & Has nol reproduced. \\
Angelica & $\sim 3$ & F & M none & Hand? & In puberty. \\
\hline
\end{tabular}


The Saarbrucken mandrills had access to a series of four rooms. One room was inside, $6 \mathrm{~m}^{2}$, with a straw layer over concrete. The front was glass, the walls were tile. This room had one ledge and one log for climbing. The middle two rooms were outside, 13 and $17 \mathrm{~m}^{2}$, with a concrete floor, tile back wall and chain-link fence front and ceiling. Most of the mandrills' food was placed on the floor of the larger of these. The final room was $4 \mathrm{~m}^{2}$, inside, with straw on a concrete floor. This room was off-exhibit to visitors and me the wall facing visitors was of translucent glass). It had one ledge. The drills were in an adjacent room, but were not visible except perhaps through small cracks. Occasionally, the mandrills were locked out of this final room and the drills were given access to it. The keepers did not often go in with the mandrills for cleaning and feeding, as they did with the drills. Instead, the mandrills would be shifted between rooms to allow one room at a time to be cleaned.

Otherwise, husbandry of the mandrills was similar to that of the drills (above).

\section{Lincoln Park Zoo (Chicago. IL, USA)}

The Lincoln Park Zoo (Chicago) mandrill group underwent several changes in composition in the months preceding my visit in December, 1994. The group had consisted of adult male Nick, adult female Sasha and three of their offspring: adult male Snickers, subadult male Merlinius and juvenile female Jalissa. I observed this group for one day in August of 1993. Between January and May of 1994 adult female Olanda was gradually introduced to the group. Olanda was receiving contraceptive injections that did not affect her perineal swellings. Sasha had a melengestrol acetate (MGA) implant for contraception. Subcutaneous MGA implants gradually release a synthetic progestin and are widely used for contraception in captive monkeys (Portal 
and Asa, 1995), including mandrills (this study: Tables below). The only systematic study in female papionins of effects of chronic MGA administration on social behavior did not find significant results, although the sample size was small: seven Hamadryas baboons in one zoo group (Portal and Asa, 1995). In November of 1994, subadult male Merlinius died. The cause of death was not apparent on necropsy, but he was found to have an ulcerated gastrointestinal tract (S. Thompson, pers. comm., Dec. 1994). On 4 December 1994, Snickers attacked and wounded Nick, delivering a long, deep slash to his father's pectoral region. Nick was removed from the group that day for medical treatment. A few days later Sasha was removed from the group to accompany Nick as he healed in a holding area near the exhibit room. Around the same time (9 December), Jalissa was removed to receive her first MGA implant. This left Snickers and Olanda on exhibit. I observed this pair for 15 hours on four days beginning 10 December, and then observed the pair with Jalissa for 15 more hours on three days, including the day Jalissa was reintroduced to Snickers and Olanda (Table A-9). I returned to the Lincoln Park Zoo for one day in August of 1995 when the groupings consisted of a healed Nick with Sasha and Jalissa on exhibit, and Snickers and Olanda in the nearby holding area.

The Lincoln Park Zoo mandrill exhibit was $70 \mathrm{~m}^{2}$, all indoor with a glass front, textured gunnite floors and painted walls. Two simulated tree trunks offered a little visual cover, and one tree had a branch for a perch. A few wood branches also allowed climbing. The central part of the exhibit had a small ( 1 $\mathrm{m}^{2}$ ) pit filled with pieces of bark to encourage foraging. A small stream and pool provided water. The mandrills were brought into a holding area each morning where they are fed. The keeper then cleaned their exhibit and 
scattered more food in the exhibit before shifting the animals back onto exhibit.

Table A-9. Mandrills on exhibit at Lincoln Park Zoo in December, 1994.

\begin{tabular}{llllll} 
House name & Age & Sex & Studbook & Rearing & Reproduction notes \\
\hline Snickers & 8 & $M$ & $M 452$ & Mother & $\begin{array}{l}\text { Has not reproduced, but has only } \\
\text { been housed with contracepted } \\
\text { females since maturity. }\end{array}$ \\
Olanda & 19 & $F$ & $M 205$ & Unknown & $\begin{array}{l}3 \text { offspring at another zoo. } \\
\text { Contraceptive vaccine permitted } \\
\text { perineal swelling cycles. }\end{array}$ \\
Jalissa & 2 & $F$ & $M 683$ & Mother & \begin{tabular}{l} 
Pre-pubescent. MGA implant. \\
\hline
\end{tabular}
\end{tabular}

Brookfield Zoo (Brookfield. IL. USA)

The Brookfield Zoo mandrill group included adult male Marco, adult female Sapphire and her adult daughter Jade, Jade's subadult son Gunnite, adult female Ruby and her subadult son Onyx, and nulliparous female Barbara (Table A-10). Sapphire, Jade and Ruby had MGA implants but Barbara had never been contracepted.

Table A-10. Mandrills at Brookfield Zoo in December, 1994.

\begin{tabular}{|c|c|c|c|c|c|}
\hline House name & Age & Sex & Studbook & Rearing & Reproduction notes \\
\hline Marco & 12 & $M$ & M 365 & Unknown & Sire of Gurnite and Onyx. \\
\hline Sapphire & 18 & $\mathrm{~F}$ & M 231 & Unknown & Dam of Jade and others. MGA. \\
\hline Jade & 8 & $F$ & M 463 & Mother & Dam of Gunnite. MGA. \\
\hline Gunnite & 4 & $M$ & M 583 & Mother & Juvenile-subadult. \\
\hline Ruby & 18 & $F$ & M 225 & Unknown & $\begin{array}{l}\text { Dam of Onyx and others } \\
\text { (including Pearl at Tulsa). MGA. }\end{array}$ \\
\hline Onyx & 4 & $M$ & M 581 & Mother & Juvenile-subadult. \\
\hline Barbara & 14 & $\mathrm{~F}$ & M 316 & Unknown & $\begin{array}{l}\text { Has not reproduced with Marco or } \\
\text { previous male. Never MGA. }\end{array}$ \\
\hline
\end{tabular}


The Brookfield Zoo mandrills were housed in "Tropic World: Africa," a large $\left(530 \mathrm{~m}^{2}\right)$ indoor exhibit with groups of three other monkey species: sooty mangabeys (Cercocebus atys), Kolb's guenons (Cercopithecus (mitis) albogularis kolbii) and black and white colobus monkeys (Colobus guerza ssp.); there was also one pygmy hippopotamus (Choeropsis liberiensis) and several bird species. An adjacent enclosure, separated with wire mesh, held gorillas (Gorilla gorilla gorilla). The enclosure had about 20 large artificial trees with interconnecting branches and artificial vines, numerous artificial metal shrubs, ledges and a stream with a waterfall and a pond. The floor was gunnite with no foraging material. The mandrills interacted with the other species, especially the sooty mangabeys. One of the adult female "mangabeys," named Kigeni, was a mandrill-mangabey hybrid (Baker and Lacy, 1992). Kigeni's father was the mandrill group's previous adult male. Kigeni was surgically ovariectomized after maturing (she had had MGA implants as a subadult). All of the other female mangabeys had MGA implants as well. The keepers brought each species into a separate holding area at the end of each afternoon. They were fed in holding and kept there overnight. The keepers scattered some food in the exhibit before shifting the animals onto exhibit in the morning.

\section{Milwaukee County Zoo (Milwaukee. WI. USA)}

The Milwaukee County Zoo mandrill group in 1994 included an adult male Earl, adult female Fauna with her subadult daughter Princess and adult female Flora (Table A-11). Five male offspring of Fauna and Flora had been sent to two other zoos in 1992 and 1993. The three females had MGA implants. 
Table A-11. Mandrills at Milwaukee County Zoo in December, 1994.

\begin{tabular}{llllll}
\hline House name & Age & Sex & Studbook & Rearing & Reproduction notes \\
\hline Eart & 15 & M & M 305 & Unknown & Many offspring. \\
Fauna & 15 & F & M 299 & Unknown & Many offspring, including \\
& & & & & Princess. MGA implanted. \\
Princess & 4 & F & M 642 & Mother & MGA implants since maturing. \\
Flora & 15 & F & M 298 & Unknown & Many offspring. MGA implanted. \\
\hline
\end{tabular}

The indoor exhibit was $40 \mathrm{~m}^{2}$. In the summer they had access to a similarly-sized outdoor enclosure. The inside exhibit had gunnite floors, a glass front, another glass window to the outside enclosure and wire mesh or concrete for the remaining walls. There were two logs for perches. The exhibit did not have a foraging substrate. The keepers shifted the mandrills into a series of three interconnected holding cages at the end of each afternoon for feeding. They were shifted back onto exhibit in the morning after the keepers scattered food on the exhibit floor.

\section{Tulsa Zoo (Tulsa. OK. USA)}

The Tulsa mandrill group was undergoing changes in composition around the time of my March, 1994 visit (Hartley and Bettinger, 1995). The adult male died in January, 1994. Two subadult males fought, and so were separated and removed from the group. The remaining group included 12 mandrills in three matrilines (Table A-12). The group has a long and welldocumented reproductive history (Bettinger et al., 1995). 
Table A-12. Mandrills on exhibit at Tulsa Zoo in March, 1994.

\begin{tabular}{|c|c|c|c|c|c|}
\hline House name & Age & Sex & Studbook & Rearing & Reproduction notes \\
\hline Annie & 18 & $\mathrm{~F}$ & $M 212$ & Unknown & $\begin{array}{l}\text { Many offspring, including. Angie, } \\
\text { Tammie and LBM; lactating. }\end{array}$ \\
\hline Angie & 3 & $F$ & M 586 & Mother & Entering puberty. \\
\hline Tammie & 2 & $F$ & M 691 & Mother & Juvenile. \\
\hline LBM & 0 & $M$ & M 828 & Mother & Infant. \\
\hline Pearl & 9 & $F$ & $M 421$ & Mother & $\begin{array}{l}3 \text { offspring, including Pandora } \\
\text { and Ed; lactating. }\end{array}$ \\
\hline Pandora & 1 & $F$ & M 692 & Mother & Juvenile. \\
\hline Ed & 0 & $M$ & M 829 & Mother & Infant. \\
\hline Darla & 14 & $\mathrm{~F}$ & M 286 & Unknown & $\begin{array}{l}\text { Many offspring, including Ivy, LC, } \\
\text { Darcy and Patience; MGA. }\end{array}$ \\
\hline Ivy & 5 & $F$ & M 518 & Mother & Has not reproduced; MGA. \\
\hline LC & 4 & $M$ & M 549 & Mother & Juvenile-subadult ( 4.5 years). \\
\hline Darcy & 3 & $\mathrm{~F}$ & M 585 & Mother & Entering puberty. \\
\hline Patience & 2 & $F$ & M 690 & Mother & Juvenile. \\
\hline
\end{tabular}

The Tulsa Zoo mandrills were exhibited in an large $\left(830 \mathrm{~m}^{2}\right)$ concrete grotto-type exhibit. It was outside and had a dry moat in front and on one side, and concrete walls in back and on the other side. It did not have climbing structures. The central part of the exhibit (about half the total area) was filled to a depth of $20 \mathrm{~cm}$ with straw to encourage foraging. The mandrills also foraged in the leaves that accumulated in the moat. The mandrills were brought into a $10 \mathrm{~m}^{2}$ holding room at the end of the afternoon for a feeding, but were given access to the exhibit except for cleaning or when the overnight temperatures were projected to be below freezing. More food was thrown into the exhibit in the morning and early afternoon. I made observations of behavior using $9 \times 25$ binoculars. 
Metro Washington Park Zee (Portland, OR. USA)

The Metro Washington Park Zoo had one male and five female mandrills housed in three "groups." Adult female Alice was kept with adult daughters Victoria and Kassari, and adult female Nikki. Adult male Jonni was housed separately because he was very aggressive to the females for a year after he was introduced to the females in February, 1991 (Terdal and Martinsen, unpub. data). Very old (32 years) adult female Lulu was housed alone, in part because of threats from her daughter Nikki with Victoria, and also because of failing health.

The Metro Washington Park Zoo mandrill groups had a $23 \mathrm{~m}^{2}$ indoor exhibit and an $35 \mathrm{~m}^{2}$ outdoor enclosure. The indoor exhibit and husbandry were described by Mellen et al. (1981). The outdoor enclosure had a natural soil substrate with grass and several logs upon which they could climb or perch. The keepers moved the three "groups" among the two enclosures and holding spaces.

\section{Potter Park Zoological Gardens (Lansing. MI. USA). San Francisce Zoological} Gardens (San Francisce. CA. USA). Henny Vilas Zoe (Madison. WI. USA)

These three zoos with mandrills have been the subject of one-day visits, primarily to view the animals and exhibits and informally interview the keepers. Potter Park Zoological Gardens had one adult male, three adult females (one hand-reared), and a juvenile male and two infants being motherreared (one offspring from each female) when I visited in 1992. The juvenile male was born shortly after its mother turned three, but was mother-reared normally despite the mother's young age. The hand-reared female did not care for her first offspring, and the male killed it during a re-introduction 
attempt (G. Brady, pers. comm., Sept. 1992); she was rearing her second infant normally, however, presumably because she had watched the two mother-reared females care for their own offspring. The animals were housed in a two-room, indoor-outdoor exhibit.

The San Francisco Zoological Gardens had one adult male and two adult females when I visited in 1993. The group was not reproducing. Their' rearing histories were not known. They were exhibited in a large outside enclosure with extensive vegetation (grasses, herbs, shrubs and small trees). They were shifted to holding areas at the end of the afternoon and fed with the male separated from the two females. The three were reunited each morning on exhibit.

The Henry Vilas Zoo mandrill group when I was there in 1993 exhibited one adult male, one adult female and their juvenile son. An older juvenile male had been removed and placed in a holding area after he received aggression from his father. The Henry Vilas Zoo mandrills were housed in a small indoor enclosure with a glass front, concrete floor and walls, and few climbing opportunities or foraging materials (the mandrills have since been moved elsewhere and the building renovated). 